NISTIR 7383

\title{
Selected Procedures for Volumetric Calibrations
}

\author{
Georgia L Harris \\ NIST \\ Weights \& Measures Division
}



NISTIR 7383

\section{Selected Procedures for Volumetric Calibrations}

Georgia L Harris

Weights and Measures Division

Technology Services

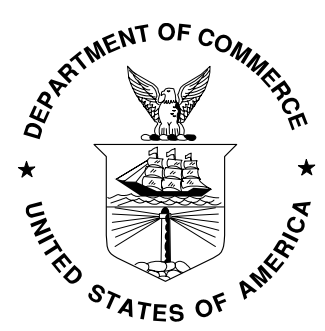

U.S. DEPARTMENT OF COMMERCE

Carlos M. Gutierrez, Secretary NATIONAL INSTITUTE OF STANDARDS AND TECHNOLOGY William Jeffrey, Director 



\section{Foreword}

This NIST IR of Selected Publications has been compiled as an interim update for a number of Good Laboratory Practices, Good Measurement Practices, and Standard Operating Procedures.

Many of these procedures are updates to procedures that were originally published in NBS Handbook 145, Handbook for the Quality Assurance of Metrological Measurements, in 1986, by Henry V. Oppermann and John K. Taylor. The updates have incorporated many of the requirements noted for procedures in ISO Guide 25, ANSI/NCSL Z 540-1-1994, and ISO/IEC 17025 laboratory [quality] management systems. The major changes incorporate 1) uncertainty analyses that comply with current international methods in the Guide to the Expression of Uncertainty in Measurements (GUM) and 2) measurement assurance techniques using check standards. No substantive changes were made to core measurement processes or equations, with the exception of SOP 18, Standard Operating Procedure for Calibration of Graduated Neck-Type Metal Volumetric Field Standards, Volume Transfer Method. Temperature limits and equations have been added to SOP 18 .

The following Practices and Procedures are new in this interim publication:

Standard Operating Procedures for:

- Small Volume Prover, Water Draw (26)

- $\quad$ Small Volume Prover, Gravimetric Calibration (SVP)

Special thanks go to the following individuals for the critical editorial reviews needed to complete this interim publication:

- Kelley Larson, AZ Department of Weights and Measures

- Dan Newcombe, ME Department of Agriculture Metrology Laboratory

- William Erickson, MI Department of Agriculture, E.C. Heffron Metrology Laboratory

- Craig VanBuren, MI Department of Agriculture, E.C. Heffron Metrology Laboratory

- Van Hyder, NC Department of Agriculture \& Consumer Services, Standards Laboratory

- $\quad$ L.F. Eason, NC Department of Agriculture \& Consumer Services, Standards Laboratory

- Val Miller, NIST, Weights and Measures Division

- Carol Hockert, NIST, Weights and Measures Division

- John Wright, NIST, Process Measurements Division

- Dan Wright, WA State Department of Agriculture (WSDA), Metrology Laboratory

Note regarding SI units: This publication conforms to the concept of primary use of the International System of Units (SI) recommended in the Omnibus Trade and Competitiveness Act of 1988 by citing SI units before customary units where both units 
appear together and placing separate sections containing requirements for SI units before corresponding sections containing requirements for customary units. In some cases, however, laboratory standards and/or trade practice are currently restricted to the use of customary units; therefore, some procedures in this publication will specify only

customary units. Non-SI units are predominately in common use in State legal metrology laboratories, and/or the petroleum industry for many volumetric measurements, therefore non-SI units have been used to reflect the practical needs of the laboratories performing these measurements as appropriate. SI units are used where practical, and where use or potential conversion errors, will not likely impact the quality of laboratory measurement results.

\section{Endorsement Disclaimer}

Certain commercial equipment, instruments, or materials are identified in this publication in order to specify the experimental procedure adequately. Such identification is not intended to imply recommendation or endorsement by the National Institute of Standards and Technology, nor is it intended to imply that the materials or equipment identified are necessarily the best available for the purpose. 


\section{Table of Contents}

Foreword

iii

Good Laboratory Practices

10 Purity of Water

GLP 10-1

13 Drying “To Contain” Volume Standards

GLP 13-1

Good Measurement Practices

3 Method of Reading A Meniscus Using Water or Other Wetting

GMP 3-1

Liquid

6 Cleaning Metal Volumetric Measures

GMP 6-1

7 Cleaning Precision Glassware

GMP 7-1

\section{Standard Operating Procedures}

13 Calibration of Volumetric Ware, Gravimetric Method

SOP 13-1

14 Gravimetric Calibration of Volumetric Ware Using an Electronic

SOP 24-1

Balance

15 Calibration of Intermediate and Large Volume Standards

SOP $15-1$

Gravimetric Method Using an Equal-Arm Balance

16 Calibration of Measuring Flasks, Volume Transfer Method

17 Control Charts of Laboratory Owned Check Standards for

SOP 16-1

Calibration of Measuring Flasks or Small Provers using Volume

SOP $17-1$

Transfer Methods

18 Calibration of Graduated Neck-Type Metal Volumetric Field

SOP 18-1

Standards, Volumetric Transfer Method

19 Calibration of Large Neck-Type Metal Provers, Volume Transfer Method

20 Control Charts for Calibration of Neck Type Provers, Volume Transfer Method

21 Calibration of LPG Provers

SOP 19-1

SOP 20-1

SOP 21-1

26 Calibration of Dynamic Small Volume Provers by the Water Draw Method

SVP Gravimetric Calibration of Dynamic Small Volume Provers

SOP SVP-1 
This page is blank. 


\section{GLP 10}

\section{Good Laboratory Practice for the Purity of Water}

Water is used in two ways in the metrology laboratory. It may be used as a cleaning fluid or it may be used as a standard of volume for purposes of calibration. In each case, it must be clean; in the latter case it must be pure, as well.

Cleanliness of water may be achieved by removal of physical contaminating substances, especially by filtration. City water is ordinarily clean but may become dirty from the distribution system and especially from prolonged standing in some kinds of pipes and tubing. Hoses used to transfer water from and into large vessels and tanks may need internal cleaning, as well. Flushing to remove visible contamination is all that is usually required.

Clean water is all that is necessary when making measurements by volumetric transfer since only volumetric comparisons are involved. When a water density value is used in an equation for volume transfer, the density values for the standard and unknown are proportional to each other; therefore, deviations in the density values from pure water are insignificant. (This is not true for gravimetric calibrations.) The coefficient of expansion for distilled water and pure water are also essentially the same. It is obvious that dirty water could cause a number of problems, including depositing residues in a volumetric vessel that could cause volumetric errors or could soil its interior, as a minimum. When in doubt of the cleanliness of the water supply, filters should be attached to the supply lines used.

Pure water is needed for gravimetric volume calibrations. For gravimetric calibrations, filtration systems alone are not adequate. Pure water requires the removal of chemical contaminants and this may be achieved by distillation, reverse osmosis, ion exchange systems, or combinations of these systems. The purity of the water from any given system and maintenance requirements is often dependent on the quality of the source water. Source water should be tested to determine the best type of system to meet laboratory needs. Density calculations may be accurate even when appreciable levels of dissolved salts remain in the water. However, since it is very difficult to know what type and quantity of salts are tolerable before density is affected, it is prudent to use the best system practical within budgetary constraints.

ASTM Type III or IV Reagent Water ${ }^{1} *$ is recommended as adequate for gravimetric calibration purposes. Such water may be produced by distillation or by ion exchange with relatively inexpensive equipment. In fact, most systems designed to meet these specifications actually provide quality better than required. Type III grade of reagent water may be prepared by distillation, ion exchange, continuous electrodeionization reverse osmosis, or a combination thereof, followed by polishing with a $0.45 \mu \mathrm{m}$ membrane filter. Type IV grade of reagent water may be prepared by distillation, ion exchange, continuous electrodeionization reverse osmosis,

\footnotetext{
${ }^{1}$ ASTM D 1193, Standard Specification for REAGENT WATER, ASTM, http://www.astm.org, 1916 Race St., Philadelphia, PA 19103.
} 
electrodialysis, or a combination thereof. Sales literature will usually specify whether the equipment will provide water of the above quality. Additionally, many manufacturers will provide a source water quality test and recommend a system to meet the purity and volume requirements of the laboratory. There are a number of commercial sources for such equipment.

A cartridge-type ion-exchange system is recommended for its simplicity and ease of operation. It can operate intermittently (on demand) and requires little or no maintenance except for change of cartridges, the need for which will be indicated. A relatively small system $(2 \mathrm{~L} / \mathrm{hr}$ to $30 \mathrm{~L} / \mathrm{hr})$ is adequate for laboratories calibrating glassware and test measures up to and including $20 \mathrm{~L}$ (5 gal) standards. It may be used on demand or to fill a small $(20 \mathrm{~L}$ to $40 \mathrm{~L})$ storage bottle to assure a continuous supply of calibration water.

There are two broad types of ion-exchange systems. Pressure cartridge systems (PCS) operate directly from line pressure (up to $700 \mathrm{kPa}$ ) and need no special operation precautions. The less expensive type operates from the water line through a needle valve to produce a specified flow rate through the cartridge. In this system, the outlet must not become blocked or turned off to prevent the water pressure from building up and bursting the cartridge. It is common practice to plumb directly from the output of this cartridge to a storage tank without using a valve in between. The unit is operated by simply turning the shut-off valve located at the water supply.

Water density may be measured with a five- or six-place oscillation-type density meter calibrated using suitable standard reference materials that are representative of the range of use. Less accurate density meters are not suitable for evaluating the quality of water needed for gravimetric calibrations. These systems typically measure the density at a specific reference temperature (generally $20^{\circ} \mathrm{C}$ ). Density meters are generally not needed if an appropriate water purification system is used that includes a way to measure conductivity or resistivity.

Conductivity and resistivity measurements do not have a direct correlation to water density, which is the critical attribute of concern for gravimetric volume calibrations. However, conductivity or resistivity measurements are a good indicator of water quality and whether the system is in good operating condition or needs service. Conductivity is simply the reciprocal of resistivity. For water quality specifications and assessment purposes, conductivity is usually measured in microSiemens per centimeter $(\mu \mathrm{S} / \mathrm{cm})$ and resistivity is usually measured in megaohms-centimeter $(\mathrm{M} \Omega \cdot \mathrm{cm})$, both usually at a reference temperature of $25{ }^{\circ} \mathrm{C}$. Conductivity is greatly influenced by temperature and is not linear. However, this is not a major concern for typical laboratory applications requiring pure water. Either a meter or indicator light should be included in laboratory systems to monitor water quality output. Standard reference materials are available to test conductivity and resistivity units. But, because the measurement values are not used to perform corrections to volume calibrations, traceable calibrations of the units are not essential.

Exposure of pure water in storage to air will likely cause degradation in the conductivity and/or resistivity measurements. However, pure water has been stored for over a year with little degradation in the density quality (provided that storage containers and lines are clean and that there is no bacterial growth, algae, or other contamination). 
The ASTM D-1193 specifications for conductivity and resistivity are noted in Table 1.

Table 1. Conductivity and resistivity specifications for water

\begin{tabular}{|l|c|c|c|c|}
\hline & Type I & Type II & Type III & Type IV \\
\hline $\begin{array}{l}\text { Electrical conductivity, max, } \\
\mu \mathrm{S} / \mathrm{cm} \text { at } 298 \mathrm{~K}\left(25^{\circ} \mathrm{C}\right)\end{array}$ & 0.056 & 1.0 & 0.25 & 5.0 \\
\hline $\begin{array}{l}\text { Electrical resistivity, min, } \\
\mathrm{M} \Omega \cdot \mathrm{cm} \text { at } 298 \mathrm{~K}\left(25^{\circ} \mathrm{C}\right)\end{array}$ & 18 & 1.0 & 4.0 & 0.20 \\
\hline
\end{tabular}

Conductivity and resistivity (along with other water quality measurements) are often used to assess the water quality used in cooling towers, boilers, relative humidity systems, micro and nanoelectronic systems and in pharmaceuticals, to ensure water of sufficient purity and to minimize corrosion or build-up within such systems.

Temperature equilibrium is another important factor in density stability of water. This is especially critical for large volumes. Water temperatures must be stable. Temperature accuracy is as important as purity for a correct density determination. If water is coming straight from the tap through the purification system into the prover, the temperature may fluctuate appreciably. Therefore, it is important to store an adequate volume of water to complete a calibration either already purified or ready to go through the system.

Water density tables (see Table 9.8 in NISTIR 6969 or Handbook 145) or calculations are used in most gravimetric calculations. For use in computer programs (most often spreadsheets), the use of a calculation is often preferred to look-up tables. The following equation is recommended for use. ${ }^{2}$

$\rho\left(T_{w}\right)=\rho_{0}\left[1-\left(A\left(T-T_{0}\right)+B\left(T-T_{0}\right)^{2}+C\left(T-T_{0}\right)^{3}+D\left(T-T_{0}\right)^{4}+E\left(T-T_{0}\right)^{5}\right)\right] \quad$ Eqn. 1

where:

$\rho=$ density of water

$\rho_{0}=999.97358 \mathrm{~kg} / \mathrm{m}^{3}$

$T_{w}=$ temperature of water in ${ }^{\circ} \mathrm{C}$

$T_{0}=3.9818^{\circ} \mathrm{C}$

$A=7.0134 \times 10^{-8}\left({ }^{\circ} \mathrm{C}\right)^{-1}$

$B=7.926504 \times 10^{-6}\left({ }^{\circ} \mathrm{C}\right)^{-2}$

$C=-7.575677 \times 10^{-8}\left({ }^{\circ} \mathrm{C}\right)^{-3}$

$D=7.314894 \times 10^{-10}\left({ }^{\circ} \mathrm{C}\right)^{-4}$

$E=-3.596458 \times 10^{-12}\left({ }^{\circ} \mathrm{C}\right)^{-5}$.

\footnotetext{
${ }^{2}$ Patterson, J. B., and Morris, E. C., Measurement of Absolute Water Density, $1{ }^{\circ} \mathrm{C}$ to $40{ }^{\circ} \mathrm{C}$, Metrologia, 31, $277-$ 288, (1994).
} 
Equation 1 provides water density in $\mathrm{kg} / \mathrm{m}^{3}$. To convert the result to units of $\mathrm{g} / \mathrm{cm}^{3}$ or $\mathrm{g} / \mathrm{mL}$, divide the result by 1000 .

\section{Additional References:}

ASTM D 1125, Standard Test Method for Electrical Conductivity and Resistivity of Water, ASTM, http://www.astm.org, 1916 Race St., Philadelphia, PA 19103.

ISO 15212-1:1998, Oscillation-type density meters - Part 1: Laboratory instruments, ISO, 1998. 


\section{GLP 13}

\section{Good Laboratory Practice \\ for Drying “To Contain” Volume Standards}

Vessels calibrated "to contain" must be dried of all measurable water in order to obtain an "empty" weight. The drying process should not contaminate the container; otherwise, it will need to be re-cleaned before further calibration or volumetric use. The following is presented as guidance when drying is required.

Drain as much of the residual water as practical before starting any drying process. If time is not a consideration, a glass tube may be inserted into the container to pass clean dry air (or nitrogen) through it to evaporate the residual water film. A filter or dust trap may be necessary to pre-clean the air used. Air lines must be selected to ensure that aging and wear do not introduce contaminants. Air may be sucked through a tube connected to a vacuum pump with some danger of drawing in dirty air from the surroundings. Clean absorbent cotton placed at the neck opening can minimize the entrance of foreign matter. Compressed air systems may introduce finely atomized oils or moisture into the air which may not be visible. If laboratory quality air is not available, nitrogen may be used.

Solvent cleaning may be used with alcohol as the preferred medium. Preliminary rinsing with acetone will remove large amounts of water, with which it is infinitely miscible, but this solvent often contains impurities such as traces of oils that could deposit on the container walls. Thus, a final alcohol (preferably ethanol or methanol) rinse is recommended, even if acetone is used to remove most of the water. Care must be taken to ensure that the alcohol is not denatured with oils to an extent that will leave residue on the standard. Care must also be taken to avoid mixing chemicals such as acetone and alcohols. The alcohol is allowed to drain as much as possible, followed by air drying as described above.

Some metal containers have been internally coated to minimize corrosion. When present, it should be ascertained that such coatings are not affected by alcohol or acetone; otherwise, solvent treatments should not be used.

The external surfaces of all containers should be clean when gravimetric calibration is used. Otherwise, any removal of external dust or dirt during the measurement process could cause errors of unknown magnitude.

Analytical glassware should not be dried by heating in an oven as the glass may suffer nonelastic expansion and put the glassware out of calibration.

Calibration Tip: After the vessel is clean and dry, cover with glass or aluminum foil to minimize contaminants from collecting inside the vessel. Clean and dry the flask one to two days prior to the calibration and allow the flask to come to equilibrium with the environment. Obtain an 
initial baseline "dry weight" of the clean container for use as a dry reference weight on subsequent weighing and drying cycles.

Safety Note: Material Safety Data Sheets (MSDSs) must be available in the laboratory and should be reviewed to ensure safe handling of all chemicals noted in this procedure. 


\section{GMP 3}

\section{Good Measurement Practice \\ for \\ Method of Reading A Meniscus Using Water or Other Wetting Liquid}

Two common methods are used for setting a meniscus. The method used in calibration should be consistent with the intended use of the volumetric standard. For interlaboratory comparisons, the method to be used should be defined during the planning stages of the comparison.

In all apparatus where the volume is defined by a concave meniscus, the reading or setting is made on the lowest point of the meniscus. In order that the lowest point may be observed, it is necessary to place a shade of some dark material immediately below the meniscus, which renders the profile of the meniscus dark and clearly visible against a light background. A convenient device for this purpose is a collar-shaped section of thick black rubber tubing, cut open at one side and of such size as to clasp the tube firmly.

Two common types of meniscus readers are available. These include black/white meniscus card readers or magnifying glasses with cross-hairs. The width of the graduation will affect the readability of the meniscus and should be estimated to the nearest $1 / 10$ of a division. Black/ white meniscus card readers are simple to create as shown in the figure below. More elaborate card readers may be purchased that allow placement around the neck of a flask.

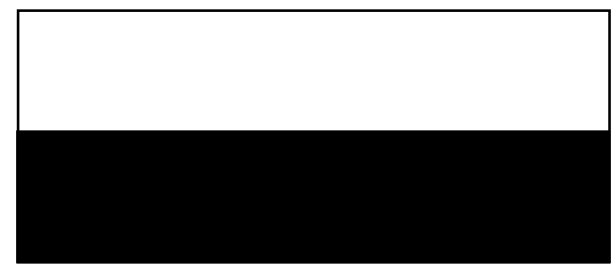

This type of meniscus reader is generally preferred for Option A method of reading the meniscus.

Another type of meniscus reader consists of a clear lens (plastic or glass) with etched lines on the front and back that are aligned to prevent parallax errors in reading. This type of reader is preferred for Option B.

The meniscus of most liquids used in volumetric standards is concave with the lowest point in the center used to determine the reading. The meniscus formed by a non-wetting liquid, such as mercury (Hg), is convex with the highest point in the center. The highest point of such a meniscus is used to make the reading. The reading of a mercurial barometer is a classical example of this kind. In making the reading, the observer's eye should be normal to and in the same horizontal plane as the meniscus. The illumination is adjusted to get a sharp definition of the meniscus. Elimination of parallax error is very important and can be judged by slight fluctuations of eye level that do not affect the reading.

The curvature of a meniscus is related to the surface tension of the liquid and inversely related to 
the diameter of the tubing in which it is formed. When reading any meniscus, it is important to ascertain that it is in an equilibrium position. Tapping of sight glasses and/or small motions of containers may be used to induce slight displacements of the meniscus. Return to the same reading is evidence of a stable meniscus.

\section{Option A - (Suitable only when graduation lines extend more than 75 percent of the circumference of the sight gage area.)}

The position of the lowest point of the meniscus with reference to the graduation line is such that it is in the plane of the middle of the graduation line. This position of the meniscus is obtained by making the setting in the center of the ellipse formed by the graduation line on the front and the back of the tube as observed by having the eye slightly below the plane of the graduation line. This is illustrated below. The setting is accurate if, as the eye is raised and the ellipse narrows, the lowest point of the meniscus remains midway between the front and rear portions of the graduation line. By this method it is possible to observe the approach of the meniscus from either above or below the line to its proper setting.

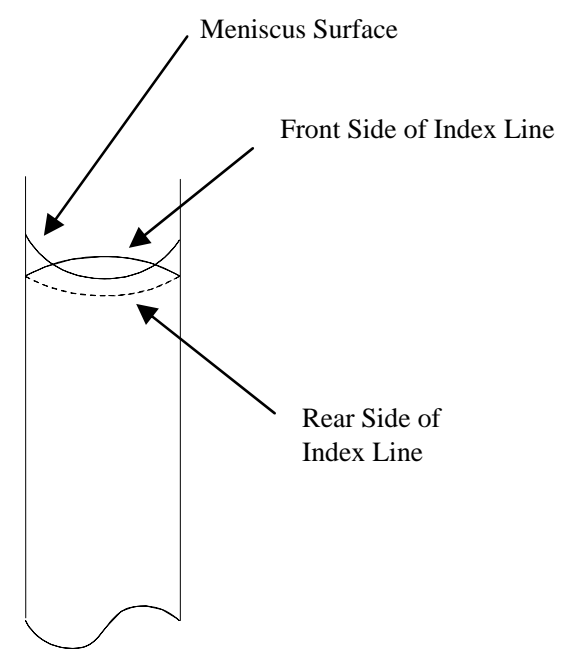

Observer's View From Slightly Below the Horizontal Level of the Graduation Line.

FRONT VIEW

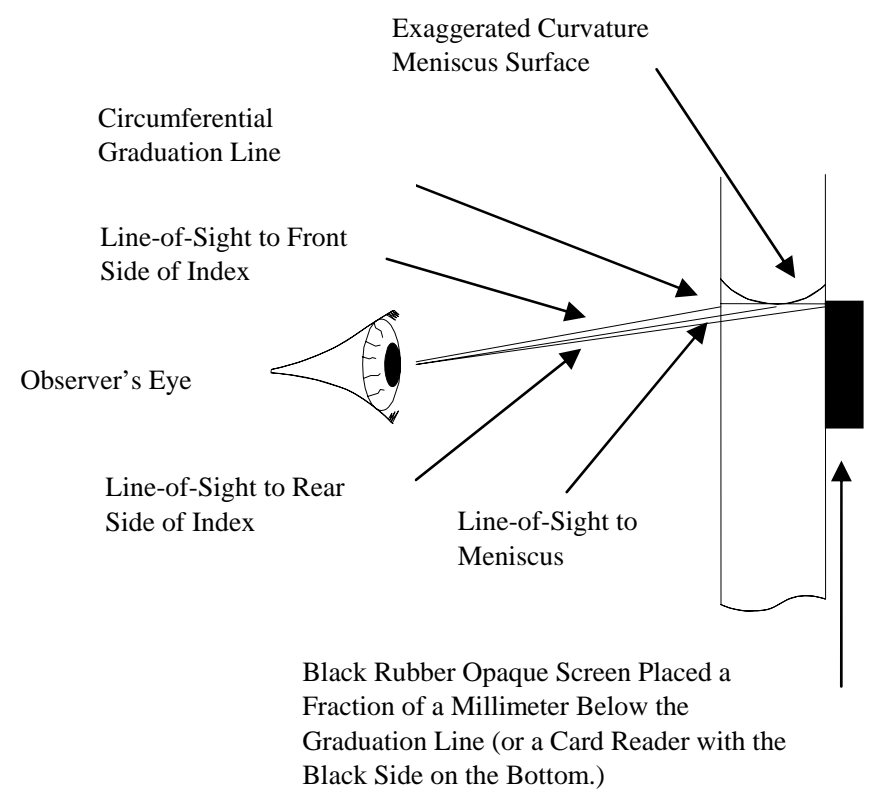

SIDE VIEW 


\section{Option B}

The position of the lowest point of the meniscus with reference to the graduation line is horizontally tangent to the plane of the upper edge of the graduation line. The position of the meniscus is obtained by having the eye in the same plane of the upper edge of the graduation line as shown below.

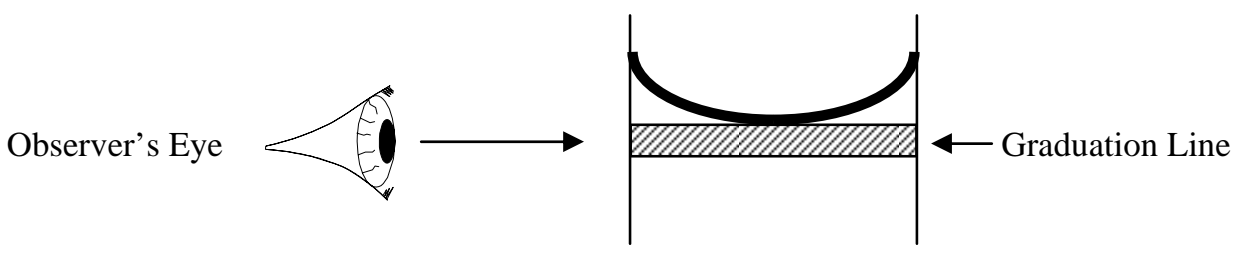

\section{Comparison of Option A and Option B Methods}

For most practical applications the difference between these two methods is insignificant compared to the tolerances of the volumetric standards. However, a component for measurement uncertainty should be included as appropriate. When performing calibrations, using the glassware as precision standards with clear liquids, or when comparing results among laboratories the difference in meniscus setting is directly related to the visible thickness of the meniscus and the volume of liquid contained in the neck between the top of a graduation line and the middle of the graduation line as shown in the following diagram as 1) which results with Option B when clear liquids are used and 2) which results with Option A and is only possible when clear liquids are used.

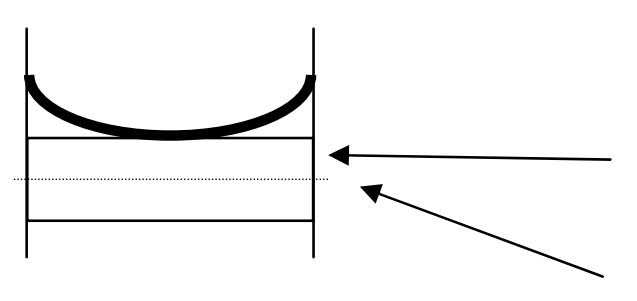

1) Top of the meniscus.

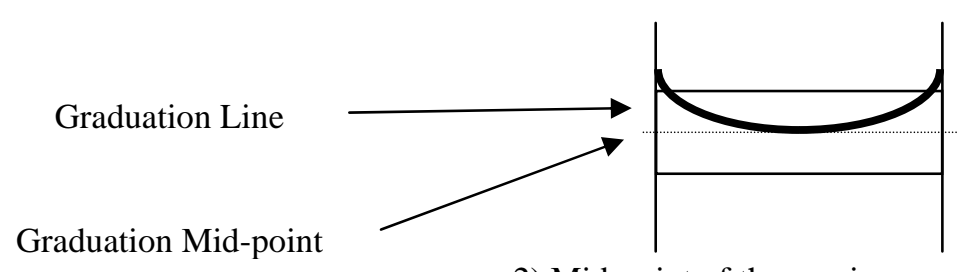

2) Mid-point of the meniscus.

When opaque liquids are used, an additional error or correction can be estimated based on the volume contained between the upper and lower edges of the meniscus. The curve of the meniscus and impact of this error is dependent on the diameter of the meniscus and surface tension of the liquid being used.

Where possible, the method of reading the meniscus during calibrations should be performed in the same way in which the meniscus will be read during normal use. 



\title{
GMP 6
}

\section{Good Measurement Practice \\ for Cleaning Metal Volumetric Measures}

\begin{abstract}
All volumetric test measures, including laboratory standards and those submitted for calibration must be clean at the time of measurement. Drainage is adversely affected by greasy and oily surfaces. Corroded surfaces raise questions that impair future use, so corrosion-damaged containers may not be worth testing.
\end{abstract}

Environmental requirements are becoming increasingly important. Many laboratories will not accept test measures and provers for calibration unless they have been suitably cleaned to remove contents such as petroleum or other chemical residues. In those cases, all surfaces (inside and out), drain lines, pumps, and hoses that may be used during the calibration process must be cleaned so that no petroleum or other product residue remains that would otherwise spill onto the laboratory floor or drain into the sewer/waste-water system.

Metal measuring vessels are best cleaned by using a non-foaming dishwashing detergent. Warm water is most effective both for cleaning and rinsing, which must be thorough. If warm water cleaning and rinsing is used, the vessel must be equilibrated to calibration temperatures before use.

The cleaning operation involves the use of a liberal amount of the detergent solution and vigorous shaking, swirling, or other motion so that the solution contacts the entire inner surface of the vessel. Depending on the condition of the surface, this operation should be repeated one or more times to ensure removal of oily films and residues. As much as possible of the detergent solution should be drained prior to the water rinses to facilitate complete removal of the detergent from the prover. Ordinarily, three rinses will be sufficient, but this should be confirmed by testing the final rinse for any visual evidence of detergent or other residues.

When detergents are not sufficient to remove oily or greasy deposits, solvents may be used, provided it is ascertained that they do not affect any coatings on the container. The surfaces should be dry before any calibrations are attempted.

If lime or scale build-up has occurred (usually only in standards that are primarily used with water), they may be cleaned with a suitable lime or scale remover. Many of these chemicals contain acids and may react with metals, so appropriate care should be taken and these chemicals should not be allowed to soak for extended periods of time. Many lime and scale removers have safety and handling requirements and may have special disposal requirements. The material safety data sheet (MSDS) should be reviewed prior to using or disposing of scale and lime removers.

After cleaning or use, vessels should be drained completely and stored in a dry place. They should be covered to prevent entrance of dust and foreign matter. Metal containers further should be protected from damage by denting and/or dropping. Once such a vessel has been visibly dented, it is difficult to ascertain whether additional changes have occurred. Even when dents have been 
removed and the vessel has been calibrated, visual deformities can compromise future use. Accordingly, protection from damage while stored and when in use should be a major concern of the metrologist or owner of the device. 


\section{GMP 7}

\section{Good Measurement Practice \\ for \\ Cleaning Precision Glassware}

The volume contained in or delivered from precision glassware depends on the cleanliness of the container. Glassware must be sufficiently clean to ensure uniform wetting of the entire internal surface of the standard. When clean, the walls will be uniformly wetted and the water will adhere to the surface in a continuous film. If films of dirt or grease are present, the meniscus may crinkle at the edges and liquids will not drain properly and will leave water drops on the internal walls. Lack of cleanliness can cause errors in setting a meniscus and incomplete wetting/drainage of the calibration liquid (generally water.)

Glassware that is submitted for calibration should be cleaned (and autoclaved if needed) prior to submission to the laboratory to ensure removal of all chemical, biological, radiological, or other contaminants.

If glassware is cleaned by the laboratory, appropriate inquiries should be made to determine prior and subsequent uses along with implications of certain cleaning methods. Some methods of cleaning glassware prior to calibration or use are ineffective or detrimental and may leave chemical contamination deposits that can be detected in some chemical analysis operations.

There are a number of suitable detergents (both liquid and powder), available from laboratory supply houses that do not contain phosphates. The catalog descriptions usually indicate whether or not they contain phosphates. Laboratory detergents that contain phosphates can leave a deposit on the glass that will cause water to "bead" on the surface making it appear to be dirty, and making it difficult to properly set a meniscus. Once a phosphate deposit has occurred, it is very difficult to remove. It may be removed with hot (approx. 65 EC) sodium dichromatesulfuric acid cleaning solution. However, use of this hot solution is hazardous and is not recommended unless proper safety equipment is available (see the next section).

If acetone is used to remove oil or grease film, always follow with alcohol (ethanol, not methanol) before drying or rinsing with water. Acetone, if allowed to dry, also leaves a film deposit.

The above solvents need not be used if the glass does not have an oil or grease film. Mechanical shaking of water and suitable non-phosphate detergents is usually adequate for cleaning glassware.

These cleaning agents do not preclude the use of other suitable methods, of which there are several. Some have special applications that would not normally be encountered by metrologists or field inspectors.

See GLP 13, Good Laboratory Practice for Drying Containers for appropriate drying techniques. 
It is not necessary to dry any container marked "to deliver."

$\underline{\text { Cleaning Methods }}^{1}$

Safety Note: Material safety data sheets (MSDS) should be available, studied, and carefully followed before using any of the following cleaning methods. Chromic acid solutions are not recommended for routine use because it is a hazardous waste and hazardous to health! Suitable education or training in the handling of chemicals is highly recommended.

Frequently it is desirable to give glassware a preliminary rinse or soak with an organic solvent such as xylene or acetone to remove grease, followed by a water rinse. The rinsing with water must be done thoroughly if acid will be used later to clean the glassware.

Unless autoclaving is necessary, glassware should be cleaned as soon as possible after use to avoid setting and caking of residues. Pipets, for example, may be placed in a jar containing a weak antiseptic solution immediately after use. Autoclaving is necessary to disinfect glassware that may have been used to contain potentially dangerous biological fluids.

A selection of general cleaning methods follows:

1. Fill with sulphuric acid-dichromate mixture and let stand. After removal of the mixture, rinse with distilled water at least six times. To make the cleaning mixture, dissolve (60 to 65) g of sodium- or potassium-dichromate by heating in (30 to 35) $\mathrm{mL}$ of water, cool and slowly add concentrated sulphuric acid to make one liter of solution. This solution is available from laboratory supply companies.

Note: Extreme care should be exercised in handling acidic solutions.

2. Scrub with a $1 \%$ to $2 \%$ hot solution of a detergent. Rinse well after brushing. A number of suitable, commercial washing compounds are available.

3. Fuming sulphuric acid (very hazardous material) is an excellent cleaning agent. Usually, cleaning can be accomplished by use of a comparatively small amount of acid, manipulating the vessel so that the acid comes in contact with all of the surface, and immediately emptying and rinsing.

When a piece of glassware is badly contaminated with stopcock grease (except silicone grease), it may be necessary to rinse with acetone once or twice before using one of the above methods. For silicone grease, the acetone can be omitted and the piece soaked for $30 \mathrm{~min}$ in fuming sulphuric acid. Warm decahydronaphthalene (decalin) also has been suggested as a solvent for silicone grease. In this case, let the piece soak for $2 \mathrm{~h}$, drain, and rinse once or twice with acetone, followed by a water rinse.

\footnotetext{
${ }^{1}$ While the metrologist is not ordinarily faced with the problems for which these procedures are necessary, they are given here in the event that they are needed.
} 


\section{$\underline{\text { Cautions }}$}

Care should be exercised when using most cleaning solutions because they can cause skin irritations or severe burns on contact. Dilute solutions become concentrated as the water evaporates; therefore, always flush the exposed area immediately with large quantities of water.

Suitable chemical-specific-resistant goggles or a face mask should be worn to protect the eyes from splashes and rubber gloves should be worn to protect the hands. It is advisable to wear an acid resistant laboratory coat or a rubber apron to protect clothing when using strong acids for cleaning. The glassware should be handled gently to avoid breakage and also to prevent spilling acids and other cleaning fluids. All cleaning should be done in a laboratory sink or on an acid-proof laboratory bench, preferably within a fume hood, to the extent possible.

Some of the cleaning materials mentioned leave minute traces or residues unless the rinsing process is carried out thoroughly. While such traces may not be harmful if the purpose of cleaning is to prepare the glassware for calibration, they can give trouble when the glassware is used in certain laboratory operations. For example, manganese and chromium compounds, even in extreme dilution, may retard or inhibit growth of micro-organisms, and traces of phosphorus may interfere with delicate tests for this element. When glassware is to be calibrated, final rinsing must be with pure distilled or deionized water.

If an article is to be dried after cleaning, as is necessary for all vessels marked "To Contain", acetone, followed by ethyl alcohol (American Chemical Society Specification) may be used. Drying may be hastened by blowing clean, dry air into the vessel (or sucking the air through the vessel).

Efficient air filters must be provided to remove any particles of oil or dirt from compressed air used for drying purposes. 



\section{SOP 13}

\section{Standard Operating Procedure for Calibration of Volumetric Ware, Gravimetric Method ${ }^{1}$}

1 Introduction

\subsection{Purpose of Test}

Volumetric flasks, pipets, graduated cylinders, burets, and similar glass and plastic volumetric ware, such as those used in chemical and clinical laboratories, need to be calibrated to ensure accuracy of measurement. This SOP describes procedures for calibration of such ware with capacities ranging from $0.1 \mathrm{~cm}^{3}$ to $2000 \mathrm{~cm}^{3}$. The method is extendable, in principle, to larger volumes, limited only by the capacity and physical dimensions of the weighing apparatus. It is not recommended for volumetric ware with capacities less than $0.1 \mathrm{~cm}^{3}$. This procedure makes use of a single pan mechanical balance. For calibrations with an electronic balance see SOP 14.

\subsection{Prerequisites}

1.2.1 Verify that valid calibration certificates are available for the standards used in the test.

1.2.2 Verify that the mass standards to be used have sufficiently small standard uncertainties for the intended level of calibration. Reference standards should not be used for gravimetric calibration.

1.2.3 Verify that the balance used is in good operating condition with sufficiently small process standard deviation, as verified by a valid control chart or preliminary experiments, to ascertain its performance quality when a new balance is put into service. The accuracy of the balance and weighing procedures should be evaluated to minimize potential bias in the measurement process.

1.2.4 Verify that the operator is experienced in precision weighing techniques and has had specific training in SOP 2, SOP 4, SOP 29, GMP 3, GMP 10, and gravimetric calibrations.

1.2.5 Verify that the laboratory facilities meet the minimum conditions shown in Table 1 to meet the expected uncertainty that is achievable with this procedure.

1.2.6 Verify that an adequate supply of distilled or deionized water (see GLP 10) is available.

1 Based on the work of J. Lembeck "The Calibration of Small Volumetric Glassware," NISTIR 74-461 (1974). 
Table 1. Laboratory environmental conditions

\begin{tabular}{||c|c|c|}
\hline \hline Procedure & Temperature & Relative Humidity \\
\hline \hline Gravimetric & $\begin{array}{c}2{ }^{\circ} \mathrm{C} \text { to } 23^{\circ} \mathrm{C} \text {, a set point } \pm 2{ }^{\circ} \mathrm{C}, \\
\text { maximum change } 1{ }^{\circ} \mathrm{C} / \mathrm{h}\end{array}$ & $\begin{array}{c}40 \% \text { to } 60 \% \\
\pm 10 \% \text { max change } / 4 \mathrm{~h}\end{array}$ \\
\hline
\end{tabular}

2 Methodology

\subsection{Scope, Precision, Accuracy}

The procedure is applicable for the calibration of any size of measuring container that, when filled with water, will not overload the balance used. The precision of calibration will depend on the care exercised in adjusting the various volumes and strict adherence to the various steps of the procedure. The accuracy attainable will depend on the uncertainties of the standard weights and the air buoyancy and thermal expansion corrections that are made.

\subsection{Summary}

This procedure is based on a determination of the mass of water contained in or delivered from the vessel that is calibrated. The volumetric determination is calculated from the above measurements and a knowledge of the temperature, pressure, and relative humidity of the air, and the temperature of the water that is weighed.

\subsection{Equipment and Standards}

2.3.1 Balance having sufficient capacity to weigh the loaded vessel. The sensitivity of the balance will be a limiting factor in the accuracy of the measurement.

2.3.2 Mass standards or built-in weights calibrated with adequate accuracy and valid calibration certificates traceable to NIST. Ordinarily, meeting ASTM Class 2 or 3 weight specifications are required.

2.3.3 Calibrated thermometer accurate to $\pm 0.1^{\circ} \mathrm{C}$ with recent calibration values that are traceable to NIST to determine water temperature.

2.3.4 Calibrated thermometer accurate to $\pm 0.5^{\circ} \mathrm{C}$ with recent calibration values that are traceable to NIST to determine air temperature. ${ }^{2}$

2.3.5 Calibrated barometer accurate to $\pm 135 \mathrm{~Pa}(1 \mathrm{~mm} \mathrm{Hg})$ with recent calibration values that are traceable to NIST to determine the air pressure.

2.3.6 Calibrated hygrometer accurate to $\pm 10 \%$ with recent calibration values that are traceable to NIST to determine relative humidity.

\footnotetext{
${ }^{2}$ Values from the thermometer, barometer and hygrometer are used to calculate the air density at the time of the measurement. The air density is used to make an air buoyancy correction. The accuracies specified are recommended for high precision calibration. Less accurate equipment can be used with only a small degradation in the overall accuracy of the measurement.
} 
2.3.7 Distilled or deionized water (See GLP 10).

2.3.8 Stopwatch or other suitable timing device (does not require calibration).

\subsection{General Considerations}

2.4.1 All glassware must be meticulously cleaned, prior to calibration. When clean, the walls will be uniformly wetted. Instructions for cleaning are given in GMP 7. An exception is plastic ware, which will not be wetted. Follow manufacturer's instructions for cleaning such vessels. Do not use cleaning agents that will attack, discolor, or swell plastic ware.

2.4.2 Volumetric calibrations are critically dependent on the setting of a meniscus. See GMP 3 for guidance in reading a meniscus.

2.4.3 Use water that is temperature-equilibrated with the laboratory environment. Equilibration can be achieved by storing the water in clean containers in the laboratory.

2.4.4 All weighings ( $\mathrm{I}_{\mathrm{L}}, \mathrm{I}_{\mathrm{E}}$ ) performed in this SOP should be determined with a mechanical balance that has verified calibration data available. A double substitution procedure(SOP 4) with air buoyancy correction may also be used. Equations must be modified if SOP 4 is used!

\subsection{Calibration Procedure for Burets}

2.5.1 Clamp the buret vertically on a support stand. Also clamp a plain glass test tube, large enough to hold a thermometer, in the vicinity of the buret.

2.5.2 Fill buret with water and test for absence of leaks from the tip and stopcock.

2.5.3 Drain and record delivery time, defined as the time of unrestricted flow from the zero mark to the lowest graduation mark with the stopcock fully open.

2.5.4 Fill the buret slightly above zero mark with temperature-equilibrated water and also fill the test tube that holds the thermometer. Record water temperature.

2.5.5 Set the meniscus on the zero mark and touch the tip with the wetted wall of a beaker to remove any excess water. The buret tip must be full.

2.5.6 Fully open the stopcock and discharge contents of buret into a previously weighed flask. The tip should be in contact with the wall of the flask. When the level in the buret is within a few millimeters above the line being calibrated, slow the discharge and make an accurate setting. When the setting is completed, move the flask horizontally to break contact with the tip. Recheck the setting.

2.5.7 Stopper and weigh the flask.

2.5.8 Measure and record the temperature of water in the test tube. 
2.5.9 Test the next interval in the same manner - from the zero mark to the next interval of test.

2.5.10 For burets with a specified waiting time, empty as in 2.5.6 to within a few millimeters of the calibration mark. Pause for the specified waiting time (e.g., $10 \mathrm{~s}$ ), then adjust the meniscus to the graduation line as in 2.5.6.

2.5.11 Make a duplicate determination.

2.5.12 Calculate the volume for each interval as described in Section 3.

2.6 Calibration Procedure for Pipets (One-Mark)

2.6.1 Fill the pipet to the index mark and measure the delivery time with the tip in contact with the internal surface of a beaker.

2.6.2 Refill the pipet by suction, slightly above the index line. Record the water temperature. Wipe tip with filter paper, then slowly lower level to the index line, using a stopcock or pinch clamp for fine control. The tip must be in contact with the wetted wall of a beaker while this setting is being made. Do not remove any water remaining on tip at this time.

2.6.3 Hold pipet in a vertical position and deliver water into a previously weighed weighing flask, with the tip in contact with the inside wall or neck.

2.6.4 After flow has ceased, wait two seconds then remove the pipet from contact with the flask.

2.6.5 Stopper the flask and weigh with its contained load.

2.6.6 Make a duplicate determination.

2.6.7 Calculate the volume as described in Section 3.

2.7 Calibration of Flasks (To Contain)

2.7.1 Clean and dry flask as described in GLP 13, then stopper and weigh the flask. Record the Empty Flask value.

2.7.2 Place an appropriate sized funnel in neck and fill flask to just below the reference graduation while maneuvering the flask to wet the entire neck below the stopper.

2.7.3 Let stand for two minutes then adjust the meniscus to the reference graduation line.

2.7.4 Determine the temperature of the water by putting some in a beaker or test tube containing a thermometer.

2.7.5 Weigh the filled flask and record the Filled Flask mass value.

2.7.6 Make a duplicate determination. 
2.7.7 Perform volume calculations as described in Section 3.

2.8 Calibration of Flasks (To Deliver)

2.8.1 Clean but do not dry flask.

2.8.2 Place an appropriately sized funnel in the neck and fill the flask to just below the reference graduation while maneuvering the flask to wet the entire neck below the stopper.

2.8.3 Let the flask stand for two minutes, then adjust the meniscus to the reference graduation line, then weigh the full vessel, with cap or stopper.

2.8.4 Empty the flask over a 30-second period by gradually inclining it so as to avoid splashing. When the main drainage has ceased, hold the flask in vertical position for 10 seconds unless another drain time is specified, then touch off the drop of water adhering to the top of the flask.

2.8.5 Place a stopper or cap on the flask and reweigh.

2.8.6 Make a duplicate determination.

2.8.7 Calculate the volume of the flask as described in Section 3.

2.9 Calibration of Other Volumetric Glassware.

2.9.1 Measuring Pipets - Calibrate in a manner similar to that used to calibrate burets (2.5).

2.9.2 Graduated Cylinders - Calibrate in a manner similar to that used for flasks $(2.7,2.8)$.

3 Calculations

3.1 Calculate the volume at $20^{\circ} \mathrm{C}$ from the weight of water, contained or delivered, for each run, as follows:

$$
V_{20}=\left(I_{L}-I_{E}\right)(Q)\left(1-\frac{\rho_{a}}{\rho_{B}}\right)\left[\frac{1}{\left(\rho_{w}-\rho_{a}\right)}\right][1-\alpha(t-20)]
$$


Table 2. Variables for volume equation

\begin{tabular}{|c|c|}
\hline Variable & Description \\
\hline$I_{L}-I_{E}$ & $\begin{array}{l}\text { the difference, in grams, obtained from the balance indications } \\
\text { associated with the loaded vessel and the empty vessel. }\end{array}$ \\
\hline$Q$ & $\begin{array}{l}\text { the apparent mass correction factor defined by the expression } \\
Q=\frac{\rho_{B}\left(D_{20}-0.0012\right)}{D_{20}\left(\rho_{B}-.0012\right)} \\
\text { where } \rho_{B} \text { is the density of the balance weights in } \mathrm{g} / \mathrm{cm}^{3}, 0.0012 \text { is the } \\
\text { density of normal air in } \mathrm{g} / \mathrm{cm}^{3} \text { and } D_{20} \text { is the apparent mass to which } \\
\text { the weights are adjusted. The factor has a maximum value of } \\
1.000013 \text { so it may be considered as unity for most calibrations. }\end{array}$ \\
\hline$\rho_{\mathrm{B}}$ & density of the balance weights in $\mathrm{g} / \mathrm{cm}^{3}$ \\
\hline$\rho_{w}$ & density of water at the temperature of measurement in $\mathrm{g} / \mathrm{cm}^{3}$ \\
\hline$\rho_{a}$ & density of air at the conditions of calibration in $\mathrm{g} / \mathrm{cm}^{3}$ \\
\hline$\alpha$ & $\begin{array}{l}\text { the thermal cubical coefficient of expansion for the vessel being } \\
\text { calibrated (in per degree units that match temperature units) }\end{array}$ \\
\hline$t$ & water temperature of calibration, ${ }^{\circ} \mathrm{C}$ \\
\hline
\end{tabular}

3.2 Air density should be calculated using formula provided in SOP 2. Water density should be calculated as described in GLP 10. Look up the cubical coefficient of expansion for the vessel material in NIST IR 6969, Table 9.10 or obtain it from the manufacturer. Calculations of these intermediate values are preferred. However, values for the density of water and air, and for the cubical coefficient of expansion may be found in Tables 9.8, and 9.9 in NISTIR 6969. These values are used in connection with equation 3.1.

3.3 Calculate the average volume at $20^{\circ} \mathrm{C}$. If a reference temperature other than $20^{\circ} \mathrm{C}$ is needed, the equation provided in 3.1 must be appropriately modified.

$4 \quad$ Measurement Assurance

4.1 Duplicate the process with a suitable check standard (See GLP 1, SOP 30, and NISTIR 6969, Sec. 7.4)

4.2 Plot the check standard value and verify that it is within established limits OR a ttest may be incorporated to check the observed value against an accepted value.

4.3 The mean of the check standard is used to evaluate bias and drift over time.

4.4 Check standard observations are used to calculate the standard deviation of the measurement process, $s_{p}$.

5 Assignment of Uncertainty

The limits of expanded uncertainty, $U$, include estimates of the standard uncertainty of the mass standards used, $u_{s}$, plus the uncertainty of measurement, $s_{p}$, at the 95 percent 
level of confidence. See SOP 29 for the complete standard operating procedure for calculating the uncertainty.

5.1 The standard uncertainty for the standard, $u_{s}$, is obtained from the calibration report. The combined standard uncertainty, $u_{c}$, for the standard is used and not the expanded uncertainty, $U$, therefore the reported uncertainty for the standard will usually need to be divided by the coverage factor $k$.

5.2 Standard deviation of the measurement process from control chart performance (See SOP 17 or 20.).

The value for $s_{p}$ is obtained from the control chart data for check standards or estimated based on the range of duplicate measurements over time. This value will incorporate a repeatability factor related to the precision of the weighings and the setting of the meniscus, but not related to the uncertainty of internal weights in the balance or errors in reading the meniscus.

5.3 Other standard uncertainties usually included at this calibration level include uncertainties associated with water temperature measurements, thermometer accuracy, calculation of air density, standard uncertainties associated with the density of the standards used, improper observance of drainage times, viscosity or the surface effects on the volume of liquid clinging to vessel walls after draining and the lack of internal cleanliness.

\section{Additional References:}

Bean, V. E., Espina, P. I., Wright, J. D., Houser, J. F., Sheckels, S. D., and Johnson, A. N., NIST Calibration Services for Liquid Volume, NIST Special Publication 250-72, National Institute of Standards and Technology, Gaithersburg, MD, (2006). 

SOP No. 14

Recommended Standard Operations Procedure

for

Gravimetric Calibration of Volumetric Ware Using an Electronic Balance

$1 \quad$ Introduction

1.1 Purpose of Test

This procedure describes the calibration of either the "to deliver" or "to contain" volume of measuring containers that may be used as volumetric measuring standards. The procedure uses gravimetric calibration principles to minimize calibration uncertainties. Accordingly, the procedure is especially useful for high accuracy calibrations. The procedure does not incorporate measurement control steps to ensure the validity of the standards and the measurement process; additional precautions must be taken. The procedure makes use of an electronic balance and is suitable for all sizes of gravimetric calibrations only limited by the capacity and resolution of the balance.

1.2 Prerequisites

1.2.1 Verify that valid calibration certificates are available for the standards used in the test.

1.2.2 Verify that the standards to be used have sufficiently small standard uncertainties for the level of calibration. Reference standards should not be used for gravimetric calibration.

1.2.3 Verify that the balance used is in good operating condition with sufficiently small process standard deviation, as verified by a valid control chart or preliminary experiments, to ascertain its performance quality when a new balance is put into service. The accuracy of the balance and weighing procedures should be evaluated to minimize potential bias in the measurement process.

1.2.4 Verify that the operator is experienced in precision weighing techniques and has had specific training in SOP 2, SOP 4, SOP 29, GMP 3, GMP 10, and gravimetric calibrations.

1.2.5 Verify that an adequate supply of distilled or deionized water (see GLP 10) is available.

1.2.6 Verify that the laboratory facilities meet the following minimum conditions to enable meeting the expected uncertainty that is achievable with this procedure:

Table 1.

Laboratory environmental conditions

\begin{tabular}{|c|c|c||}
\hline Procedure & Temperature & Relative Humidity \\
\hline \hline Gravimetric & $\begin{array}{c}20^{\circ} \mathrm{C} \text { to } 23^{\circ} \mathrm{C} \text {, a set point } \pm 2{ }^{\circ} \mathrm{C}, \\
\text { maximum change } 1{ }^{\circ} \mathrm{C} / \mathrm{h}\end{array}$ & $\begin{array}{c}40 \% \text { to } 60 \% \\
\pm 10 \% \text { max change } / 4 \mathrm{~h}\end{array}$ \\
\hline
\end{tabular}


2.1 Scope, Precision, Accuracy

The procedure is applicable for the calibration of any size of measuring container that, when filled with water, will not overload the electronic balance used. Typical containers range in capacity from $1 \mathrm{~mL}$ to $20 \mathrm{~L}$; however, this procedure is also applicable for larger provers provided that facility, equipment and standards meet the requirements in this SOP. When larger provers (e.g., 100 gal or more) are tested, also see the Test Notes in SOP 15. The precision of calibration will depend on the care exercised in adjusting the various volumes and strict adherence to the various steps of the procedure. The accuracy attainable will depend on the uncertainties of the standard weights and the air buoyancy and thermal expansion corrections that are made.

\subsection{Summary}

The electronic balance used is first calibrated by weighing a standard mass. The volumetric vessel to be calibrated is then weighed dry or "wetted down," depending on whether the calibration is to be made on a "to contain" or "to deliver" basis. The container is filled with pure water of known temperature and re-weighed. The difference in mass is used to calculate the capacity of the container at various neck graduations. The processes of this section and section 3 should be repeated as required to verify all neck graduations for which a calibrated volume is desired.

\subsection{Equipment and Standards}

2.3.1 Electronic balance having sufficient capacity to weigh the loaded vessel. The sensitivity of the balance will be a limiting factor in the accuracy of the measurement. The resolution and repeatability should be smaller than the accepted uncertainty of the calibration.

2.3.2 Calibrated mass standards with adequate accuracy and traceable to NIST. Ordinarily, standards of ASTM Class 2 or 3 weight specifications are required.

2.3.3 Calibrated thermometer accurate to $\pm 0.1^{\circ} \mathrm{C}$ with recent calibration values that are traceable to NIST to determine water temperature.

2.3.4 Calibrated thermometer accurate to $\pm 0.5^{\circ} \mathrm{C}$ with recent calibration values that are traceable to NIST to determine air temperature. ${ }^{1}$

2.3.5 Calibrated barometer accurate to $\pm 135 \mathrm{~Pa}(1 \mathrm{~mm} \mathrm{Hg})$ with recent calibration values that are traceable to NIST to determine the air pressure. ${ }^{1}$

2.3.6 Calibrated hygrometer accurate to $\pm 10 \%$ with recent calibration values that are traceable to NIST to determine relative humidity. ${ }^{1}$

\footnotetext{
${ }^{1}$ Values from the thermometer, barometer and hygrometer are used to calculate the air density at the time of the measurement. The air density is used to make an air buoyancy correction. The accuracies specified are recommended for high precision calibration. Less accurate equipment can be used with only a small degradation in the overall accuracy of the measurement.
} 


\subsubsection{Distilled or deionized water (See GLP 10).}

2.3.8 Stopwatch or other suitable timing device (does not need to be calibrated.)

\section{$2.4 \quad$ Procedure}

\subsubsection{Cleanliness check}

Verify that all containers to be calibrated are clean as evidenced by uniform drainage of water. No water droplets should remain on any interior surface as the water drains from the container. A reproducible "wet-down" weight is evidence for cleanliness in cases where it is not possible to visually check for uniform drainage. Use GMP 6 or 7 to clean vessels as necessary.

\subsubsection{Drying procedure}

Use GLP 13 as the procedure to dry any container to be calibrated on a "to contain” basis.

\subsubsection{Wet down}

Fill the container to capacity with distilled or deionized water, then empty over a $30 \mathrm{~s}$ period while avoiding splashing. Drain for $10 \mathrm{~s}$ unless another drain time is specified. (This is commonly called a "30 s pour, $10 \mathrm{~s}$ drain" emptying procedure.) A $30 \mathrm{~s}( \pm 5 \mathrm{~s})$ pour followed by a $10 \mathrm{~s}$ drain, with the measure held between a 10 degree and 15 degree angle from vertical, is required during calibration and use for glass flasks. A wet-down is not required if a transfer vessel is used to weigh a delivered volume of water.

\subsubsection{Weighings (Option A)}

2.4.4.1 Zero the balance and record reading as $O_{1}$. Place a standard mass, $M_{S}$, on the balance platform $\left(M_{S}\right.$ should be slightly larger than the mass of the filled vessel.) Record reading as $\mathrm{O}_{2}$.

2.4.4.2 Zero the balance. Place dry or "wet-down" container on balance platform, as appropriate, and record reading as $\mathrm{O}_{3} \cdot{ }^{2}$ Caution: all containers must be dry on the outside for all weighings.

2.4.4.3 Fill container to its reference mark. Read and record the temperature of the water used to fill the container. Carefully adjusting the meniscus (if present) to minimize filling error (see GMP No. 3). Zero the balance. Weigh the filled vessel and record reading as $\mathrm{O}_{4}$.

2.4.4.4 Immediately after weighing, check the temperature of the water in the filled container. If the temperature differs by more than $0.2{ }^{\circ} \mathrm{C}$ from that of 2.4.4.3, refill and reweigh as described in 2.4.4.3.

\footnotetext{
2 When calibrating “to deliver” vessels, O4 may be measured before O3. If a transfer vessel is used, the drained mass or empty mass is usually measured before the filled mass.
} 
2.4.4.5 Record air temperature, barometric pressure, and relative humidity at the time of the above measurements.

2.4.4.6 Make a duplicate determination (Run 2).

\subsubsection{Weighings (Option B)}

2.4.5.1 Zero the balance and record reading as $O_{1}$. Place a standard mass, $M_{S 1}$, on the balance platform $\left(M_{S 1}\right.$ should be slightly larger than the mass of the drained or dry vessel.) Record reading as $\mathrm{O}_{2}$.

2.4.5.2 Zero the balance. Place dry or "wet-down” container on balance platform, as appropriate, and record reading as $\mathrm{O}_{3}$. Caution: all containers must be dry on the outside for all weighings.

2.4.5.3 After removing empty vessel, zero the balance and record reading as $\mathrm{O}_{4}$. Place a standard mass, $M_{S 2}$, on the balance platform $\left(M_{S 2}\right.$ should be slightly larger than the mass of the filled vessel.) Record reading as $\mathrm{O}_{5}$.

2.4.5.4 Fill container to its reference mark. Read and record the temperature of the water used to fill the container. Carefully adjusting the meniscus (if present) to minimize filling error (see GMP 3). Zero the balance. Weigh the filled vessel and record reading as $\mathrm{O}_{6}$.

2.4.5.5 Immediately after weighing, check the temperature of the water in the filled container. If the temperature differs by more than $0.2{ }^{\circ} \mathrm{C}$ from that of 2.4.5.4, refill and reweigh as described in 2.4.5.4.

2.4.5.6 Record air temperature, barometric pressure, and relative humidity at the time of the above measurements.

2.4.5.7 Make a duplicate determination (Run 2).

3 Calculations

3.1 Compute the volume, $V_{t}$, for each determination using the equation:

Option A

$$
V_{t}=\left(O_{4}-O_{3}\right)\left(\frac{M_{s}}{O_{2}-O_{1}}\right)\left(1-\frac{\rho_{a}}{\rho_{s}}\right)\left(\frac{1}{\rho_{w}-\rho_{a}}\right) \quad \text { Eqn. } 3.1
$$


Option B

$V_{t}=\left[O_{6(\text { filled })} \frac{M_{s 2}\left(1-\frac{\rho_{a}}{\rho_{s}}\right)}{\left(O_{5}-O_{4}\right)}-O_{3 \text { (drained })} \frac{M_{s 1}\left(1-\frac{\rho_{a}}{\rho_{s}}\right)}{\left(O_{2}-O_{1}\right)}\right]\left(\frac{1}{\rho_{w}-\rho_{a}}\right)$ Eqn. 3.2

Table 2. Variables for volume equations

\begin{tabular}{|c|l||}
\hline Variable & \multicolumn{1}{|c||}{ Description } \\
\hline \hline $\begin{array}{c}M_{s}, M_{s 1}, \\
M_{s 2}\end{array}$ & mass of standards (i.e., true mass, vacuum mass) (g) \\
\hline$\rho_{s}$ & density of $M_{S}\left(\mathrm{~g} / \mathrm{cm}^{3}\right)$ \\
\hline$\rho_{w}$ & density of water at the temperature of measurement $\left(\mathrm{g} / \mathrm{cm}^{3}\right)$ \\
\hline$\rho_{a}$ & density of air at the conditions of calibration $\left(\mathrm{g} / \mathrm{cm}^{3}\right)$ \\
\hline$V_{t}$ & $\begin{array}{l}\text { represents either the "to contain" or "to deliver" volume }(\text { depending } \\
\text { on whether } O_{3} \text { or } O_{6} \text { represent a dry or a "wet down" container at the } \\
\text { temperature of the measurement }\left(\mathrm{cm}^{3} \text { or } \mathrm{mL}\right)\end{array}$ \\
\hline
\end{tabular}

3.2 Compute $V_{20}$, the volume at $20^{\circ} \mathrm{C}$, for each run, using the expression:

$$
V_{20}=V_{t}[1-\alpha(t-20)]
$$

where $\alpha$ is the cubical coefficient of expansion of the container being calibrated, (see NISTIR 6969, Table 9.10), and, $t$, is the temperature $\left({ }^{\circ} \mathrm{C}\right)$ of the water.

3.3 Compute the mean $V_{20}$ for the duplicate measurements.

3.4 If using a different reference temperature, use the following equation and be sure to match the cubical coefficient of expansion units with the units of temperature:

$$
V_{\text {ref }}=V_{t}\left[1-\alpha\left(t-\mathrm{t}_{\text {ref }}\right)\right]
$$


4.1 Duplicate the process with a suitable check standard (See GLP 1, SOP 30, and NISTIR 6969, Sec. 7.4)

4.2 Plot the check standard value and verify it is within established limits OR a t-test may be incorporated to check the observed value against an accepted value.

4.3 The mean of the check standard is used to evaluate bias and drift over time.

4.4 Check standard observations are used to calculate the standard deviation of the measurement process, $s_{p}$.

\section{$5 \quad$ Assignment of Uncertainties}

The limits of expanded uncertainty, $U$, include estimates of the standard uncertainty of the mass standards used, $u_{c}$, plus the uncertainty of measurement, $s_{p}$, at the 95 percent level of confidence. See SOP 29 for the complete standard operating procedure for calculating the uncertainty.

5.1 The standard uncertainty for the standard, $u_{s}$, is obtained from the calibration report. The combined standard uncertainty, $u_{c}$, is used and not the expanded uncertainty, $U$, therefore the reported uncertainty for the standard will usually need to be divided by the coverage factor $k$. When multiple mass standards are used, see SOP 29 for treatment of dependencies.

5.2 Standard deviation of the measurement process from control chart performance (See SOP No. 17 or 20.)

The value for $s_{p}$ is obtained from the control chart data for check standards or estimated based on the range of duplicate measurements over time. This value will incorporate a repeatability factor related to the precision of the weighings and the setting of the meniscus, but not related to the errors in reading the meniscus.

5.3 Other standard uncertainties usually included at this calibration level include uncertainties associated with water temperature measurements, thermometer accuracy, calculation of air density, standard uncertainties associated with the density of the standards used, coefficients of expansion, viscosity or surface effects on the volume of liquid clinging to vessel walls after draining, improper observance of drainage times, and the lack of internal cleanliness.

\section{Additional References:}

Bean, V. E., Espina, P. I., Wright, J. D., Houser, J. F., Sheckels, S. D., and Johnson, A. N., NIST Calibration Services for Liquid Volume, NIST Special Publication 250-72, National Institute of Standards and Technology, Gaithersburg, MD, (2006) 
Appendix A

Gravimetric Calibration Data Sheet (Option A)

\section{Laboratory data and conditions:}

\begin{tabular}{|r|r|r|r||}
\hline Vessel ID & Operator & \\
\hline Date & & Air Temperature & \\
\hline Balance & & Pressure & \\
\hline Load & & Relative Humidity & \\
\hline \multicolumn{3}{|c||}{ Process standard deviation from control chart, $s_{p}$} & \\
\hline
\end{tabular}

Mass standard(s) data:

\begin{tabular}{|c|c|c|c|c|c|c|c||}
\hline ID & Nominal & $\begin{array}{c}\text { Mass } \\
\text { Correction }\end{array}$ & $\begin{array}{c}\text { Density } \\
\mathrm{g} / \mathrm{cm}^{3}\end{array}$ & ID & Nominal & $\begin{array}{c}\text { Mass } \\
\text { Correction }\end{array}$ & $\begin{array}{c}\text { Density } \\
\mathrm{g} / \mathrm{cm}^{3}\end{array}$ \\
\hline S - filled & & & S - empty & & & \\
\hline \multicolumn{2}{|r|}{$u_{s}$, and $k$ factor } & & & $u_{s}$, and $k$ factor & \\
\hline
\end{tabular}

\section{Observations:}

\begin{tabular}{|c|c|c|c|}
\hline Run 1 & Weights & \multicolumn{2}{|c|}{ Balance Observations, Units } \\
\hline 1 & Zeroed Balance & $O_{1}$ & 0 \\
\hline 2 & $M_{S}$ & $\mathrm{O}_{2}$ & \\
\hline 3 & Empty or Drained & $\mathrm{O}_{3}$ & \\
\hline 4 & Filled & $\mathrm{O}_{4}$ & \\
\hline & $t_{w}:$ & & \\
\hline Run 2 & Weights & \multicolumn{2}{|c|}{ Balance Observations, Units } \\
\hline 1 & Zeroed Balance & $O_{1}$ & 0 \\
\hline 2 & $M_{S}$ & $\mathrm{O}_{2}$ & \\
\hline 3 & Empty or Drained & $\mathrm{O}_{3}$ & \\
\hline 4 & Filled & $\mathrm{O}_{4}$ & \\
\hline & $t_{w}:$ & & \\
\hline
\end{tabular}

Note: dotted line represents decimal point. 


\section{Example \\ Gravimetric Calibration Data Sheet (Option A)}

Laboratory data and conditions:

\begin{tabular}{|r|r|r|r||}
\hline Vessel ID & & Operator & GH \\
\hline Date & $10 / 1 / 99$ & Air Temperature & $22.5^{\circ} \mathrm{C}$ \\
\hline Balance & LC 5100 & Pressure & $747.8 \mathrm{~mm} \mathrm{Hg}$ \\
\hline Load & $2 \mathrm{~L}$ & Relative Humidity & $45 \%$ \\
\hline \multicolumn{3}{|c|}{ Process standard deviation from control chart, $\mathrm{s}_{\mathrm{p}}$} & $0.042 \mathrm{~mL}$ \\
\hline
\end{tabular}

\section{Mass standard(s) data:}

\begin{tabular}{|c|c|c|c|c|c|c|c||}
\hline \hline ID & Weights & $\begin{array}{c}\text { Mass } \\
\text { Correction }\end{array}$ & $\begin{array}{c}\text { Density } \\
\mathrm{g} / \mathrm{cm}^{3}\end{array}$ & ID & Nominal & $\begin{array}{c}\text { Mass } \\
\text { Correction }\end{array}$ & $\begin{array}{c}\text { Density } \\
\mathrm{g} / \mathrm{cm}^{3}\end{array}$ \\
\hline $\mathrm{M}_{\mathrm{s}}$ - filled & $2 \mathrm{~kg}$ & $0.000123 \mathrm{~g}$ & 7.95 & $\mathrm{M}_{\mathrm{s}}$ - empty & not used & & \\
\hline \multicolumn{3}{r|r}{$u_{s}$, and $k$ factor } & \multicolumn{2}{|c|}{$u_{s}$, and $k$ factor } & \\
\hline
\end{tabular}

Observations:

\begin{tabular}{|c|c|c|c|}
\hline Run 1 & Weights & \multicolumn{2}{|c|}{ Balance Observations, Units__ g } \\
\hline 1 & Zeroed Balance & $O_{1}$ & 0 \\
\hline 2 & $M_{s}$ & $\mathrm{O}_{2}$ & 2000 \\
\hline 3 & Empty or Drained & $\mathrm{O}_{3}$ & $654: 729$ \\
\hline \multirow[t]{2}{*}{4} & Filled & $\mathrm{O}_{4}$ & $2648: 747$ \\
\hline & $t_{w}: 22.8^{\circ} \mathrm{C}$ & & \\
\hline Run 2 & Weights & \multicolumn{2}{|c|}{ Balance Observations, Units } \\
\hline 1 & Zeroed Balance & $O_{1}$ & 0 \\
\hline 2 & $M_{s}$ & $\mathrm{O}_{2}$ & 1999 \\
\hline 3 & Empty or Drained & $\mathrm{O}_{3}$ & 667:351 \\
\hline 4 & Filled & $\mathrm{O}_{4}$ & 2661:365 \\
\hline & $t_{w}: 22.6^{\circ} \mathrm{C}$ & & ! \\
\hline
\end{tabular}

Note: dotted line represents decimal point. 
Calculate the air density (SOP 2) $\rho_{a}$ :

$\rho_{a}=1.170 \mathrm{mg} / \mathrm{cm}^{3}=0.001170 \mathrm{~g} / \mathrm{cm}^{3}$

Look up or calculate the density of the water, $\rho_{w}$ :

$22.8{ }^{\circ} \mathrm{C}=0.997587 \mathrm{~g} / \mathrm{cm}^{3}$

$22.6{ }^{\circ} \mathrm{C}=0.997634 \mathrm{~g} / \mathrm{cm}^{3}$

Compute the volume, $V_{t}$, for each determination using the equation:

$$
V_{t}=\left(O_{4}-O_{3}\right)\left(\frac{M_{s}}{O_{2}-O_{1}}\right)\left(1-\frac{\rho_{a}}{\rho_{s}}\right)\left(\frac{1}{\rho_{w}-\rho_{a}}\right)
$$

\section{Run 1:}

$$
\begin{aligned}
& V_{t}=(2648.747-654.729)\left(\frac{2000.000123}{2000.003-0}\right)\left(1-\frac{0.001170}{7.95}\right)\left(\frac{1}{0.997587-0.001170}\right) \\
& V_{t}=(1994.018)(0.99999856)(0.99985283)(1.0035959) \\
& V_{t}=(1994.018)(1.003446756)=2000.890865 \mathrm{~mL}
\end{aligned}
$$

Compute $V_{20}$, the volume at $20^{\circ} \mathrm{C}$, for Run 1 using the expression:

$V_{20}=V_{t}[1-\alpha(t-20)]$

$V_{20}=2000.890865[1-0.000025(22.8-20)]=2000.750802 \mathrm{~mL}$

\section{Run 2:}

$V_{t}=(2661.365-667.351)\left(\frac{2000.000123}{1999.998-0}\right)\left(1-\frac{0.001170}{7.95}\right)\left(\frac{1}{0.997634-0.001170}\right)$

$V_{t}=(1994.014)(1.00000106)(0.99985283)(1.00354855)$

$V_{t}=(1994.014)(1.003400858)=2000.797478 \mathrm{~mL}$

Compute $V_{20}$, the volume at $20^{\circ} \mathrm{C}$, for Run 2 using the expression:

$V_{20}=V_{t}[1-\alpha(t-20)]$ 
$V_{20}=2000.797478[1-0.000025(22.6-20)]=2000.667426 \mathrm{~mL}$

Calculate the mean $V_{20}$ :

$$
\bar{V}_{20}=\frac{(2000.750802+2000.667426)}{2}=2000.709114 \mathrm{~mL}
$$

Calculate the uncertainty for the calibration:

$U=u_{c} * 2$

$$
u_{c}=\sqrt{u_{s}^{2}+s_{p}^{2}+u_{o}^{2}}
$$

The uncertainty for the standard must be divided by the $k$ factor for the standard, $u_{s}$. All values must be represented in like units.

$$
\begin{aligned}
& U_{s}=2 \mathrm{mg}, k=2 \quad u_{s}=2 \mathrm{mg} / 2=1 \mathrm{mg} \quad \text { converted to volume }=0.000987 \mathrm{~mL} \\
& s_{p}=0.042 \mathrm{~mL} \\
& u_{o}=0.00018 \mathrm{~mL} \\
& u_{c}=\sqrt{(0.000987)^{2}+(0.042)^{2}+(0.00018)^{2}} \\
& u_{c}=0.042012 \mathrm{~mL} \\
& U=0.042012 * 2=0.084024 \mathrm{~mL}
\end{aligned}
$$

The volume correction and uncertainty would be reported as follows when rounded to two significant digits according to NISTIR 6969, GMP 9:

$V_{20}=2000.709 \mathrm{~mL} \pm 0.084 \mathrm{~mL}$ 


\section{Appendix B}

\section{Gravimetric Calibration Data Sheet (Option B)}

\section{Laboratory data and conditions:}

\begin{tabular}{|r|r|r|r||}
\hline Vessel ID & Operator & \\
\hline Date & & Air Temperature & \\
\hline Balance & & Pressure & \\
\hline Load & & Relative Humidity & \\
\hline \multicolumn{3}{|r|}{ Process standard deviation from control chart, $s_{p}$} & \\
\hline
\end{tabular}

\section{Mass standard(s) data:}

\begin{tabular}{|c|c|c|c|c|c|c|c||}
\hline ID & Nominal & $\begin{array}{c}\text { Mass } \\
\text { Correction }\end{array}$ & $\begin{array}{c}\text { Density } \\
\mathrm{g} / \mathrm{cm}^{3}\end{array}$ & ID & Nominal & $\begin{array}{c}\text { Mass } \\
\text { Correction }\end{array}$ & $\begin{array}{c}\text { Density } \\
\mathrm{g} / \mathrm{cm}^{3}\end{array}$ \\
\hline$M_{s 1}$ - filled & & & $M_{s 2}$ - empty & & & \\
\hline \multicolumn{2}{|r|}{$u_{s}$, and $k$ factor } & & & $u_{s}$, and $k$ factor & \\
\hline
\end{tabular}

Observations:

\begin{tabular}{|c|c|c|c|}
\hline Run 1 & Weights & \multicolumn{2}{|c|}{ Balance Observations, Units } \\
\hline 1 & Zeroed Balance & $O_{1}$ & 0 \\
\hline 2 & $M_{\mathrm{s} 1}$ & $\mathrm{O}_{2}$ & \\
\hline 3 & Empty or Drained & $\mathrm{O}_{3}$ & \\
\hline 4 & Zeroed Balance & $\mathrm{O}_{4}$ & o:000 \\
\hline 5 & $M_{S 2}$ & $\mathrm{O}_{5}$ & \\
\hline \multirow[t]{2}{*}{6} & Filled & $\mathrm{O}_{6}$ & \\
\hline & $t_{w}:$ & & \\
\hline Run 2 & Weights & \multicolumn{2}{|c|}{ Balance Observations, Units } \\
\hline 1 & Zeroed Balance & $O_{1}$ & 0 \\
\hline 2 & Zeroed Balance & $\mathrm{O}_{2}$ & \\
\hline 3 & $M_{s 1}$ & $\mathrm{O}_{3}$ & \\
\hline 4 & Empty or Drained & $\mathrm{O}_{4}$ & 0 \\
\hline 5 & Zeroed Balance & $\mathrm{O}_{5}$ & \\
\hline 6 & $M_{S 2}$ & $\mathrm{O}_{6}$ & $?$ \\
\hline & $t_{w}:$ & & \\
\hline
\end{tabular}

Note: dotted line represents decimal point. 



\section{SOP No. 15}

\section{Recommended Standard Operations Procedure for Calibration of Intermediate and Large Volume Standards Gravimetric Method' ${ }^{1}$ Using an Equal-Arm Balance ${ }^{2}$}

\section{$1 \quad$ Introduction}

\subsection{Purpose of Calibration}

This procedure is applicable to calibrations where high accuracy is needed, or where the volumetric transfer method is not possible. It is especially useful for the capacity range of 5 gal to 100 gal (or larger) using an equal-arm balance and the double substitution weighing method as described in SOP 4. It may also be used for smaller volumes with an equal-arm balance. If an electronic balance is used, see SOP 14.

\subsection{Prerequisites}

1.2.1 Verify that valid calibration certificates are available for the standards used in the test.

1.2.2 Verify that the standards to be used have sufficiently small standard uncertainties for the intended level of calibration. Reference standards should not be used for gravimetric calibration.

1.2.3 Verify that the balance used is in good operating condition with sufficiently small process standard deviation as verified by a valid control chart, or preliminary experiments to ascertain its performance quality when a new balance is put into service. The accuracy of the balance and weighing procedures should be evaluated to minimize potential bias in the measurement process.

1.2.4 Verify that the operator is experienced in precision weighing techniques and has had specific training in SOP 2, SOP 4, SOP 29, and GMP 1, GMP 3, GMP 10, and gravimetric calibrations.

1.2.5 Verify that the laboratory facilities meet the minimum conditions shown in Table 1 to meet the expected uncertainty achievable with this procedure.

1.2.6 Verify that an adequate supply of distilled or deionized water (see GLP 10) is available.

\footnotetext{
${ }^{1}$ Based on the work of J. Houser "Procedure for the Calibration of Volumetric Test Measures" NISTIR 73-287.

${ }^{2}$ Non-SI units are predominately in common use in State legal metrology laboratories, and/or the petroleum industry for many volumetric measurements, therefore non-SI units have been used to reflect the practical needs of the laboratories performing these measurements as appropriate. The reference temperature for petroleum products is $60{ }^{\circ} \mathrm{F}$ and volume values are typically in gallons.
} 
Table 1. Laboratory environmental conditions

\begin{tabular}{|c|c|c|}
\hline Procedure & Temperature & Relative Humidity \\
\hline \hline Gravimetric & $\begin{array}{c}2{ }^{\circ} \mathrm{C} \text { to } 23^{\circ} \mathrm{C} \text {, a set point } \pm 2{ }^{\circ} \mathrm{C}, \\
\text { maximum change } 1{ }^{\circ} \mathrm{C} / \mathrm{h}\end{array}$ & $\begin{array}{c}40 \% \text { to } 60 \% \\
\pm 10 \% \text { max change } / 4 \mathrm{~h}\end{array}$ \\
\hline
\end{tabular}

2 Methodology

2.1 Summary

This procedure may be used to determine three calibration values:

2.1.1 The contained volume, $V_{C}$, which is the volume of water required to fill the vessel at a specified temperature (usually $60{ }^{\circ} \mathrm{F}$ for petroleum products).

2.1.2 The delivered volume, $V_{D}$, which is the volume of water that may be poured or drained from the vessel at a specified temperature (usually $60{ }^{\circ} \mathrm{F}$ for petroleum products) under specified conditions (see note 1).

2.1.3 The neck scale calibration value, $N S C V$, which relates the true volume of the neck to the value indicated by the neck scale.

The mass of water required to fill the vessel is measured at an observed temperature. The known density of water and coefficient of expansion of the vessel are used to calculate the volume of the vessel at a reference temperature.

The precision attained will depend on the sensitivity of the balance and on the care exercised in carrying out the various operations of the procedure. Cleanliness of the vessel and strict adherence to the prescribed drainage procedure are critical for high precision. The accuracy of calibration depends on all of the above plus the uncertainties of the various weighings, accuracy in reading a meniscus (where present), the volumetric temperature equilibration and corrections, the proper correction for air buoyancy, and the purity of the water used as the standard. The metrologist must critically consider all of the above factors when assigning uncertainty limits to the calibrated volumes.

With careful observance of good measurement practices, an overall relative uncertainty of $\pm 0.02 \%$ should be attainable.

2.2 Apparatus

2.3.1 Equal-arm balance of adequate capacity and sensitivity (standard deviation of $500 \mathrm{mg}$ or better for 5 gal level).

2.3.2 Weights (meeting ASTM Class 2 or 3 specifications) as appropriate for the accuracy requirements.

2.3.3 Calibrated thermometer accurate to $\pm 0.1^{\circ} \mathrm{C}$ with recent calibration values that are traceable to NIST to determine water temperature. ${ }^{3}$

\footnotetext{
${ }^{3}$ Values from the thermometer, barometer and hygrometer are used to calculate the air density at the time of the measurement. The air density is used to make an air buoyancy correction. The accuracies specified are
} 
2.3.4 Calibrated thermometer accurate to $\pm 0.5^{\circ} \mathrm{C}$ with recent calibration values that are traceable to NIST to determine air temperature.

2.3.5 Calibrated barometer accurate to $\pm 135 \mathrm{~Pa}(1 \mathrm{~mm} \mathrm{Hg})$ with recent calibration values that are traceable to NIST to determine the air pressure.

2.3.6 Calibrated hygrometer accurate to $\pm 10 \%$ with recent calibration values that are traceable to NIST to determine relative humidity.

2.3.7 Distilled or deionized water (See GLP 10).

2.3.8 Stopwatch or other suitable timing device (does not need to be calibrated.)

2.3.9 Cap to place over neck of the vessel.

2.3 Procedure

\subsubsection{Preliminary Operations}

2.3.1.1 Clean the interior of the vessel with biodegradable low-sudsing detergent (see GMP 6) with gentle scrubbing as necessary. Rinse several times with clean water to remove all detergent, followed by pure water. Check for leaks and for uniform drainage.

2.3.1.2 Clean and dry outside of container to remove any material which might subsequently dislodge and cause an erroneous weighing.

2.3.1.3 Dry inside by rinsing with small amounts of alcohol or by drawing clean, filtered air through the vessel (several hours required). For large vessels the heat from a low wattage light bulb suspended inside the vessel overnight will aid in drying by slightly heating the vessel and creating convection currents through the interior. Allow the vessel to come to thermal equilibrium with the room before proceeding.

\subsubsection{Empty Weight}

2.3.2.1 Weigh the empty vessel and cap using the double substitution procedure (SOP 4) with air buoyancy correction.

2.3.2.2 Record air temperature, humidity, and barometric pressure as needed for calculating air density (SOP 2) and performing buoyancy corrections.

2.3.2.3 The empty weight is determined as shown in the calculations (Section 3.1, Eqn 2).

\subsubsection{Filled Weight}

recommended for high precision calibration. Less accurate equipment can be used with only a small degradation in the overall accuracy of the measurement. 
2.3.3.1 Fill the vessel with pure water to the zero point on the neck scale. Be sure the vessel is level. Bounce the liquid to disturb the meniscus to assure it has reached equilibrium level. Record the water temperature and readjust level if necessary. Be sure that no water remains on the outside of the vessel when it is weighed. (See note 2.) The filled weight is determined as shown in the calculations (Section 3.1, Eqn 2).

2.3.3.2 Weigh filled vessel and cap as in 2.3.2.

\subsubsection{Drained Weight}

2.3.4.1 Drain vessel using appropriate discharge/pour and drain times (see note 1). Replace cap. The empty weight is determined as shown in the calculations (Section 3.1, Eqn 2).

2.3.4.2 Weigh drained vessel and cap as in 2.3.2.

2.3.5 Make a duplicate determination of steps 2.3.2 through 2.3.4 (Run 2).

2.3.6 Neck scale plate verification

2.3.6.1 Fill vessel with water to a scale division near the bottom of the scale range. Record reading $\left(s_{r 1}\right)$.

2.3.6.2 Make appropriate successive additions of water from a calibrated buret or other suitable volumetric measuring device. Record scale readings after each addition .

2.3.6.3 A plot of scale readings with respect to volume added should be linear and will be a gross check of the validity of this calibration.

2.3.6.4 Calculate the neck scale calibration value, NSCV, using the expression

$$
N S C V=\frac{V_{W}}{\left(s r_{f}-s r_{i}\right)}
$$

Table 1. Variables for neck scale calibration value equation

\begin{tabular}{|c|l||}
\hline \hline Variable & \multicolumn{1}{|c|}{ Description } \\
\hline \hline$N S C V$ & Neck scale calibration value \\
\hline$V_{W}$ & Total volume of water added to neck \\
\hline$s r_{i}$ & Scale reading, initial \\
\hline$s r_{f}$ & Scale reading, final \\
\hline
\end{tabular}


3.1 To calculate the filled, empty, or drained mass, use the following equation from SOP 4 using Option A.

$M_{\text {(filled, empty, drained })}=M_{S}\left(1-\frac{\rho_{a}}{\rho_{S}}\right)+\frac{\left(O_{2}-O_{1}+O_{3}-O_{4}\right)}{2}\left[\frac{M_{s w}\left(1-\frac{\rho_{a}}{\rho_{s w}}\right)}{\left(O_{3}-O_{2}\right)}\right]$

Eqn.2

Table 2. Variables for Equation 2

\begin{tabular}{|c|c|}
\hline Symbol & Description \\
\hline$S$ & standard reference weight \\
\hline$s w$ & $\begin{array}{l}\text { small calibrated weight used to evaluate the sensitivity of the } \\
\text { balance }\end{array}$ \\
\hline$M$ & $\begin{array}{l}\text { the mass (true mass) of a specific weight. Subscripts } s \text {, sw, filled, } \\
\text { empty, drained are used to identify the weight (equals Nominal } \\
\text { plus Correction in the case of mass standards) }\end{array}$ \\
\hline$\rho_{a}$ & density of air at time of calibration \\
\hline$\rho$ & $\begin{array}{l}\text { density of masses; subscripts } s, x, t_{s}, t_{x}, s w \text { are used to identify the } \\
\text { weight. }\end{array}$ \\
\hline$O$ & $\begin{array}{l}\text { Balance observations, designated with subscripts } 1,2,3 \ldots \text {, for the } \\
\text { observation number }\end{array}$ \\
\hline
\end{tabular}

3.2 To calculate containment volume, $V_{C}$, at temperature of measurement, $t$,

$$
\begin{gathered}
V_{C t}=\left(M_{\text {filled }}-M_{\text {empty }}\right)\left[\frac{1}{\left(\rho_{w}-\rho_{a}\right)}\right] \\
V_{D t}=\left(M_{\text {filled }}-M_{\text {drained }}\right)\left[\frac{1}{\left(\rho_{w}-\rho_{a}\right)}\right]
\end{gathered}
$$

Eqn. 3

3.3 To calculate delivered volume, $V_{D}$, at temperature of measurement, $t$,

Eqn. 4

3.4 To correct volumes to reference temperature, $t_{r e f}$, (be sure to match units for cubical coefficient of expansion, $\alpha$, with temperature units (e.g., degrees $\mathrm{C}$ with $\left.{ }^{\circ} \mathrm{C}^{-1}\right)$.

$$
V_{\text {tref }}=V_{t}\left[1-\alpha\left(t-t_{\text {ref }}\right)\right]
$$

Eqn. 5 
3.5 To convert the volume measured in $\mathrm{mL}\left(\mathrm{cm}^{3}\right)$ to gal:

$V_{\text {gal }}=(0.000264172) V_{m L}$ (There are $3785.411784 \mathrm{~mL}$ per gal.)

Table 2. Variables for volume equation

\begin{tabular}{|c|l||}
\hline Symbol & \multicolumn{1}{|c|}{ Description } \\
\hline$\rho_{w}$ & density of water at temperature of filling \\
\hline$\rho_{a}$ & density of air \\
\hline$t$ & temperature at time of test \\
\hline$t_{\text {ref }}$ & reference temperature, usually $60^{\circ} \mathrm{F}$ (or $20^{\circ} \mathrm{C}$ ) \\
\hline$\alpha$ & $\begin{array}{l}\text { cubical coefficient of expansion of the vessel } \\
\text { (must match temperature units in }{ }^{\circ} \mathrm{C}^{-1} \mathrm{or}^{\circ} \mathrm{F}^{-1} \text { ) }\end{array}$ \\
\hline
\end{tabular}

3.6 Calculate the average volume at reference temperature $\left(V_{t \text { ref }}\right)$

3.7 Physical Constants

\subsubsection{Density of Air}

Value at environmental conditions at time of weighings calculated from the equation given in the Appendix to SOP 2.

\subsubsection{Density of Water}

Calculate the density of water using the formula given in GLP 10 or look up the value from appropriate tables.

\subsubsection{Cubical Coefficient of Expansion}

Values for the cubical coefficient of expansion of various materials are given in NISTIR 6969, Table 9.10 and are normally printed on the vessel identification plate (for test measures and provers).

4 Measurement Assurance

4.1 Duplicate the process with a suitable check standard (See GLP 1, SOP 30, and NISTIR 6969, Sec. 7.4)

4.2 Plot the check standard value and verify that it is within established limits OR a $t$-test may be incorporated to check the observed values against an accepted value.

4.3 The mean of the check standard is used to evaluate bias and drift over time.

4.4 Check standard observations are used to calculate the standard deviation of the measurement process, $s_{p}$. 
The limits of expanded uncertainty, $U$, include estimates of the standard uncertainty of the mass standards used, $u_{s}$, plus the uncertainty of measurement, $\mathrm{s}_{\mathrm{p}}$, at the 95 percent level of confidence. See SOP 29 for the complete standard operating procedure for calculating the uncertainty.

5.1 The standard uncertainty for the mass standard, $u_{s}$, is obtained from the calibration report. The combined standard uncertainty, $u_{c}$, is used and not the expanded uncertainty, $U$; therefore, the reported uncertainty for the standard will usually need to be divided by the coverage factor $k$. See SOP 29 for proper handling of uncertainties when multiple standards are used.

5.2 Standard deviation of the measurement process from control chart performance (See SOP 17 or 20.) The value for $s_{p}$ is obtained from the control chart data for check standards or estimated based on the range of duplicate measurements over time. This value will incorporate a repeatability factor related to the precision of the weighings and the setting of the meniscus, but not related to errors in reading the meniscus.

5.3 Other standard uncertainties usually included at this calibration level include uncertainties associated with water temperature measurements, thermometer accuracy, the coefficient of expansion, viscosity, reading the meniscus, calculation of air density, standard uncertainties associated with the density of the standards used, improper observance of drainage times, viscosity or the surface effects on the volume of liquid clinging to vessel walls after draining and lack of internal cleanliness.

\section{Additional References:}

Bean, V. E., Espina, P. I., Wright, J. D., Houser, J. F., Sheckels, S. D., and Johnson, A. N., NIST Calibration Services for Liquid Volume, NIST Special Publication 250-72, National Institute of Standards and Technology, Gaithersburg, MD, (2006). 


\section{Appendix}

Test Notes

$1 \quad$ Pour and drain times.

It is impractical to completely drain a filled container, because some of the contents will remain as a film. By strict adherence to a specified procedure, the residual contents can be held essentially constant so that, reproducible calibration constants can be obtained. The conditions conventionally selected are as follows:

a For bottom-drain containers: open drain valve fully and allow contents to discharge at maximum rate. When flow ceases, wait $30 \mathrm{~s}$, close valve, and touch off any drops adhering to spout.

b For pour-type containers: pour contents by gradually tilting container to an $85^{\circ}$ angle, so that virtually all is delivered in $30 \mathrm{~s}$. Allow to drain for an additional $10 \mathrm{~s}$, then touch off any drops adhering to the lip.

The instructions described above must be precisely followed during calibration and use of the calibrated vessels.

2 Evaporation losses.

A suitable cap (an empty glass beaker, for example) should be placed on the top of open vessels to minimize evaporation losses. If used, the cap must be included in all weighings.

3 Slicker-plate.

When a slicker-plate standard is calibrated, the plate should be used to fix the water level in it. This plate must be weighed with the standard during each such operation. 


\section{SOP 16}

\section{Standard Operating Procedure for \\ Calibration of Measuring Flasks \\ Volume Transfer Method}

1 Introduction

\section{$1.1 \quad$ Purpose of Test}

This procedure describes a method for volume transfer calibration of the "to deliver" volume of measuring flasks from calibrated volumetric standards that, in turn, are used as volumetric measurement standards, often for packaged commodity verification. If "to contain" calibrations are to be performed, appropriate modifications are needed in the procedure to ensure complete drying of the flask between calibration runs.

\subsection{Prerequisites}

1.2.1 Verify that valid calibration certificates are available for the standards used in the test.

1.2.2 Verify that the standards to be used have sufficiently small standard uncertainties for the intended level of calibration.

1.2.3 Verify that the standard burets and pipets are clean, free of leaks, and in good operational condition.

1.2.4 Verify the availability of an adequate supply of pure distilled or deionized water (See GLP 10).

1.2.5 Verify that the operator has had specific training and is proficient in SOP 16, GMP 3, GMP 7, and is familiar with the operating characteristics and conditioning of pipets and burets.

1.2.6 Verify that the laboratory facilities meet the minimum conditions shown in Table 1 to meet the expected uncertainty that is achievable with this procedure.

Table 1. Laboratory environmental conditions

\begin{tabular}{|c|c|c|}
\hline Procedure & Temperature & Relative Humidity \\
\hline $\begin{array}{l}\text { Volume } \\
\text { Transfer }\end{array}$ & $\begin{array}{c}18^{\circ} \mathrm{C} \text { to } 27^{\circ} \mathrm{C}, \\
\text { maximum change } 1^{\circ} \mathrm{C} / \mathrm{h}\end{array}$ & $\begin{array}{c}40 \% \text { to } 60 \% \\
\pm 20 \% \text { max change / } 4 \mathrm{~h}\end{array}$ \\
\hline
\end{tabular}


2 Methodology

2.1 Scope, Precision, Accuracy

The method is applicable for the calibration of any size of measuring flask for which standard pipets of comparable volume are available. Typical flasks have volumes in the range of $100 \mathrm{~mL}$ to $5 \mathrm{~L}$ ( 1 gill to 1 gallon). The precision of calibration depends on the care exercised in adjusting the various volumes and strict adherence to the various steps of the procedure. The accuracy will depend on the accuracy of calibration of the volumetric standards used, accuracy in reading the meniscus, together with the precision of the comparison. Clean glassware and strict adherence to the drainage instructions are essential for precise and accurate results.

\subsection{Summary}

The flask to be calibrated is given an initial wet-down using the correct drain procedure, then nearly filled with water delivered from a calibrated pipet. (Calibrated pipets generally deliver slightly less than the full nominal volume.) Additional water is added from a calibrated buret until the meniscus in the test item coincides with the calibration graduation mark. The sum of the volumes delivered into the wetted flask is equivalent to its "to deliver" volume. The process described assumes that the flask is marked with a 10-second drain time. If the flask is marked with a drain time other than $10 \mathrm{~s}$, the specified drain time should be used rather than the $10 \mathrm{~s}$ drain time described. A 30-second drain time should be used when a flask has no drain time specified.

2.3 Equipment

2.3.1 Calibrated standard pipet(s) of suitable volume with recent calibration certificates and values traceable to NIST. These standards are typically made of borosilicate glass.

2.3.2 Calibrated standard buret(s) of $10 \mathrm{~mL}$ (or 120 minim $^{1}$ ) capacity with recent calibration certificates and values traceable to NIST. These standards are typically made of borosilicate glass.

2.3.3 Calibrated thermometer, accurate to $0.1{ }^{\circ} \mathrm{C}$ with recent calibration certificates and values traceable to NIST.

2.3.4 Supply of pure distilled or deionized water (See GLP 10) at thermal equilibrium with the calibration environment.

\footnotetext{
${ }^{1} 1$ [US] minim $=0.061615496$ milliliter $(\mathrm{mL}) .120$ minim standards were provided to the States as reference standards for use in volume transfer calibrations. These standards have higher resolution than metric standards provided at the same time.
} 
2.3.5 Meniscus reading device (See GMP 3).

2.3.6 Stopwatch or other suitable timing device (does not need to be calibrated).

\section{$2.4 \quad$ Procedure}

\subsubsection{Cleanliness check}

Verify that all glassware, including the standards used and the vessels to be calibrated, are internally clean, as evidenced by uniform drainage of water. No water droplets should remain on the internal surfaces as the water drains from the vessels. If this occurs, the glassware must be cleaned with suitable agents and rinsed with pure water until uniform drainage is obtained. (See GMP 7).

\subsubsection{Wet-down of pipet and flask}

2.4.2.1 Fill the standard pipet to until water flows from the top tip, then completely drain into an empty vessel. Check for uniform drainage. Touch off the pipet outlet tip against the container wall to remove excess droplets and to establish a constant tip retention volume. The pipet and bore of the delivery side of the stopcock should appear to be "empty" and the delivery tip should contain a small volume of water retained in it. This is the "wet-down" condition of the pipet. It must be done at the beginning of each test sequence. Ensure that the outside of the standard pipet is free of water droplets that may fall into the unknown flask.

2.4.2.2 Refill the pipet and use it to fill the flask to be calibrated. Empty the flask in a $30 \mathrm{~s} \pm 5 \mathrm{~s}$ period by gradually inclining the flask so as to avoid splashing of the walls as much as possible. When the main drainage stream has ceased, the flask will be nearly vertical. Allow an additional 10 second drainage after discharge of the flask contents while holding the flask at a $10^{\circ}-15^{\circ}$ angle from vertical, then touch off the rim of the flask to remove any drops adhering to it. At the same time, check that uniform drainage has been achieved. This establishes the "to deliver" condition of the flask. Note that some small amount of water will remain in the flask. Each flask to be calibrated must be given this "wet-down" treatment immediately before the start of the test.

\subsubsection{Conditioning the buret}


2.4.3.1 Fill the standard buret to overflow and drain several times to verify uniform drainage. Refill with water. Note that the stopcock bore and delivery tip should be filled with water at all times, in contrast to the condition for the pipet.

2.4.3.2 Touch off the delivery tip against the wall of the receiving vessel, to remove any droplet adhering to the external surface of the tip. This is an operation that must be done every time a measured volume of water is delivered from the buret to ensure consistent volume delivery.

\subsubsection{Calibration}

2.4.4.1 Run 1. Fill the standard pipet to overflow. The delivery bore and the delivery tip will be empty, except for the small volume retained in the tip. Place the inside of the flask neck in contact with the tip of the pipet or buret, to avoid splashing but in a manner that does not block the flow of water.

2.4.4.2 Deliver the contents of the pipet into the "wet-down" flask. Repeat as necessary to nearly fill the flask to the calibration line. The value recorded for the standard pipet will be the total of the deliveries used.

2.4.4.3 Add water to the flask from the buret until the meniscus coincides with the calibration mark. (See GMP 3 for instructions on how to read a meniscus.) Read the volume of water delivered from the buret and record on a suitable data sheet such as the one in the Appendix. Note: If multiple deliveries of the complete buret contents are required, ensure that at no time the buret water level drops below the lowest graduation mark, or the entire process must be started over. The value recorded for the standard buret will be the sum of the delivered volumes.

2.4.4.4 Empty the measuring flask as described in 2.4.2.2 to re-establish "wet-down."

2.4.4.5 Record all data using the form given in the Appendix or a similar format.

2.4.5 Run 2. Replicate Measurement. Repeat the procedure described in 2.4.4. The test measure must be capable of repeating to $0.01 \%$ of the test volume during calibration. Repeatability problems may be due to contamination, poor meniscus readings, lack of cleanliness, or when calibration is conducted in an unstable environment. Repeatability problems must be corrected before calibration can be completed. 
2.4.6 Calibration Note: If the vessel has a graduated neck (in addition to the nominal mark) additional graduations should be inspected for proper marking and calibrated as well.

3 Computations

3.1 Compute the individual "to deliver" volumes, $V_{T D}$, for Run 1 and Run 2.

$$
V_{T D}=V_{P}+V_{B} \quad \text { Eqn. } 1
$$

Table 2. Variables for volume equation

\begin{tabular}{|c|l||}
\hline \hline Variable & \multicolumn{1}{|c||}{ Description } \\
\hline \hline$V_{T D}$ & "To deliver” Volume \\
\hline$V_{P}$ & "to deliver" calibrated volume of the standard pipet \\
\hline$V_{B}$ & $\begin{array}{l}\text { volume of water delivered from the buret, corrected for any calibration } \\
\text { values }\end{array}$ \\
\hline
\end{tabular}

\subsection{Temperature correction}

For calibration of glassware that is not made of borosilicate glass, not only should the above temperature conditions be realized but the water temperature must also be known. The water used must be stored in the laboratory until its temperature is equilibrated with its surroundings and the temperature of the discharged water is measured, using the calibrated thermometer. The "to deliver" volume of the flask, corrected to the reference temperature of $20{ }^{\circ} \mathrm{C}, V_{T D 20}$, is computed, using the expression:

$$
V_{T D 20}=V_{T D}[1+(\alpha-\beta)(t-20)] \quad \text { Eqn. } 2
$$

Table 3. Variables for volume temperature correction equation

\begin{tabular}{|c|l|}
\hline \hline Variable & \multicolumn{1}{c|}{ Description } \\
\hline \hline$V_{T D}$ & observed delivered volume as computed in 3.1 \\
\hline$V_{T D 20}$ & "To deliver” volume at the reference temperature of $20{ }^{\circ} \mathrm{C}$ \\
\hline$t$ & temperature of water at time of calibration \\
\hline$\alpha$ & $\begin{array}{l}\text { cubical coefficient of expansion of glass of standard (e.g., } 0.000010^{\circ} \mathrm{C}^{-1} \\
\text { for borosilicate glass) }\end{array}$ \\
\hline$\beta$ & $\begin{array}{l}\text { cubical coefficient of expansion of glass of flask (e.g., } 0.000025^{\circ} \mathrm{C}^{-1} \text { for } \\
\text { soda-lime glass) }\end{array}$ \\
\hline
\end{tabular}

The volumetric standards are typically made of borosilicate glass. If borosilicate flasks are calibrated, no temperature correction is required. This procedure relies on the fact that since deliveries are made over a short period of time, the 
temperature remains the same in the standard as in the unknown. When standards and flasks are not of the same material, the water temperature change must be less than $0.5^{\circ} \mathrm{C}$ while the water is in the standards and the flask.

3.3 Report the average volume $V_{T D 20}$ as the value for the flask after the temperature correction has been applied to each Run.

4 Measurement Assurance

4.1 Duplicate this process with a suitable check standard or have a suitable range of check standards for the laboratory. See SOP 17 and SOP 30.

4.2 Plot the check standard volume and verify that it is within established limits. Alternatively a $t$-test may be incorporated into the process to check the observed value against an accepted reference value. (See NISTIR 6969, Section 8).

4.3 The mean of the check standard value is used to evaluate bias and drift over time.

4.4 Check standard observations are used to calculate the standard deviation of the measurement process.

$5 \quad$ Assignment of Uncertainties

The limits of expanded uncertainty, $U$, include estimates of the standard uncertainty of the laboratory volumetric standards used, $u_{s}$, plus the standard deviation of the process, $s_{p}$, at the 95 percent level of confidence. See SOP 29 for the complete standard operating procedure for calculating the uncertainty.

5.1 The standard uncertainty for the standard, $u_{s}$, is obtained from the calibration report. The combined standard uncertainty, $u_{c}$, from the calibration report must be used and not the expanded uncertainty, $U$. Therefore, the reported uncertainty for the standard will usually need to be divided by a coverage factor, $k$. Multiple standards are used in this procedure; however, they are typically calibrated independently. Multiple standard uncertainties are handled according to SOP 29.

5.2 The standard deviation of the measurement process is obtained from control chart performance (See SOP 17 or 20, and SOP 30).

5.2.1 The value for $s_{p}$ is obtained from the control chart data of the check standard using the same volume transfer procedures on flasks of comparable size and neck dimensions.

5.3 Other standard uncertainties usually included at this calibration level include uncertainties associated with the ability to read the meniscus, only part of which is included in the process variability, the cubical coefficient of expansion for the flask under test, use of proper temperature corrections, the accuracy of temperature measurements, round robin data showing reproducibility, environmental variations over time, and bias or drift of the standard. 
6.1 Report results as described in SOP 1, Preparation of Calibration/Test Results, with the addition of the following items:

6.1.1 Volume, uncertainty, reference temperature, material, thermal coefficient of expansion (assumed or measured), construction, any identifying markings, tolerances (if appropriate), laboratory temperature, water temperature at time of test, barometric pressure, relative humidity, and any out-of-tolerance conditions.

$7 \quad$ Alternative Reference Temperatures

7.1 Reference temperatures other than $20^{\circ} \mathrm{C}\left(68^{\circ} \mathrm{F}\right)$ may occasionally be used. Common reference temperatures for other liquids follow:

\begin{tabular}{|l|c||}
\hline \multicolumn{1}{|c|}{ Commodity } & Reference Temperature \\
\hline \hline Frozen food labeled by volume (e.g., fruit juice) & $-18^{\circ} \mathrm{C}\left(0^{\circ} \mathrm{F}\right)$ \\
\hline Beer & $3.9^{\circ} \mathrm{C}\left(39.1^{\circ} \mathrm{F}\right)$ \\
\hline Food that must be kept refrigerated (e.g., milk) & $4.4^{\circ} \mathrm{C}\left(40^{\circ} \mathrm{F}\right)$ \\
\hline Distilled spirits or petroleum & $15.56{ }^{\circ} \mathrm{C}\left(60^{\circ} \mathrm{F}\right)$ \\
\hline Petroleum (International Reference) & $15^{\circ} \mathrm{C}\left(59^{\circ} \mathrm{F}\right)$ \\
\hline Wine & $20^{\circ} \mathrm{C}\left(68^{\circ} \mathrm{F}\right)$ \\
\hline Unrefrigerated liquids (e.g., sold unchilled, like soft drinks) & $20^{\circ} \mathrm{C}\left(68^{\circ} \mathrm{F}\right)$ \\
\hline Petroleum (Hawaii) & $26.67^{\circ} \mathrm{C}\left(80^{\circ} \mathrm{F}\right)$ \\
\hline
\end{tabular}

7.2 When alternative reference temperatures are used, at the request of the user of the field standard, and when the glassware is not marked with a reference temperature, the calibrated value of the standard may be reported at a different reference temperature, $t_{\text {ref }}$, by using this equation:

$$
V_{\text {TDtref }}=V_{T D}\left\lfloor 1+(\alpha-\beta)\left(t-t_{\text {ref }}\right)\right\rfloor
$$

Eqn. 3

\section{Additional References:}

Bean, V. E., Espina, P. I., Wright, J. D., Houser, J. F., Sheckels, S. D., and Johnson, A. N., NIST Calibration Services for Liquid Volume, NIST Special Publication 250-72, National Institute of Standards and Technology, Gaithersburg, MD, (2006). 


\section{Appendix}

\section{Calibration of Measuring Flask \\ (Volume Transfer Method)}

Laboratory data and conditions:

\begin{tabular}{|r|r|r||}
\hline Date & Temperature & \\
\hline Operator & Pressure & \\
\hline Test Number & Relative Humidity & \\
\hline Vessel Calibrated & Vessel ID & \\
\hline Process standard deviation from control chart, $s_{p}$ & \\
\hline
\end{tabular}

Volume standard(s) data:

\begin{tabular}{||c|c|c|c|c|c|c|c||}
\hline \hline ID & Nominal & $\begin{array}{c}\text { Calib. } \\
\text { Volume }\end{array}$ & $\begin{array}{c}\text { Coeff. of } \\
\text { Exp }\end{array}$ & ID & Nominal & $\begin{array}{c}\text { Volume } \\
\text { Correction }\end{array}$ & $\begin{array}{c}\text { Coeff. of } \\
\text { Exp }\end{array}$ \\
\hline \hline Pipet & & & & Buret & & & \\
\hline $\begin{array}{c}\text { Unknown } \\
\text { Flask }\end{array}$ & & & & & & \\
\hline \multicolumn{2}{|c|}{$u_{s}$, and $k$ factor } & & & & & & \\
\hline
\end{tabular}

\section{Observations:}

\begin{tabular}{||r|r|r||}
\hline \hline Final Reading & TRIAL NO. 1 & TRIAL NO. 2 \\
\hline Calibrated Pipet Volume: $V_{p}$ & & \\
\hline Buret Volume: & & \\
\hline Difference & & \\
\hline Calibration Correction (if required) & & \\
\hline Corrected Buret Volume, $V_{B}$ & & \\
\hline$V_{T D}=V_{P}+V_{B}$ & & \\
\hline Water Temperature & & \\
\hline$V_{T D 20}=V_{T D}[1+(\alpha-\beta)(t-20)]$ & & \\
\hline Average $V_{T D 20}$ & & \\
\hline
\end{tabular}




\section{SOP 17}

\section{Standard Operating Procedure for \\ Control Charts of Laboratory Owned Check Standards for Calibration of Measuring Flasks or Small Provers using Volume Transfer Methods ${ }^{1}$}

1 Introduction

\subsection{Purpose}

This procedure may be used to develop and maintain control charts to monitor the statistical control of the volume transfer method for calibration of measuring flasks or 5 gallon test measures, especially when using the Standard Operating Procedures (SOP 16 or 18) for this purpose. The same principles may be applied to the development of control charts for other calibration procedures.

\subsection{Prerequisites}

1.2.1 The procedure to be monitored must match the calibration procedure that is used.

1.2.2 A clean quality assurance reference flask(QARF), suitable check standard (see 3.1), or a 5 gallon check standard must be available. Verify the cleanliness of the vessel or take corrective actions.

\section{Summary}

A reference volumetric flask (or a series of such) or check standard is obtained and calibrated several times initially to establish a reliable mean value and to estimate the standard deviation of calibration. All such calibrations are made using SOP 16, 18, or an equivalent procedure. Directions for preparing and using an $\bar{x}$ and an R control chart are given. The $\bar{x}$ control chart monitors the process with respect to both the standard and the variability, while the R control chart monitors its short-term precision. When the calibration process is determined to be in a state of statistical control, the calibrations made at that time may be considered to be valid and the process standard deviation may be used, as appropriate, to calculate the uncertainty for the calibrations using SOP 29.

Note: If a full evaluation of the process bias is desired, it is best if the reference value of the QARF or check standard are provided by an independent laboratory such as NIST or a laboratory accredited to perform volume calibrations, preferably using gravimetric methods.

\footnotetext{
1 Non-SI units are predominately in common use in State legal metrology laboratories, and/or the petroleum industry for many volumetric measurements, therefore non-SI units have been used to reflect the practical needs of the laboratories performing these measurements as appropriate.
} 
3 Equipment

3.1 A quality assurance reference flask(s) (QARF) or check standard is required, constructed of similar materials and design as the standards under calibration. A 1 pt and a $1 / 2$ gal flask or a 2 pt and 1 qt flask are recommended for glass flasks when monitoring SOP 16 (or other suitable volumetric standards that match the range of items calibrated by the laboratory). A 5 gal check standard is recommended for monitoring SOP 18.

3.2 All equipment designated in SOP 16 or SOP 18 as appropriate.

4 Procedure

\subsection{Initial Measurements}

4.1.1 Calibrate the QARF or 5 gallon check standard a minimum of 12 times to establish the baseline chart. A calibration is defined as the result of duplicate measurements as required by the SOP (i.e., a complete test consists of two runs). Calibrations may be made on successive days, but no two complete tests should be made on any single day. Note: 25 to 30 points are recommended to determine uncertainties.

4.1.2 Tabulate the measurement data using the notation and a form such as the one contained in the Appendix of this SOP. The data may be maintained in a spreadsheet or other electronic program in lieu of a paper form.

4.1.3Calculate the mean of the two trials $\bar{x}_{\mathrm{i}}$ and the ranges between runs. The ranges $R_{\mathrm{i}}$, are the absolute differences between run 1 and run 2 for the $n$ tests. Calculate the average range $|\bar{R}|$ of the trials, for the $n$ tests as follows:

$$
\bar{R}=\frac{\sum\left|R_{i}\right|}{n}
$$

4.1.4Estimate the standard deviation of the process $s_{p}$, based on the check standard volume on each of $\mathrm{n}$ occasions, as follows:

$$
s_{p}=\sqrt{\frac{\sum\left(\bar{x}_{i}-\bar{x}\right)^{2}}{(n-1)}} \quad \text { Eqn. } 2
$$

where:

\begin{tabular}{|l|l|}
\hline $\bar{x}_{i}$ & The mean value of each complete test. \\
\hline $\bar{x}$ & The mean value of all averages made on n occasions \\
\hline
\end{tabular}

4.1.5For a smaller number of measurements (less than 30) the standard deviation may be calculated using the average range as follows (obtain values for $d_{2}^{*}$ from NISTIR 6969 Table 9.10 and see NISTIR 6969 Section 8.3 for additional notes): 


$$
s_{p}=\frac{\bar{R}}{d_{2}^{*}} \quad \text { Eqn. } 3
$$

Be sure that only absolute values are used in the determination of the range and average range!

\subsection{Construction of Control Charts}

Construct the following control charts using the data of section 4.1.

4.2.1Construct an $\bar{x}$ control chart for a check standard with the following control limits:

Reference value (if available)

Central Line $=\quad \overline{\bar{x}}$ (mean of the average values)

Lower warning limit $(\mathrm{LWL})=\quad \begin{aligned} & \bar{x}-2 s_{p} \\ & =\end{aligned}$

Lower control limit $(\mathrm{LCL})=\quad \begin{aligned} & \bar{x}-3 s_{p} \\ & =\end{aligned}$

Upper warning limit $(\mathrm{UWL})=\quad \begin{aligned} & \bar{x}+2 s_{p} \\ & \end{aligned}$

Upper control limit $(\mathrm{UCL})=\quad \stackrel{\bar{x}}{x+3 s_{p}}$

4.2.2Construct an $R$ (range chart) control chart for duplicate measurements having the following control (or action) limits. Note that $R$ (the range) and $|d|$ (absolute difference of duplicate measurements) are equivalent for duplicate measurements.

Central Line $=\bar{R}$ (average range)
LCL $=$ LWL $=0$

(There should be no negative numbers recorded when using absolute values!)

$\begin{array}{lll}\text { UWL } & =2.512 \bar{R} \\ \text { UCL } & =3.267 \bar{R}\end{array}$

These limits are $t$ values for $95 \%$ and $99.7 \%$ confidence intervals for a sample size of 30.

\subsection{Use of Control Charts}

4.3.1 An appropriate QARF or check standard is calibrated each time the laboratory performs calibrations using the SOP. If the calibrations extend over several days, the check standard is calibrated daily. The values of $\bar{x}$ and $R$ for each calibration of the check standard are plotted on the respective control charts, preferably in sequential order. The limits on the charts are such that $95 \%$ of the values should fall within the warning limits and rarely should a value fall outside of the control limits, provided that the system is in a state of statistical control.

4.3.2 If the plotted value of $\bar{x}$ lies outside of the control limits and the corresponding value 
on the $R$ chart is within the control limits, a source of systematic error is suspected. Poor drainage is a possible source of bias for low values and changes of drainage technique should be considered as a cause for high values. Sources of error can result from the use of the volumetric standards as well as of the vessels being calibrated. Changes in criteria for reading the meniscus are also possible sources of error or difference.

4.3.3 If the values for the $R$ chart fall outside of the warning limits but inside of the control limits, a decrease in precision is indicated. Cleanliness and procedural problems should be investigated.

4.3.4 No calibration data should be accepted when the system is out of control.

4.3.5 If the plotted values for either $\bar{x}$ or $R$ are outside of the warning limits but inside of the control limits, a second set of duplicate calibrations should be made. If the new values are within the warning limits, the process may be considered to be in control. If they lie outside of the warning limits, lack of control is indicated. Corrective actions should be taken and attainment of control demonstrated before calibration measurements are considered to be acceptable.

4.3.6Even while the system is in an apparent state of control, incipient troubles may be indicated when the control data show short- or long-term trends, shifts, or runs. The $t$-test and $F$-test may be used to assess the significance of such observations (see NIST IR 6969 Section 8.9, 8.10, and 8.11).

5.1 Demonstration of "in control" status indicates that the calibration process is consistent with the past experience of the laboratory. That is to say, there is no reason to believe that excessive systematic error or changes in precision have occurred.

5.2 To the extent appropriate, the precision of measurement of the QARF or check standard may be extended to the calibration of other glassware or small volume provers calibrated using the same SOP. This means that the process standard deviation, $s_{p}$, is transferable to measurements of similar nominal size made by the same measurement method.

5.3 Extension of the $s_{p}$ for the QARF to other calibrations assumes that all aspects of its calibration correspond to those for the other calibration. If the volumes of the respective glassware are comparable as well as the sizes of necks and graduation lines, this may be justified. It may be necessary to have a series of QARF's or check standards with corresponding control charts to monitor the calibration process for a range of volumetric calibrations. 
Appendix

Control Chart Data

QARF/Check Std ID

Nominal Capacity

\begin{tabular}{|c|c|c|c|c|c|c|}
\hline $\begin{array}{c}\text { Test } \\
\text { Number }\end{array}$ & Date & $\begin{array}{c}\text { Trial No. } 1 \\
V_{T D} \\
\mathrm{X}_{1}\end{array}$ & $\begin{array}{c}\text { Trial No. } 2 \\
V_{T D} \\
\mathrm{X}_{2}\end{array}$ & $\begin{array}{c}V_{T D M} \\
(\bar{x})\end{array}$ & $\begin{array}{c}|d|= \\
\left|\mathrm{X}_{1}-\mathrm{X}_{2}\right|^{*}\end{array}$ & $\begin{array}{c}\text { standard } \\
\text { deviation*** }\end{array}$ \\
\hline 1 & & & & & & \\
\hline 2 & & & & & & \\
\hline 3 & & & & & & \\
\hline 4 & & & & & & \\
\hline 5 & & & & & & \\
\hline 6 & & & & & & \\
\hline 7 & & & & & & \\
\hline 8 & & & & & & \\
\hline 9 & & & & & & \\
\hline 10 & & & & & & \\
\hline 11 & & & & & & \\
\hline 12 & & & & & & \\
\hline 13 & & & & & & \\
\hline 14 & & & & & & \\
\hline 15 & & & & & & \\
\hline \multicolumn{7}{|c|}{ SUM } \\
\hline & & & & $\sum \bar{x}$ & $\sum|d|$ & $\begin{array}{l}\text { pooled std } \\
\text { dev: }\end{array}$ \\
\hline
\end{tabular}

$n^{* *}=$

$\bar{x}=\frac{\sum \bar{x}}{n}=$

$\bar{R}=\frac{\sum|R|}{n}=$

$\mathrm{UWL}=2.512 \bar{R}=$

$s=\sqrt{\frac{\sum(\bar{x}-\bar{x})^{2}}{(n-1)}}$

$\mathrm{UCL}=3.267 \bar{R}=$

* This is the range, $R$, of the two trials and is actually the larger value minus the smaller value.

$* * n$ is the number of tests used to calculate the control limits.

***Use of the standard deviation and pooled standard deviations are preferred when a standard artifact is maintained in the laboratory as a check standard. 



\section{SOP 18}

\section{Standard Operating Procedure for Calibration of Graduated Neck-Type Metal Volumetric Field Standards Volumetric Transfer Method ${ }^{1}$}

1 Introduction

\subsection{Purpose of Test}

This procedure may be used to calibrate small non-pressurized, graduated necktype, metal field standards such as the 5 gal (or 20 L) standards used by weights and measures officials to test liquid dispensing equipment, gasoline pumps, for example. The procedure assumes that the water temperature is stable during the transfer from the standard to the unknown test measure. SOP 19 is a more appropriate procedure when temperature corrections are needed due to lack of water equilibration, temperature differences between the standard and unknown provers, or unstable environments.

Limiting factors: For a 5 gal test with a stainless steel standard and stainless steel unknown test measure, the temperature change between the standard and unknown must be less than $0.5{ }^{\circ} \mathrm{C}$ during the calibration. If the unknown test measure is mild steel, the change in temperature between standard and unknown must be less than $0.2{ }^{\circ} \mathrm{C}$ during the calibration. If these limits are exceeded, use SOP 19. This is to ensure that the impact on measured values is less than the resolution and repeatability on a 5 gal test measure with $1 \mathrm{in}^{3}$ graduations. If smaller graduations are present, error due to temperature variations must be evaluated further.

\subsection{Prerequisites}

1.2.1 Verify that the unknown prover has been properly cleaned and vented with all petroleum products removed prior to submission for calibration to ensure laboratory safety.

1.2.2 Verify that valid calibration certificates are available for the standards used in the test.

1.2.3 Verify that the standards to be used have sufficiently small standard uncertainties for the intended level of calibration

\footnotetext{
${ }^{1}$ Non-SI units are predominately in common use in State legal metrology laboratories, and/or the petroleum industry for many volumetric measurements, therefore non-SI units have been used to reflect the practical needs of the laboratories performing these measurements as appropriate. Most laboratory standards for this calibration procedure are 5 gal "slicker-plate” type standards. Very few laboratories have 20 L “slicker-plate” type standards.
} 
1.2.4 Verify the availability of an adequate supply of clean water (GLP 10).

1.2.5 Verify that the operator has had specific training and is proficient in SOP 18, GMP 3, SOP 17 and is familiar with the operating characteristics and conditioning of the standards used.

1.2.6 Verify that the laboratory facilities meet the following minimum conditions to enable meeting the expected uncertainty achievable with this procedure:

Table 1. Laboratory environmental conditions

\begin{tabular}{|c|c|c||}
\hline \hline Procedure & Temperature & Relative Humidity \\
\hline \hline Volume transfer & $\begin{array}{c}18{ }^{\circ} \mathrm{C} \text { to } 27^{\circ} \mathrm{C}, \text { maximum } \\
\text { change } 2.0^{\circ} \mathrm{C} / \mathrm{h}\end{array}$ & $\begin{array}{c}40 \% \text { to } 60 \% \\
\pm 20 \% \text { maximum change / } 4 \mathrm{~h}\end{array}$ \\
\hline
\end{tabular}

\section{$1.3 \quad$ Field tests}

1.3.1 A "field" calibration is considered one in which a calibration is conducted in an uncontrolled environment, such as out-of-doors. Calibrations conducted under field and laboratory conditions are not considered equivalent and uncertainties must reflect the conditions of the calibration.

1.3.2 The care required for field calibrations includes proper safety, a clean and air-free water supply, measurement control programs, and a stable temperature environment shaded from direct sunshine to allow the prover, field standard, and test liquid (water) to reach an equilibrium temperature with minimal evaporation. Environmental conditions should be selected to be as close to laboratory conditions as possible. All data and appropriate environmental conditions must be documented regardless of test location. SOP 19 is a more suitable procedure when poor conditions are noted.

1.3.3 An increased number of check standard verifications are required to ensure continued suitability of calibration values generated in field conditions.

2 Methodology

\section{$2.1 \quad$ Scope, Precision, Accuracy}

This procedure is applicable for the calibration of a small test measure within the limitations of the standards available. The precision attainable will depend on the care used in the various volumetric adjustments and readings, in the strict observance of drainage times, and the internal cleanliness of the various volu- 
metric vessels which can influence their drainage characteristics. The accuracy will depend on the uncertainties of the calibrations of the standards used.

\subsection{Summary}

Water is delivered from the standard to the vessel under calibration. Because the "to deliver" volume of the latter is calibrated, the delivery must be into a "wetdown" vessel. The gauge scale is adjusted to a correct reading, as necessary, and then sealed.

\subsection{Equipment}

2.3.1 Calibrated slicker-plate standard made of stainless steel, with recent calibration certificate traceable to NIST, and whose volume equals that of the vessel to be calibrated.

2.3.2 Calibrated thermometer, accurate to $\pm 0.1{ }^{\circ} \mathrm{C}$, with recent calibration certificate traceable to NIST.

\subsubsection{Meniscus reading device. (See GMP 3).}

2.3.4 Timing device (Calibration is not required.)

2.3.5 Supply of clean water, preferably soft water (filtered if necessary).

\section{$2.4 \quad$ Procedure}

2.4.1 Cleanliness Verification - Fill and drain both standard and vessel to be calibrated and check for any soiling that would affect drainage, as evidenced by clinging droplets, greasy films, and the like. Clean either or both with detergent and water, as necessary, and rinse thoroughly. (See GMP 6).

2.4.2 Fill vessel with water to its nominal level and pour contents during a $30 \pm$ $5 \mathrm{~s}$ period then drain for a $10 \mathrm{~s}$ period after cessation of flow. Touch off any adhering drop from the neck. This constitutes the "wet-down" condition. Filling the vessel from the standard following the instructions in steps 2.4.3 and 2.4.4 will ensure that both the standard and vessel are properly "wet-down".

2.4.3 Run 1 - Fill slicker-plate standard with water, raised by surface tension, slightly higher than the rim. Use slicker-plate to strike off excess water, checking to see that no air bubbles are entrained in the water during the leveling process. 
2.4.4 Open valve at base and transfer water from the standard to the wet-down vessel. Allow a $30 \mathrm{~s}$ drain period after cessation of flow.

2.4.5 Level vessel (or suspend it by its handle, if appropriate) and read scale on its neck. Record reading.

2.4.6 Adjust the scale of the vessel as described in 3.3. Seal the scale adjustment device.

2.4.7 Run 2 - Make a duplicate determination, which should agree with the former within $\pm 0.02 \%$ of the volume ( \pm 0.2 in $^{3}$ for 5 gal test measure). If excess disagreement, check all vessels for cleanliness and repeat duplicate determinations until satisfactory agreement between consecutive runs is obtained.

2.4.8 The test measure or prover must be capable of repeating within $0.02 \%$ of the test volume during calibration. Repeatability problems may be due to contamination or lack of cleanliness, or poor field conditions, such as when calibration is conducted in an unstable environment. Repeatability problems must be corrected before calibration can be completed.

3 Calculations

3.1 Because the water temperature is usually reasonably close to $60{ }^{\circ} \mathrm{F}$, the coefficients of expansion of the standard and the test vessel are sufficiently close together, and the deliveries and readings are made over a short period of time, no temperature corrections are made. When conditions are not reasonably close to $60{ }^{\circ} \mathrm{F}$ and temperature corrections are needed, use SOP 19. If prover volumes, errors and/or corrections are reported, use calculations provided in SOP 19.

3.2 Within the accuracy requirements, no corrections arising from dissimilarities of the standard and vessel are necessary. If differences are suspected, use SOP 19.

3.3 The reading of Run 1 is used to adjust the scale of the vessel, if necessary, to the correct reading, which is set at the calibrated volume of the slicker-plate standard at $60^{\circ} \mathrm{F}$. Record the adjusted value as the "as left" value.

Note: If the accuracy requirements necessitate a temperature correction, the temperature of the water must be measured in both the standard and the unknown and the calibration is made according to the procedure given in SOP 19.

3.4 Determination of the test vessel volume:

Prover volume $=V_{\text {Nom }}+C_{s}-$ gauge reading $\quad$ Eqn. 1

where: 


$$
\begin{array}{lll}
V_{\text {Nom }}= & \text { Nominal Volume (taking care to match units) } \\
C_{s}= & \text { Correction on standard }
\end{array}
$$

\section{Measurement Assurance}

4.2 Duplicate the process with a suitable check standard or have a suitable range of check standards for the laboratory. See SOP 17 and SOP 30.

4.3 Plot the check standard volume and verify it is within established limits OR a t-test may be incorporated to check the observed value against an accepted value.

4.4 The mean of the check standard observations is used to evaluate bias and drift over time.

4.5 Check standard observations are used to calculate the standard deviation of the measurement process.

\section{Assignment of Uncertainties}

The limits of expanded uncertainty, $U$, include estimates of the standard uncertainty of the laboratory volumetric standards used, $\mathrm{u}_{\mathrm{s}}$, plus the standard deviation of the process, $s_{p}$, at the $95 \%$ level of confidence. See SOP 29 for the complete standard operating procedure for calculating the uncertainty.

5.2 The standard uncertainty for the standard, $u_{s}$, is obtained from the calibration report. The combined standard uncertainty, $u_{c}$, is used and not the expanded uncertainty, $U$, therefore the reported uncertainty for the standard will usually need to be divided by the coverage factor $k$.

5.3 Standard deviation of the measurement process, $s_{p}$, is obtained from control chart performance (See SOP 17 or 20, and SOP 30).

5.4 Other standard uncertainties usually included at this calibration level include uncertainties associated with the ability to read the meniscus, only part of which is included in the process variability, the cubical coefficient of expansion for the prover under test, use of proper temperature corrections, the accuracy of temperature measurements, round robin data showing reproducibility, environmental variations over time, and bias or drift of the standard.

5.5 To properly evaluate uncertainties and user requirements (tolerances), assessment of additional user uncertainties may be required by laboratory staff. Through proper use of documented laboratory and field procedures, additional uncertainty factors may be minimized to a level that does not contribute significantly to the previously described factors. Additional standard uncertainties in the calibration of field standards and their use in meter verification may include: how the prover level is established, how 
delivery and drain times are determined, the use of a proper "wet-down" prior to calibration or use, the cleanliness of the prover and calibration medium, prover retention characteristics related to inside surface, contamination or corrosion, total drain times, and possible air entrapment in the water.

\section{Report}

6.2 Report results as described in SOP 1, Preparation of Calibration/Test Results, with the addition of the following:

6.2.1 Volume, uncertainty, reference temperature, material, thermal coefficient of expansion (assumed or measured), construction, any identifying markings, tolerances (if appropriate), laboratory temperature, water temperature(s), barometric pressure, relative humidity, and out-oftolerance conditions. 


\section{SOP 19}

\section{Standard Operating Procedure for Calibration of Large Neck-Type Metal Provers (Volume Transfer Method) ${ }^{1}$}

1 Introduction

\subsection{Purpose of Test}

This procedure is used to calibrate large graduated neck type metal provers (40 L (10 gal) and larger) that are used in verification of petroleum, biodiesel, ethanol, milk, and/or water meters. It may also be used for the calibration of test measures (20 L (5 gal)) when temperature corrections are needed.

\subsection{Prerequisites}

1.2.1 Verify that the unknown prover has been properly cleaned and vented, with all petroleum products removed prior to submission for calibration to ensure laboratory safety and compliance with environmental disposal requirements.

1.2.2 Verify that valid calibration certificates are available for the standards used in the test.

1.2.3 Verify that the standards to be used have sufficiently small standard uncertainties for the intended level of calibration.

1.2.4 Verify the availability of an adequate supply of clean water (GLP 10) (Note: this is critical when calibrating food-grade provers.)

1.2.5 Verify that the operator has had specific training and is proficient in SOP 19, SOP 17, GMP 3, and is familiar with the operating characteristics and conditioning of the standards used.

1.2.6 Verify that the laboratory facilities meet the following minimum conditions to make possible the expected uncertainty achievable with this procedure:

\footnotetext{
${ }^{1}$ Non-SI units are predominately in common use in State legal metrology laboratories, and/or the petroleum industry for many volumetric measurements, therefore non-SI units have been used to reflect the practical needs of the laboratories performing these measurements as appropriate.
} 
Table 1. Laboratory environmental conditions

\begin{tabular}{||c|c|c||}
\hline \hline Procedure & Temperature & Relative Humidity \\
\hline \hline $\begin{array}{c}\text { Volume } \\
\text { Transfer }\end{array}$ & $\begin{array}{c}18^{\circ} \mathrm{C} \text { to } 27^{\circ} \mathrm{C}, \text { maximum } \\
\text { change } 2.0^{\circ} \mathrm{C} / \mathrm{h}\end{array}$ & $\begin{array}{c}40 \% \text { to } 60 \% \\
\text { maximum change } / 4 \mathrm{~h}\end{array}$ \\
\hline
\end{tabular}

\subsection{Field tests}

1.3.1 A "field" calibration is considered one in which a calibration is conducted in uncontrolled environments, such as out-of-doors. Calibrations conducted under field and laboratory conditions are not considered equivalent.

1.3.2 The care required for field calibrations includes proper safety, clean and air-free water supply, measurement control programs, and a stable temperature environment shaded from direct sunshine to allow the prover, field standard, and test liquid (water) to reach an equilibrium temperature, with minimal evaporation. Environmental conditions should be selected to be as close to laboratory conditions as possible. All data and appropriate environmental conditions must be documented regardless of test location.

2 Methodology

2.1 Scope, Precision, Accuracy

This procedure is applicable for the calibration of any size metal prover within the limitations of the standards available. The precision attainable will depend on strict adherence to the procedure, the care in volumetric adjustments, and the number of transfers, in the case of multiple transfers. The accuracy will depend on the standards used.

\subsection{Summary}

Water is delivered from a volumetric standard to the prover being calibrated. Depending on the respective volumes, multiple transfers may be required. While these should be minimized, a maximum number of 15 transfers are permitted to ensure that final uncertainties and systematic errors are sufficiently small for the intended applications. The temperature cannot be considered to be constant during multiple transfers; hence, the temperature of the water for each transfer must be measured. Because of the large volumes, the difference in thermal expansion of the respective vessels must be considered. 


\subsection{Equipment}

2.3.1 Calibrated volumetric standard with recent calibration certificate traceable to NIST.

2.3.2 Calibrated 1 gal flask (or other suitable size) to calibrate neck of prover and a funnel.

2.3.3 Meniscus reading device (See GMP 3).

2.3.4 Calibrated thermometer, accurate to $\pm 0.1{ }^{\circ} \mathrm{C}$, with recent calibration certificate traceable to NIST.

2.3.5 Timing device (calibration is not required.)

2.3.6 Supply of clean water, preferably soft water (filtered if necessary).

2.3.7 Sturdy platform, with appropriate safety conditions, with sufficient height to hold standard and to permit transfer of water from it to the prover by gravity flow.

2.3.8 Clean pipe or tubing (hoses) to facilitate transfer of water from the laboratory standard to prover. Pipe and hose lengths should be minimized to reduce water retention errors. Care must be taken during wet-downs and runs to ensure complete drainage and consistent retention in all hoses or pipes.

\subsection{Procedure}

\subsubsection{Cleanliness verification}

Fill and drain both standard and prover to be calibrated and check for visual evidence of soiling and of improper drainage. If necessary, clean with detergent and water (see GMP 6).

\subsubsection{Neck scale plate verification}

2.4.2.1 Fill the prover with water from the standard. Check the prover level condition in the same way in which it will be used and adjust if necessary. Check the prover system for leaks. This is a wet-down run.

2.4.2.2 Bleed the liquid level down to a graduation near the bottom of the upper neck. "Rock" the prover to "bounce" the liquid level, momentarily, to ensure that it has reached an equilibrium level. 
Read and record this setting. This is in preparation for verification of the neck scale plate.

2.4.2.3 Recheck the scale reading, then add water from calibrated standards equal to $1 / 4$ or $1 / 5$ of the graduated neck volume and record the scale reading.

2.4.2.4 Repeat 2.4.2.3 by successive additions until water is near the top of the scale. Record scale readings after each addition. The closer the water is to the top of the neck, the harder it may be to "bounce" the liquid in the gauge.

2.4.2.5 A plot of scale readings with respect to volume added should be linear and will be a gross check of the validity of this calibration.

2.4.2.6 Calculate and check accuracy of the neck scale for each interval. The error should be less than $0.5 \%$ of the graduated neck volume or $1 / 4$ of a graduation (whichever is smaller). If more than this, the scale should be replaced. Otherwise issue the NSCV and instructions to user.

2.4.2.7 The neck scale calibration value is calculated as follows:

$$
N S C V=\frac{V_{w}}{\left(s r_{f}-s r_{i}\right)}
$$

Table 2. Variables for neck scale verification value equation

\begin{tabular}{|c|c|}
\hline \hline$N S C V$ & Neck scale calibration value \\
\hline$V w$ & Total volume of water added to neck \\
\hline$s r_{f}$ & Scale reading, final \\
\hline$s r_{i}$ & Scale reading, initial \\
\hline
\end{tabular}

\subsubsection{Body Calibration}

2.4.3.1 Fill prover with water and level it. Drain water, then wait $30 \mathrm{~s}$ after cessation of full flow, before closing drain valve. This establishes a "wet-down" condition for provers with no bottom zero. If a bottom zero is present, follow the guidance provided in SOP 21 for LPG provers as follows: When the liquid reaches the top of the lower gage glass, close the valve and allow the water to drain from the interior of the prover into the lower neck for $30 \mathrm{~s}$. Then bleed slowly with the bleed valve (4) until the bottom of the liquid meniscus reaches the zero graduation. (This step should be started during the $30 \mathrm{~s}$ drain period but should not be completed 
before the end of the drain period.) Alternatively, the prover may be completely drained with a $30 \mathrm{~s}$ drain time and then refilled with a funnel and small volume of water to set the zero mark (which will add to the prover calibration uncertainty due to variable retention characteristics).

2.4.3.2 Run 1. Fill the standard and measure and record the temperature.

2.4.3.2.1 Measure and record the temperature of the water, $t_{i}$, then adjust the standard prover to its reference mark or record the neck reading, and then discharge into the unknown prover. Wait $30 \mathrm{~s}$ after cessation of full flow to attain specified drainage, then close the delivery valve.

2.4.3.2.2 Repeat step 2.4.3.2.1. as many times as necessary (note the 15-drop limit) to fill the unknown prover to its nominal level. Level the prover if necessary and record the neck reading. Measure the temperature of the water in the prover, $t_{w}$, and record.

2.4.3.2.3 Perform the calculations described in section 3 to find the prover volume.

2.4.3.4 Adjust the scale as needed. If adjusted, record the adjusted prover gauge reading for determining the "as left" value for Run 1.

2.4.3.5 Run 2 - Repeat the process described in 2.4.3.2.

2.4.3.6 The test measure or prover must be capable of repeating to $0.02 \%$ of the test volume during calibration. Repeatability problems may be due to a leak in the valves or seals of the prover, contamination or lack of cleanliness, air bubbles, inconsistent retention in delivery hoses, or poor field conditions such as when a calibration is conducted in an unstable environment. If excessive disagreement is found, clean the prover and take other corrective actions as necessary, then recalibrate until consecutive duplicate determinations agree within $0.02 \%$ of the nominal volume. Repeatability problems must be corrected before the calibration can be completed.

2.4.3.7 Seal equipment as specified in laboratory policy.

The following calculations assume that the standard was calibrated using a reference temperature of $60^{\circ} \mathrm{F}\left(15.56{ }^{\circ} \mathrm{C}\right)$ and that you are calibrating a field standard to a 
reference temperature of $60^{\circ} \mathrm{F}\left(15.56^{\circ} \mathrm{C}\right)$. Equations for situations where different reference temperatures are involved will follow.

\subsection{Single Delivery}

3.1.1 Calculate $V_{X 60}$, the volume of the unknown prover at $60{ }^{\circ} \mathrm{F}$, using the following equation:

$$
V_{X 60}=\frac{\rho_{1}\left\{\left(V_{S 60}+\Delta_{1}\right)\left[1+\alpha\left(t_{1}-60^{\circ} \mathrm{F}\right)\right]\right\}}{\rho_{x}\left[1+\beta\left(t_{x}-60^{\circ} \mathrm{F}\right)\right]}
$$

\subsection{Multiple Deliveries}

3.2.1 Calculate $V_{X 60}$, the volume of the unknown prover at $60{ }^{\circ} \mathrm{F}$, using the following equation:

$$
V_{X 60}=\frac{\rho_{\{}\left\{\left(V_{S 60}+\Delta_{1}\right)\left[1+\alpha\left(t_{1}-60^{\circ} \mathrm{F}\right)\right]\right\}+\rho_{2}\left\{\left(V_{S 60}+\Delta_{2}\right)\left[1+\alpha\left(t_{2}-60^{\circ} \mathrm{F}\right)\right]\right\}+\ldots+\rho_{N}\left\{\left(V_{S 60}+\Delta_{N}\right)\left[1+\alpha\left(t_{N}-60^{\circ} \mathrm{F}\right)\right]\right\}}{\rho_{x}\left[1+\beta\left(t_{x}-60^{\circ} \mathrm{F}\right)\right]} \text { Eqn. } 2
$$

\begin{tabular}{|c|c|}
\hline \multicolumn{2}{|r|}{ Symbols Used in Equations } \\
\hline$V_{X 60}$ & volume of the unknown vessel at $60^{\circ} \mathrm{F}$ \\
\hline$V_{S 60}$ & volume of the standard vessel at $60^{\circ} \mathrm{F}$ \\
\hline$\rho_{1}, \rho_{2}, \ldots, \rho_{N}$ & $\begin{array}{l}\text { density of the water in the standard prover where } \rho_{1} \text { is the density of the water } \\
\text { for the first delivery, } \rho_{2} \text { is the density of the water for the second delivery, and } \\
\text { so on until all } \mathrm{N} \text { deliveries are completed }\end{array}$ \\
\hline$\Delta_{1}, \Delta_{2}, \ldots, \Delta_{N}$ & $\begin{array}{l}\text { volume difference between water level and the reference mark on the standard } \\
\text { where the subscripts } 1,2, \ldots, \mathrm{N} \text {, represent each delivery as above. If the water } \\
\text { level is below the reference line, } \Delta \text { is negative. If the water level is above the } \\
\text { reference line, } \Delta \text { is positive. If the water level is at the reference line, } \Delta \text { is } \\
\text { zero } \\
\text { NOTE: units must match volume units for the standard }\end{array}$ \\
\hline$t_{1}, t_{2}, \ldots, t_{N}$ & temperature of water for each delivery with the subscripts as above \\
\hline$\alpha$ & coefficient of cubical expansion for the standard in units $/{ }^{\circ} \mathrm{F}$ \\
\hline$\beta$ & coefficient of cubical expansion for the prover in units $/{ }^{\circ} \mathrm{F}$ \\
\hline$t_{x}$ & temperature of the water in the filled unknown vessel in units ${ }^{\circ} \mathrm{F}$ \\
\hline$\rho_{x}$ & density of the water in the unknown vessel in $\mathrm{g} / \mathrm{cm}^{3}$ \\
\hline
\end{tabular}

Table 3. Variables for $V_{X 60}$ equations 


\subsection{Prover Error/Correction or Deviation From Nominal}

The total calculated volume of the prover at its reference temperature should be reported on the calibration report.

The prover volume for an open neck prover equals the $V_{x 60}$ value minus the gauge reading that is the difference from the nominal volume (with matched units).

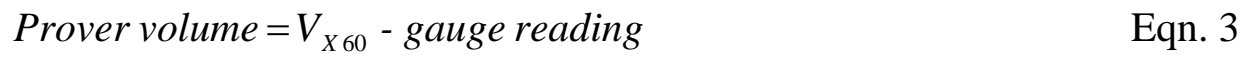

Prover error $=$ Prover volume $-V_{\text {Nom }} \quad$ Eqn. 4

Prover error $=V_{X 60}-$ gauge reading $-V_{\text {Nom }} \quad$ Eqn. 5

where:

$V_{\text {Nom }}=$ Nominal Volume (taking care to match units)

$V_{X 60}$ is the calculated volume of water that should be observed in the prover. A positive prover error means that the prover is larger than nominal. A negative prover error means that the prover is smaller than nominal.

Example 1: If $V_{X 60}$ is $100.02 \mathrm{gal}$ and gauge reading is 0.02 gal (above nominal); then the prover volume at nominal is 100.00 gal; and the prover error and correction are 0 ; and no adjustment is needed.

Example 2: If $V_{X 60}$ is 100.02 gal and gauge reading is -0.02 gal (below nomival); then the prover volume at nominal is 100.04 gal; the prover error is +0.04 gal; and to adjust the prover, set the gauge to read 0.02 gal (the volume level will show a gauge reading of 0.02 gal, which is $4.62 \mathrm{in}^{3}$ or about $5 \mathrm{in}^{3}$, above nominal.) 


\subsection{Alternative Reference Temperatures}

3.4.1 Reference temperatures other than $60^{\circ} \mathrm{F}\left(15.56{ }^{\circ} \mathrm{C}\right)$ may occasionally be used. Common reference temperatures for other liquids follow:

\begin{tabular}{|l|c|}
\hline \multicolumn{1}{|c|}{ Commodity } & $\begin{array}{c}\text { Reference } \\
\text { Temperature }\end{array}$ \\
\hline Frozen food labeled by volume (e.g., fruit juice) & $-18^{\circ} \mathrm{C}\left(0^{\circ} \mathrm{F}\right)$ \\
\hline Beer & $3.9^{\circ} \mathrm{C}\left(39.1^{\circ} \mathrm{F}\right)$ \\
\hline Food that must be kept refrigerated (e.g., milk) & $4.4^{\circ} \mathrm{C}\left(40^{\circ} \mathrm{F}\right)$ \\
\hline Distilled spirits or petroleum & $15.56^{\circ} \mathrm{C}\left(60^{\circ} \mathrm{F}\right)$ \\
\hline Petroleum (International Reference) & $15^{\circ} \mathrm{C}\left(59^{\circ} \mathrm{F}\right)$ \\
\hline Wine & $20^{\circ} \mathrm{C}\left(68^{\circ} \mathrm{F}\right)$ \\
\hline Unrefrigerated liquids (e.g., sold unchilled, like soft drinks) & $20^{\circ} \mathrm{C}\left(68^{\circ} \mathrm{F}\right)$ \\
\hline Petroleum (Hawaii) & $26.67^{\circ} \mathrm{C}\left(80^{\circ} \mathrm{F}\right)$ \\
\hline
\end{tabular}

Equations for calculations when using alternative reference temperatures follow:

\subsection{Single Delivery}

3.5.1 Calculate $\mathrm{V}_{\mathrm{Xtref}}$, the volume of the unknown prover at its designated reference temperature $\left({ }^{\circ} \mathrm{F}\right)$, using the following equation:

$$
V_{\text {Xtref }}=\frac{\rho_{1}\left\{\left(V_{\text {Stref }}+\Delta_{1}\right)\left[1+\alpha\left(t_{1}-\mathrm{t}_{\text {ref S }}\right)\right]\right\}}{\rho_{x}\left[1+\beta\left(t_{x}-\mathrm{t}_{\text {ref } \mathrm{X}}\right)\right]}
$$

\subsection{Multiple Deliveries}

3.5.1 Calculate $\mathrm{V}_{\mathrm{Xtref}}$, the volume of the unknown prover at its designated reference temperature, using the following equation:

$$
V_{\text {XtrefX }}=\frac{\rho_{1}\left\{\left(V_{\text {Strefs }}+\Delta_{1}\right)\left[1+\alpha_{1}\left(t_{1}-t_{\text {refs }}\right)\right]\right\}+\rho_{2}\left\{\left(V_{\text {StrefS }}+\Delta_{2}\right)\left[1+\alpha_{2}\left(t_{2}-t_{\text {refs }}\right)\right]\right\}+\ldots+\rho_{N}\left\{\left(V_{\text {Strefs }}+\Delta_{N}\right)\left[1+\alpha_{N}\left(t_{N}-t_{\text {ref }}\right)\right]\right\}}{\rho_{x}\left[1+\beta\left(t_{x}-t_{\text {refX }}\right)\right]} \text { Eqn. } 7
$$


Table 3A. Variables for $V_{X t r e f X}$ equations

\begin{tabular}{|c|c|}
\hline \multicolumn{2}{|r|}{ Symbols Used in Equations } \\
\hline$V_{X t r e f X}$ & $\begin{array}{l}\text { volume of the unknown vessel, } V_{X} \text { at its designated reference } \\
\text { temperature, } t_{r e f}\end{array}$ \\
\hline$V_{\text {Strefs }}$ & $\begin{array}{l}\text { volume of the standard vessel, } V_{S} \text { at its designated reference } \\
\text { temperature, } t_{r e f} S\end{array}$ \\
\hline$\rho_{1}, \rho_{2}, \ldots, \rho_{N}$ & $\begin{array}{l}\text { density of the water in the standard where } \rho_{1} \text { is the density of the water } \\
\text { for the first delivery, } \rho_{2} \text { is the density of the water for the second } \\
\text { delivery, and so on until all } \mathrm{N} \text { deliveries are completed }\end{array}$ \\
\hline$\Delta_{1}, \Delta_{2}, \ldots, \Delta_{N}$ & $\begin{array}{l}\text { volume difference between water level and the reference mark on the } \\
\text { standard where the subscripts } 1,2, \ldots, \mathrm{N} \text {, represent each delivery as } \\
\text { above. If the water level is below the reference line, } \Delta \text { is negative. If } \\
\text { the water level is above the reference line, } \Delta \text { is positive. If the water } \\
\text { level is at the reference line, } \Delta \text { is zero } \\
\text { NOTE: units must match volume units for the standard }\end{array}$ \\
\hline$t_{1}, t_{2}, \ldots, t_{N}$ & temperature of water for each delivery with the subscripts as above \\
\hline$\alpha$ & coefficient of cubical expansion for the standard in its designated units \\
\hline$\beta$ & coefficient of cubical expansion for the prover in its designated units \\
\hline$t_{x}$ & $\begin{array}{l}\text { temperature of the water in the filled unknown vessel in designated } \\
\text { units }\end{array}$ \\
\hline$\rho_{x}$ & density of the water in the prover in $\mathrm{g} / \mathrm{cm}^{3}$ \\
\hline \multicolumn{2}{|c|}{$\begin{array}{l}\text { Note: Values for the density of water at the respective temperatures may be found in } \\
\text { Table } 9.8 \text { (in NISTIR 6969) or it may be calculated from the equation given in GLP } 10 . \\
\text { Note: The cubical coefficient of the material used must match the unit assigned to the } \\
\text { temperature measurement. }\end{array}$} \\
\hline
\end{tabular}

4 Measurement Assurance

4.1. If a check standard is used (See SOP 20, SOP 30), repeat the process for the unknown artifact on the check standard, without adjustments.

4.2 Plot the check standard volume and verify it is within established limits.

Alternatively a $t$-test may be incorporated to check the observed value against an accepted value.

4.3 The mean of the check standard values is used to evaluate bias and drift over time.

4.4 Check standard values are used to calculate the standard deviation of the measurement process. 
4.5 When a check standard is not used, a range chart may be used to monitor repeatability and estimate the standard deviation of the measurement process using the equation (see SOP 20 for details):

$$
s_{p}=\frac{\bar{R}}{d_{2}^{*}}
$$

\section{Assignment of Uncertainties}

5.1 The limits of expanded uncertainty, $U$, include estimates of the standard uncertainty of the laboratory volumetric standards used, $u_{s}$, plus the standard deviation of the process, $s_{p}$, at the $95 \%$ level of confidence. See SOP 29 for the complete standard operating procedure for calculating the uncertainty.

5.2 The standard uncertainty for the standard, $u_{s}$, is obtained from the calibration report. The combined standard uncertainty, $u_{c}$, is used and not the expanded uncertainty, $U$, therefore the reported uncertainty for the standard will usually need to be divided by the coverage factor $k$. See SOP 29 for the complete standard operating procedure for calculating the uncertainty when multiple deliveries or multiple standards are used.

5.3 Neck calibration uncertainty should be estimated based on the uncertainty of standards used, errors observed during calibration and the repeatability of the neck calibration.

5.4 The standard deviation of the measurement process from control chart performance (See SOP 20 and SOP 30).

5.4.1 The value for $s_{p}$ is obtained from the control chart data of the check standard, or may be estimated using the range from the control chart, using large volume transfer procedures. Fifteen is the maximum recommended number of deliveries from a laboratory standard to a prover under test to minimize calibration uncertainties to the levels identified previously.

5.5 Other standard uncertainties usually included at this calibration level may include uncertainties associated with the ability to read the meniscus, only part of which is included in the process variability, the cubical coefficient of expansion for the prover under test, use of proper temperature corrections, the accuracy of temperature measurements, water density equation, uncertainties due to water viscosity, round robin data showing reproducibility, environmental variations over time, and bias or drift of the standard.

5.5.1 To properly evaluate uncertainties and user requirements (tolerances), assessment of additional user uncertainties may be required by laboratory staff. Through proper use of documented laboratory and field procedures, additional uncertainty factors may be minimized to a level that does not contribute significantly to the previously described factors. Additional standard uncertainties in the calibration of field standards and their use in meter verification may include: how the prover level is established, how 
delivery and drain times are determined, the use of a proper "wet-down" prior to calibration or use, whether gravity drain is used during calibration or whether the volume of water is eliminated by pumping, the cleanliness of the prover and calibration medium, prover retention characteristics related to inside surface, contamination or corrosion, and total drain times, and possible air entrapment in the water, and connecting pipes. Systematic errors may be observed between laboratory calibration practices where a gravity drain is used and field use where the pumping system is used.

\section{Report}

6.1 Report results as described in SOP 1, Preparation of Calibration/Test Results, with the addition of the following:

6.1.1 Total prover volume, uncertainty, reference temperature, material, thermal coefficient of expansion (assumed or measured), construction, any identifying markings, tolerances (if appropriate), laboratory temperature, water temperature, barometric pressure, relative humidity, out-of-tolerance conditions, and the total drain time from opening of the valve, including the $30 \mathrm{~s}$ drain after cessation of flow.

\section{Additional References:}

Bean, V. E., Espina, P. I., Wright, J. D., Houser, J. F., Sheckels, S. D., and Johnson, A. N., NIST Calibration Services for Liquid Volume, NIST Special Publication 250-72, National Institute of Standards and Technology, Gaithersburg, MD, (2006). 

SOP 20

\section{Standard Operating Procedure \\ for \\ Control Charts for Calibration of Neck-Type Provers \\ (Volume Transfer Method)}

1 Introduction

\subsection{Purpose}

This procedure describes a process to be followed to monitor the statistical control of the volume transfer method for the calibration of neck-type provers, especially when using the Standard Operating Procedure (SOP) 19 for this purpose. The same principles may be adapted to the development of control charts for other calibration procedures.

\subsection{Prerequisites}

The verification procedure is the same as that required by SOP 19 .

2 Summary

Because of the size and cost of neck-type provers, it is not always practical to have check standards remain in the laboratory for the purposes of measurement control. However, it is practical to maintain a range $(R)$ chart for each size prover to establish the standard deviation of the measurement process. Directions for preparing and using an $R$ control chart that monitors the precision of the test procedure are given. It is assumed that provers of the same nominal capacity and design will have similar characteristics with respect to the repeatability of tests. Since it is not practical to run a sufficient number of tests on each unknown prover to determine the repeatability, the absolute difference between two test results on individual provers of the same nominal size are graphed on the same $R$ chart to reflect the repeatability of measurement of the provers tested in the laboratory. Provers of similar readability may be grouped together on the same chart (e.g., provers greater than and equal to 500 gal generally have $20 \mathrm{in}^{3}$ graduations and similar repeatability.)

3 Equipment

All equipment is designated in SOP 19. 
4 Procedure

\subsection{Data Collection}

4.1.1 Conduct a minimum of two runs on each prover. A minimum of 12 provers must be tested before a reasonably adequate data base is established. Note: 25 to 30 points are recommended to determine uncertainties.

4.1.2 Tabulate the measured errors as determined by each of the two trials using a form such as the one contained in the Appendix. The data may be maintained in a spreadsheet or other electronic program in lieu of a paper form. (If the prover is adjusted after the first trial to indicate zero error at a reference temperature, the first trial reading is evaluated after the adjustment.)

4.1.3 Calculate the absolute difference $|d|$ of the two trials and the summation $\Sigma|d|$. Note that $|d|=R$, the range of the two trials.

4.1.4 Calculate the average range of the trials, $\bar{R}$, for the $n$ tests as follows:

$$
\bar{R}=\frac{\sum|d|}{n}
$$

Eqn. 1

\subsection{Construct a Range Control Chart}

4.2.1 Construct an $R$ control chart having the following limits:

Central Line $\quad=\bar{R}$

Lower control and warning limits LCL $=\mathrm{LWL}=0$

(There should be no negative numbers recorded when using absolute values!)

Upper warning limit UWL $\quad=2.512 \bar{R}$

Upper Control limit UCL $\quad=3.267 \bar{R}$

4.2.2 The recommended format for construction of $R$ control charts is given in NISTIR 6969, Section 7.4.

\subsection{Use of Control Charts}

4.3.1 Two trials are run on each prover submitted to the laboratory for calibration. The values for $R$ are plotted on the appropriate control chart, preferably in sequential order. The limits of the charts are such that $95 \%$ of the values should fall within the warning limits and rarely should a value fall outside the control limits, provided that the system is in a state of statistical control.

4.3.2 If the values plotted on the $R$ chart fall outside of the control limit, a decrease in precision is indicated. Cleanliness, valve leaks, or procedural problems (e.g., 
meniscus reading, drain times) should be investigated.

4.3.3 No calibration data should be accepted when the system is out of control.

4.3.4 If a plotted value for $R$ is outside of the warning limit but inside the control limit, a second set of duplicate calibrations should be made. If the new value for $R$ is within the warning limit, the process may be considered in control. If it lies outside of the warning limit, lack of control is indicated. Corrective action should be taken and attainment of control demonstrated before calibration measurements are considered to be acceptable.

4.3.5 Even while the system is in an apparent state of control, incipient troubles may be indicated when the control data show short- or long-term trends, shifts, or runs.

\section{Interpretation of Control Chart Data}

5.1 Demonstration of "in control" indicates that the calibration process is consistent with the past experience of the laboratory. That is to say, there is no reason to believe that excessive changes in precision have occurred.

5.2 The accuracy is inferred from a consideration of control of the sources of bias. These include drain characteristics of the prover, time required to drain the prover, and prover design (geometry and piping).

5.3 To the extent appropriate, the precision of measurement of provers may be extended to the calibration of other provers of the same capacity and design. Care must be exercised in this approach because each prover is custom made and has unique metrological characteristics. The lack of precision in the test of a prover may indicate a defect in that particular standard and may not reflect inconsistency in the measurement process. Uncertainty values may need to be adjusted when prover design problems are indicated.

5.4 It is expected that the maximum imprecision (the upper control limit) of the volumetric method of prover calibration will be less than one-third of the applicable prover tolerance in field applications. If this is not the case, contact the NIST Weights and Measures Division to discuss the problem. 


\section{Appendix}

\section{Control Chart Data}

Prover Capacity \& Graduation Size:

\begin{tabular}{|c|c|c|c|c|c|}
\hline $\begin{array}{l}\text { Test } \\
\text { Number }\end{array}$ & Date & $\begin{array}{l}V_{T D}, X_{1} \\
\text { Trial No. } 1\end{array}$ & $\begin{array}{l}V_{T D}, X_{2} \\
\text { Trial No. } 2\end{array}$ & $\frac{V_{T D M}}{x}$ & $\begin{array}{l}|d|=\mid \text { Trial } 1- \\
\text { Trial 2|}\left.\right|^{*}\end{array}$ \\
\hline 1 & & & & & \\
\hline 2 & & & & & \\
\hline 3 & & & & & \\
\hline 4 & & & & & \\
\hline 5 & & & & & \\
\hline 6 & & & & & \\
\hline 7 & & & & & \\
\hline 8 & & & & & \\
\hline 9 & & & & & \\
\hline 10 & & & & & \\
\hline 11 & & & & & \\
\hline 12 & & & & & \\
\hline 13 & & & & & \\
\hline 14 & & & & & \\
\hline 15 & & & & & \\
\hline \multirow{2}{*}{\multicolumn{4}{|c|}{ SUM }} & & \\
\hline & & & & $\sum \bar{x}$ & $\sum|d|$ \\
\hline
\end{tabular}

$n^{* *}=$

$\mathrm{UWL}=2.512 \bar{R}=$

$$
\bar{R}=\frac{\sum|d|}{n}=
$$

$\mathrm{UCL}=3.267 \bar{R}=$

* This is the range, $R$, of the two trials and is actually the larger value minus the smaller value.

$* * n$ is the number of tests used to calculate the control limits. 


\section{SOP 21}

\section{Standard Operating Procedure for Calibration of LPG Provers ${ }^{1}$}

1 Introduction

\subsection{Purpose of Test}

This procedure may be used to calibrate a volume standard used to test systems designed to measure and deliver liquefied petroleum gas (LPG) in the liquid state by definite volume, whether installed in a permanent location or mounted on a vehicle. A schematic diagram of such a prover is shown in Figure 1, together with numbers, e.g., 1, 2, 3, and 4 to clarify the various operations described in the procedure. The parts labeled $\mathrm{A}, \mathrm{B}$, and $\mathrm{C}$ are hose connections used in meter testing (versus prover calibrations).

\subsection{Prerequisites}

1.2.1 Verify the unknown prover has been properly cleaned and vented with all petroleum products removed prior to submission for calibration to ensure laboratory safety.

1.2.2 Verify that valid calibration certificates are available for the standard used in the test.

1.2.3 Verify that the standards to be used have sufficiently small standard uncertainties for the intended level of the calibration.

1.2.4 Verify the availability of an adequate supply of clean water (GLP 10).

1.2.5 Verify that the operator has had specific training in SOP 18, SOP 19, SOP 21, GMP 3, and SOP 20.

1.2.6 Cylinder of nitrogen or compressed air and a proper pressure regulator.

1.2.7 Verify that the laboratory facilities meet the following minimum conditions to make possible the expected uncertainty achievable with this procedure:

\footnotetext{
${ }^{1}$ Non-SI units are predominately in common use in State legal metrology laboratories, and/or the petroleum industry for many volumetric measurements, therefore non-SI units have been used to reflect the practical needs of the laboratories performing these measurements as appropriate. The majority of LPG provers in use are 20 gal, 25 gal, and 100 gal nominal sizes. The volume of LPG provers is established at $60^{\circ} \mathrm{F}$ and 100 psig.
} 
Table 1. Laboratory environmental conditions

\begin{tabular}{|c|c|c|}
\hline Procedure & Temperature & Relative Humidity \\
\hline $\begin{array}{l}\text { Volume } \\
\text { Transfer }\end{array}$ & $\begin{array}{c}18^{\circ} \mathrm{C} \text { to } 27^{\circ} \mathrm{C} \text {, maximum } \\
\text { change } 2.0^{\circ} \mathrm{C} / \mathrm{h}\end{array}$ & $\begin{array}{c}40 \% \text { to } 60 \% \\
\pm 20 \%, \text { maximum change } / 4 \mathrm{~h}\end{array}$ \\
\hline
\end{tabular}

\subsection{Field tests}

1.3.1 A "field" calibration is considered one in which a calibration is conducted in an uncontrolled environment, such as out-of-doors. Calibrations conducted under field and laboratory conditions are not considered equivalent.

1.3.2 The care required for field calibrations includes proper safety, a clean and air-free water supply, measurement control programs, and a stable temperature-controlled environment shaded from direct sunshine to allow the prover, field standard, and test liquid (water) to reach an equilibrium temperature, with minimal evaporation. Environmental conditions should be controlled (or selected) to be as close to laboratory conditions as possible. All data and appropriate environmental conditions must be documented regardless of test location.

2 Methodology

2.1 Scope, Precision, Accuracy

This procedure is applicable for the calibration of LPG provers with capacities of $100 \mathrm{~L}$ to $500 \mathrm{~L}$ ( $20 \mathrm{gal}$ to $100 \mathrm{gal}$ ) or larger when appropriate. Provers of the latter capacity (gal and in $^{3}$ units) are encountered most frequently, hence the procedure is written with that in mind. The changes necessary for testing provers of other capacities will be obvious and are not described in this document. The agreement of duplicate measurements made within a short period of time on a given 100-gal prover should be within $5 \mathrm{in}^{3}$ (0.02 gal). The accuracy will depend on the uncertainty in the volume of the standard, on the care exercised in making the various measurements and temperature readings, and on correct application of the corresponding corrections.

\subsection{Summary}

The procedure is a modification of one described by M.W. Jensen in NBS Handbook 99, "Examination of Liquefied Petroleum Gas Liquid- Measuring Devices." The LPG prover is calibrated with a known volume of water delivered into it from a standard prover of calibrated volume. Depending on the respective volumes, multiple transfers may be required. While these should be minimized, a 
maximum number of 15 transfers are permitted to ensure that final calibration uncertainties are sufficiently small to meet user applications. The LPG prover is pressurized and the liquid level is measured at each of several values of applied pressure. The calibration thus defines the capacity of the prover over its expected range of operational pressure.

\subsection{Equipment}

2.3.1 Calibrated standard prover of minimum volume of 10 gal but preferably of the same volume as the LPG prover, with recent calibration certificate traceable to NIST.

2.3.2 A funnel and a calibrated 1 gal flask (or other suitable size) with recent calibration certificate traceable to NIST, to calibrate the neck of prover.

2.3.3 Calibrated thermometers (2) accurately calibrated to $0.1{ }^{\circ} \mathrm{C}$, with recent calibration certificate traceable to NIST.

\subsubsection{Meniscus reading device (See GMP 3).}

2.3.5 Timing device (calibration is not required.)

2.3.6 Supply of clean water, preferably soft water (filtered if necessary) (GLP $10)$.

2.3.7 Sturdy platform, with appropriate safety conditions, with sufficient height to hold standard and to permit transfer of water from it to the prover by gravity flow.

2.3.8 Clean the pipe or tubing (hoses) to facilitate transfer of water from the laboratory standard to prover. Nearly all LPG provers require reducers to be used between normal laboratory piping and the top hole on the prover. Pipe and hose lengths should be minimized to reduce water retention errors. Care must be taken during wet-downs and runs to ensure complete drainage and consistent retention in all hoses or pipes.

2.3.9 Compressed nitrogen cylinder or air, suitable regulator, and an appropriate pressure gauge. The calibration relies on the accuracy of the pressure gauge on the prover. It assumes that systematic errors in the prover pressure gauge will be present in field applications as well, thus calibration of the laboratory pressure gauge is not essential.

\section{$2.4 \quad$ Procedure}

\subsubsection{Preliminary Operations}


2.4.1.1 Install and level the standard(s) on a raised platform with appropriate security and safety ensured for the prover(s) and operator(s). Provide pipe or tubing for delivery of water by most direct route to prover.

2.4.1.2 Position and level the unknown prover where it can be reached from the elevated standard by the shortest feasible delivery system.

2.4.1.3 Remove the plug and relief valve (1) from the top, and extend the pipe into the hole. This may require the use of a reducer and a short length of hose (about 1 inch in diameter). If this is a tight fit, open the vapor return line valve (2) to provide an air bleed.

Use the prover inlet line (3) as a gravity drain. If necessary, remove the fitting on the end and connect a hose or pipe to make the necessary drain line.

Warning: ensure that a check valve is not plumbed into the prover inlet line. If it is, remove the check valve, otherwise the prover will need to be drained via the plug in the bottom of the lower neck.

\subsubsection{Cleanliness Check}

Both the standard and the prover must be internally clean. This should be verified by checking that water drains properly from them. If necessary, either or both should be cleaned with water and detergent (see GMP No. 6) to attain good drainage characteristics.

\subsubsection{Neck scale plate verification}

2.4.3.1 Fill the prover with water from the standard. Check the prover levels and adjust if necessary. Check the prover system for leaks. This is a wet-down run.

2.4.3.2 Bleed the liquid level down to a graduation near the bottom of the upper neck. "Rock" the prover to "bounce" the liquid level, momentarily, to ensure that it has reached an equilibrium level. Read and record this setting. This is in preparation for calibration of the neck scale.

2.4.3.3 Remove the fill hose or pipe from the top and insert a funnel. 
2.4.3.4 Recheck the scale reading, then add 1 gal of water (or a volume equal to approximately $1 / 4$ or $1 / 5$ of the graduated neck volume) from a suitable standard; record the scale reading.

2.4.3.5 Repeat 2.4.3.4 by successive additions until water is near the top of the scale (the neck capacity is usually about 5 gal). Record scale readings after each addition. The closer the water is to the top of the neck, the harder it may be to "bounce" the liquid in the gauge.

A plot of scale readings with respect to volume added should be linear and will be a gross check of the validity of this calibration.

2.4.3.6 Calculate and check accuracy of the neck scale for each interval. The error should be less than $0.5 \%$ of the graduated neck volume. If more than this, the scale should be replaced or issue the NSCV and instructions to user.

2.4.3.7 The neck scale calibration value is calculated as follows:

$$
N S C V=\frac{V_{w}}{\left(s r_{f}-s r_{i}\right)}
$$

where:

\begin{tabular}{|c|l|}
\hline NSCV & \multicolumn{1}{|c|}{ Neck scale calibration value } \\
\hline $\mathrm{V}_{\mathrm{w}}$ & $\begin{array}{l}\text { Total volume of water added to } \\
\text { neck }\end{array}$ \\
\hline$s r_{f}$ & Scale reading, final \\
\hline$s r_{i}$ & Scale reading, initial \\
\hline
\end{tabular}

\subsubsection{Body Calibration}

2.4.4.1 Drain the prover through its inlet valve and the liquid bleeder valve. When the liquid reaches the top of the lower gauge glass, close the inlet valve and allow the water to drain from the interior of the prover into the lower neck for $30 \mathrm{~s}$, while controlling the water flow and level with the bleeder valve until the liquid meniscus reaches the zero graduation. The liquid level should be exactly at the zero graduation and the bleeder valve closed simultaneously at the $30 \mathrm{~s}$ drain time. (Draining with the bleeder valve close to the zero mark should be started during the $30 \mathrm{~s}$ drain period but should not be completed before the end of the drain period.) 
Alternatively, though not recommended, the prover may be completely drained with a $30 \mathrm{~s}$ drain time and then refilled with a funnel that has been wet down, and small volume of water to set the zero mark. Errors from this process will result due to the additional drain and retention time and other factors associated with the process.

2.4.4.2 Transfer 100 gal (or other suitable volume) from the standard in the usual manner, and record the standard and prover temperature readings. If multiple transfers are required, record temperature of the standard at the time of each transfer, but that of the prover only after the final transfer. "Rock" the prover to "bounce" the liquid in the upper gauge glass before reading. Record the scale reading after the nominal volume has been transferred into the unknown LPG prover.

Note regarding temperature measurements: A digital temperature sensing device with a long cable can allow insertion of the probe into the standard and the unknown to enable direct liquid measurements at the bottom, middle, and top of the provers. If the prover thermometer wells are used, ensure that the prover has equalized with the temperature of the water.

2.4.4.3 Drain the LPG prover as described in 2.4.4.1 and make another test run. Record the temperatures of the standard(s) and the unknown and final scale reading. Calculate the prover error at 0 psig for each run using the appropriate equations in Section 3; these values are used to evaluate repeatability of the test only. The error at 0 psig for the test runs should agree within $0.02 \%$ of the prover volume or approximately one-half the prover tolerance (i.e., $5 \mathrm{in}^{3}$ on a 100 gal LPG prover). If the repeatability is larger than $0.02 \%$ of the prover volume, continue until replicates agree within these limits, taking care to ensure that poor cleanliness, contamination, bubbles in hoses, leaking valves or seals are not contributing to poor repeatability. Repeatability problems may also be due to poor field conditions, such as when calibration is conducted in unstable environments. Repeatability problems must be corrected before calibration can be completed.

2.4.4.4 Replace the relief valve and plug in the top of the prover using suitable pipe joint compound or tape. Allow water from 2.4.4.3 (the second run) to remain in prover.

\subsubsection{Prover Adjustments}


2.4.5.1 The internal pressure and hence the volume of the prover may vary during use. Accordingly, a pressure correction must be made using the data of steps 2.4.6.

To minimize the amount of correction needed when the prover is in use, the prover should be adjusted to indicate its nominal capacity when 100 psig is applied. (An internal pressure of 100 psig is suggested as being convenient.) If the actual volume of the prover is not near a convenient whole gallon value and cannot easily be adjusted to a whole gallon value, a prover correction value can be computed (see 3.4) and added to the pressure correction values to obtain a set of combined prover and pressure correction values to be computed. The pressure correction is computed in 3.4.

2.4.5.2 Use a cylinder of nitrogen or compressed air and a proper pressure regulator with an integrated pressure gauge.

Connect the cylinder regulator output to the vapor return fitting (2) near the top of the neck. This may require fashioning a connection with steel pipe nipples or other appropriate materials and the existing fittings.

Caution: Ensure that all piping and fittings are rated for the pressures to which they will be exposed.

Make sure all valves are closed except the vapor return valve. Verify that the final scale reading has not changed since it was recorded (if it has changed it may signal a leak in one of the valves or fittings), and then slowly introduce pressure until the installed prover gauge reads $100 \mathrm{psig}$. Lightly tap the gauge to ensure that the gauge needle is not sticking. "Bounce" the liquid in the neck, then read and record the liquid level at this applied pressure.

Return pressure to 0 psig and reapply pressure as above. This reading at 100 psig should agree with the above recorded reading within $0.02 \%$ of the nominal volume of the prover. Leaking seals or valves may cause problems with repeatability of the gauge readings under pressure.

2.4.5.3 With the pressure in the prover at 100 psig, adjust the upper scale to read the nominal volume. This is accomplished by adjusting the upper scale so that the water level reading is: 
Desired scale reading $=V_{X 60}-\left(V_{N O M} * 1.00032\right) \quad$ Eqn. 2

Take care to use like units in the calculation. The calculation for $V_{X 60}$ is given in 3.1, Eqn 5.

Note: The correction factor 1.00032 corrects for the compressibility of the water at 100 psig. If the upper scale is not adjustable, see 2.4.5.4.

2.4.5.4 For provers with only an adjustable lower scale (or one in which the upper scale is not adjustable), a prover correction, $L_{C}$, may be calculated at 100 psig as follows:

$$
L_{C}=V_{X 60}-\left(V_{\text {NOM }} * 1.00032\right)-s r_{u}
$$

where:

\begin{tabular}{|c|l|}
\hline$L_{C}$ & Prover correction at 100 psig \\
\hline$V_{X 60}$ & Volume of unknown prover at $60^{\circ} \mathrm{F}$ \\
\hline$V_{N O M}$ & Nominal volume of prover \\
\hline$s r_{u}$ & Upper scale reading at 100 psig \\
\hline 1.00032 & $\begin{array}{l}\text { Correction factor for the compressibility } \\
\text { of water at } 100 \text { psig }\end{array}$ \\
\hline
\end{tabular}

Take care to use like units in the calculation.

If the prover correction is negative, move the bottom scale down to increase the prover volume. If the prover correction is positive, move the bottom scale up to decrease the prover volume. The distance $h$ that the bottom scale is to be moved is:

$$
h=\frac{4\left|L_{C}\right|}{\pi d^{2}}
$$

Eqn. 4

where:

\begin{tabular}{|c|l|}
\hline$h$ & $\begin{array}{l}\text { Distance in inches the bottom scale is to be } \\
\text { moved, up or down }\end{array}$ \\
\hline$L_{C}$ & Prover correction at 100 psig in cubic inches \\
\hline$d$ & $\begin{array}{l}\text { Inside diameter of the lower neck of the } \\
\text { prover in inches (as noted on identification } \\
\text { plate) }\end{array}$ \\
\hline
\end{tabular}

\subsubsection{Pressure Correction}


2.4.6.1 Return pressure to 0 psig. Record the reading. Slowly introduce pressure until the installed prover gauge reads 50 psig. Lightly tap the gauge to ensure that the gauge needle is not sticking. "Bounce" the liquid in the neck, then read and record the liquid level at this applied pressure.

2.4.6.2 Repeat step 2.4.6.1 at 100, 150, and 200 psig. Other pressure points in between those listed may be tested if so desired. (The water level should decrease 10 in $^{3}$ to 15 in $^{3}$ for each 50 psig increase in pressure, although this varies depending on the geometry and age of the LPG prover. Water level changes significantly greater than indicated may be due to leaking seals and/or valves.) Erratic pressure readings may also be due to air entrapment based on prover design; repeated pressurizing of the prover should eliminate entrapped air. Air entrapment problems due to design may need to be investigated and corrected.

2.4.6.3 Repeat step 2.4.6.1 as the pressure is bled down to 150, 100, 50, and 0 psig (atmospheric pressure). The readings should agree with those previously obtained within approximately $0.02 \%$ of the nominal prover volume. If the data are not linear with respect to pressure, repeat the series of measurements above to verify the nonlinearity of the readings. Leaking seals or valves may cause problems with repeatability of the gauge readings under pressure. The cause of repeatability errors must be identified and corrected before continuing the calibration.

\subsubsection{Final Operations}

2.4.7.1 Seal the bottom and top scales as specified by laboratory policy and as appropriate.

2.4.7.2 Drain prover, then remove plug (5) at the lower neck to facilitate drainage below the lower gauge. If time permits, let the prover drain overnight.

2.4.7.3 With the nitrogen cylinder or compressed air connected, blow nitrogen or air through the prover to remove remaining moisture. Be sure to blow out the drain line and any other portions of the system that may have become contaminated with water.

2.4.7.4 If water has entered the pump-off system, pour several gallons of alcohol into the prover and pump the alcohol 
3 Calculations

through the system to remove the water to prevent it from freezing in the pump when LP gas is used.

\subsection{Single Delivery}

3.1.1 Calculate $V_{X 60}$, the volume of the unknown prover at $60^{\circ} \mathrm{F}$, using the following equation:

$$
V_{X 60}=\frac{\rho_{1}\left\{\left(V_{S 60}+\Delta_{1}\right)\left[1+\alpha\left(t_{1}-60^{\circ} \mathrm{F}\right)\right]\right\}}{\rho_{x}\left[1+\beta\left(t_{x}-60^{\circ} \mathrm{F}\right)\right]} \text { Eqn. } 5
$$

\subsection{Multiple Deliveries}

3.2.1 Calculate $V_{X 60}$, the volume of the unknown prover at $60^{\circ} \mathrm{F}$, using the following equation:

$$
V_{X 60}=\frac{\rho_{1}\left\{\left(V_{S 60}+\Delta_{1}\right)\left[1+\alpha\left(t_{1}-60^{\circ} \mathrm{F}\right)\right]\right\}+\rho_{2}\left\{\left(V_{S 60}+\Delta_{2}\right)\left[1+\alpha\left(t_{2}-60^{\circ} \mathrm{F}\right)\right]\right\}+\ldots+\rho_{N}\left\{\left(V_{S 60}+\Delta_{N}\right)\left[1+\alpha\left(t_{N}-60^{\circ} \mathrm{F}\right)\right]\right\}}{\rho_{x}\left[1+\beta\left(t_{x}-60^{\circ} \mathrm{F}\right)\right]} \text { Eqn. } 6
$$

Table 2. Variables for $V_{X 60}$ equations

\begin{tabular}{|c|l||}
\hline \multicolumn{1}{|c||}{ Symbols Used in Equations } \\
\hline \hline$V_{X 60}$ & volume of the unknown vessel at $60^{\circ} \mathrm{F}$ \\
\hline$V_{S 60}$ & volume of the standard vessel at $60^{\circ} \mathrm{F}$ \\
$\rho_{1}, \rho_{2}, \ldots, \rho_{N}$ & $\begin{array}{l}\text { density of the water in the standard prover where } \rho_{1} \text { is the density of the water for } \\
\text { the first delivery, } \rho_{2} \text { is the density of the water for the second delivery, and so on } \\
\text { until all N deliveries are completed }\end{array}$ \\
\hline$\Delta_{1}, \Delta_{2}, \ldots, \Delta_{N}$ & $\begin{array}{l}\text { volume difference between water level and the reference mark on the standard } \\
\text { where the subscripts } 1,2, \ldots, \mathrm{N}, \text { represent each delivery as above. If the water } \\
\text { level is below the reference line, } \Delta \text { is negative. If the water level is above the } \\
\text { reference line, } \Delta \text { is positive. If the water level is at the reference line, } \Delta \text { is zero } \\
\text { NOTE: units must match volume units for the standard }\end{array}$ \\
\hline$t_{1}, t_{2}, \ldots, t_{N}$ & temperature of water for each delivery with the subscripts as above \\
\hline$\alpha$ & coefficient of cubical expansion for the standard in units / ${ }^{\circ} \mathrm{F}$ \\
\hline$\beta$ & coefficient of cubical expansion for the prover in units / ${ }^{\circ} \mathrm{F}$ \\
\hline$t_{x}$ & temperature of the water in the filled unknown vessel in units ${ }^{\circ} \mathrm{F}$ \\
\hline$\rho_{x}$ & density of the water in the unknown vessel in g/cm ${ }^{3}$ \\
\hline $\begin{array}{l}\text { Note: Values for the density of water at the respective temperatures may be found in Table } 9.8 \\
\text { (in NISTIR 6969). It may also be calculated using the formula given in GLP 10. }\end{array}$ \\
\hline
\end{tabular}


Compute the pressure correction, $\mathrm{P}_{\text {corr }}$, at each pressure that the prover was read, after any adjustments, by correcting for the compressibility of the water. The equation is:

$P_{\text {corr }}=$ Scale reading @100 psig - scale reading @X psig

$+($ water compressiblity factor $)\left(\frac{100 \mathrm{psig}-X \mathrm{psig}}{100}\right) \quad$ Eqn. 7

where the water compressibility factor is 7.4 in $^{3}$ or 0.032 gal for a 100 gallon prover and $1.8 \mathrm{in}^{3}$ or $0.008 \mathrm{gal}$ for a 25 gallon prover. The compressibility value is 0.00032 gal per gallon for 100 psig. The compressibility factor is given in both cubic inches and gallons so the proper unit can be selected depending upon the unit used for the scale readings.

Plot the pressure corrections. If the corrections versus the pressure are linear, make a straight line best fit of the data and interpolate to obtain the pressure corrections for any desired pressure. If the data is nonlinear, then perform a straight line interpolation between adjacent pressure readings to obtain pressure corrections at any desired intermediate pressures. Alternatively, a best fit curve can be drawn for the nonlinear data and the pressure corrections interpolated from the graph for intermediate pressures. See Appendix A for an example of the pressure corrections.

\subsection{Prover Volume}

LPG provers are generally adjusted to the nominal value using 100 psig as the reference pressure. At 100 psig, the prover reading will be lower by at least 0.032 $\mathrm{gal} / \mathrm{gal}$ than it was at 0 psig due to the compressibility of water under pressure. Therefore, a prover of $100 \mathrm{gal}$ should be set to read the $V_{X 60}$ value at 0 psig minus $7.4 \mathrm{in}^{3}$. (The water level on the prover's upper scale will be below the calculated $V_{X 60}$ reading when pressurized to $100 \mathrm{psig}$ ). The prover must not be set to read the $V_{X 60}$ value plus the compressibility factor at 0 psig because, in addition to compressibility of water, the prover expands as pressure is applied.

4.1 If a check standard is used (See SOP 20, SOP 30), repeat the process for the unknown prover on the check standard without adjustments.

4.2 Plot the check standard volume and verify that it is within established limits. Alternatively a $t$-test may be incorporated to check the observed value against an accepted value. 
4.3 The mean of the check standard values is used to evaluate bias and drift over time.

4.4 Check standard values may be used to calculate the standard deviation of the measurement process.

4.5 If a check standard is not used, the laboratory will need to maintain a Range chart according to SOP 20 to determine the repeatability for this procedure.

$5 \quad$ Assignment of Uncertainties

5.1 The limits of expanded uncertainty, $U$, include estimates of the standard uncertainty of the laboratory volumetric standards used, $u_{s}$, plus the uncertainty of measurement, $u_{m}$, at the $95 \%$ level of confidence. See SOP 29 for the complete standard operating procedure for calculating the uncertainty.

5.2 The standard uncertainty for the standard, $u_{s}$, is obtained from the calibration report. The combined standard uncertainty, $u_{c}$, is used and not the expanded uncertainty, $U$, therefore the reported uncertainty for the standard will usually need to be divided by the coverage factor $k$.

5.3 Neck calibration uncertainty should be estimated based on the uncertainty of standards used, errors observed during calibration, and the repeatability of the neck calibration.

5.4 Standard deviation of the measurement process from control chart performance (See SOP No. 20 and SOP 30)

5.4.1 The value for $s_{p}$ is obtained by estimation using the range from the control chart data for large volume transfer procedures.

Note: Fifteen is the maximum recommended number of deliveries from a laboratory standard to a prover under test to minimize calibration uncertainties to the levels identified previously.

5.5 Other standard uncertainties usually included at for this type of calibration level include uncertainties associated with the ability to read the meniscus, only part of which is included in the process variability, viscosity effects, the cubical coefficient of expansion for the prover under test, use of proper temperature corrections, the accuracy of temperature measurements, water density equation, the compressibility of water, round robin data showing reproducibility, environmental variations over time, and bias or drift of the standard.

5.5.1 To properly evaluate uncertainties and user requirements (tolerances), assessment of additional user uncertainties may be required by laboratory staff. Through proper use of documented laboratory and field procedures, additional uncertainty factors may be minimized to a level that does not 
contribute significantly to the previously described factors. Additional standard uncertainties in the calibration of field standards and their use in meter verification may include: how the prover level is established, how delivery and drain times are determined, the use of a proper "wet-down" prior to calibration or use, whether gravity drain is used during calibration or whether the volume of water is eliminated by pumping, the cleanliness of the prover and calibration medium, prover retention characteristics related to inside surface, contamination or corrosion, and total drain times, and possible air entrapment in the water. Systematic errors may be observed between laboratory calibration practices where a gravity drain is used and field use where the pumping system is used.

6 Report

6.1 Report results as described in SOP No. 1, Preparation of Calibration/Test Results, with the addition of the following:

6.1.1 For LPG provers, the total prover volume and uncertainty, reference temperature, material, coefficient of expansion (assumed or measured), any identifying markings, tolerances (if appropriate), laboratory temperature, water temperature, barometric pressure, relative humidity, out-of-tolerance conditions, and the total drain time from opening of the valve, including the $30 \mathrm{~s}$ drain after cessation of flow.

The report should also include a pressure correction table or chart, along with a note regarding possible differences in retention characteristics between water, the calibration medium, and LPG products. 
Figure 1. LPG Prover Schematic

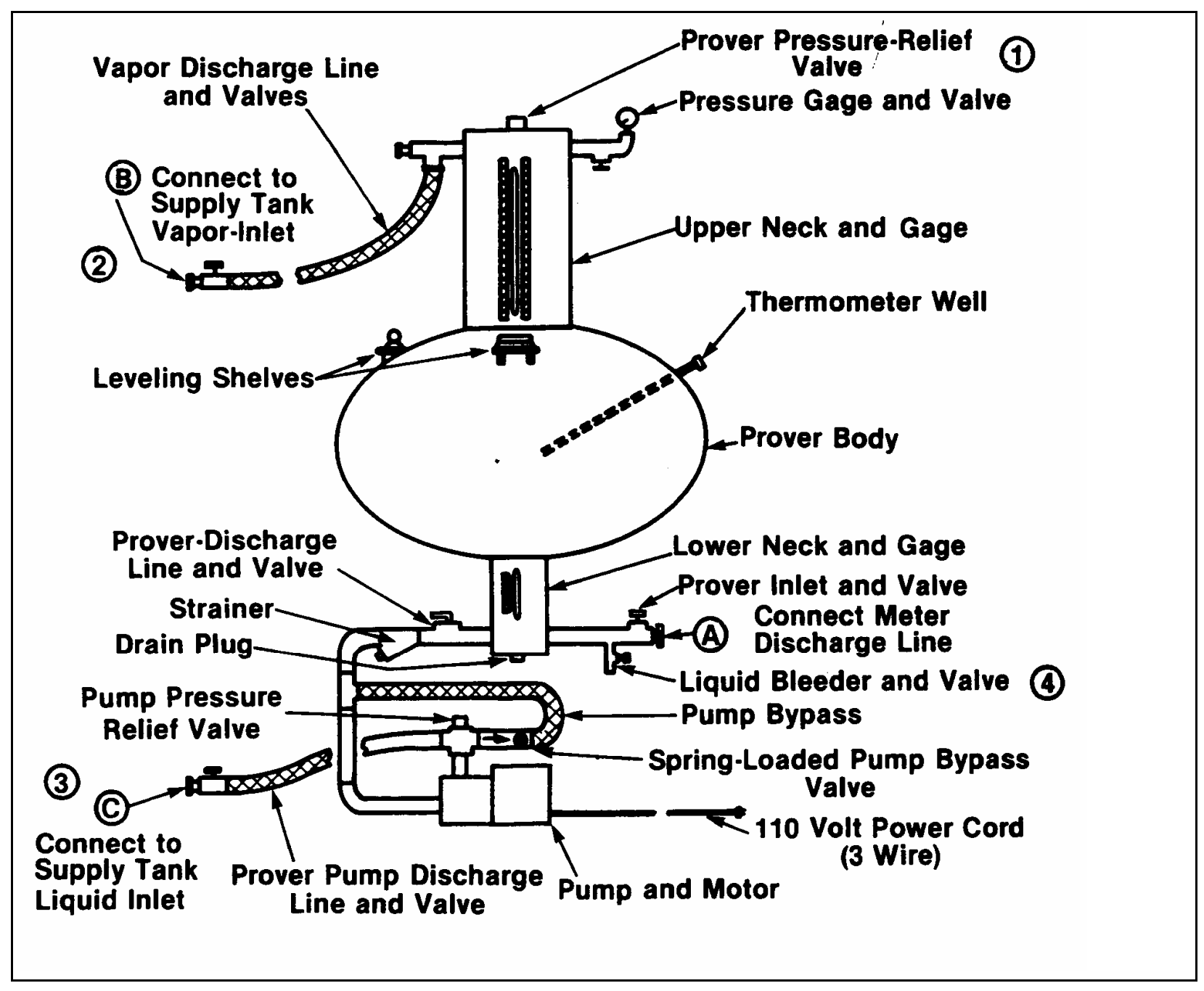




\section{Appendix A}

\section{SOP No. 21 \\ Recommended Standard Operations Procedure for Calibration of LPG Provers}

The water compressibility factor is calculated based on an equation given in a paper by Frank E. Jones and Georgia L. Harris, "ITS-90 Density of Water Formulation for Volumetric Standards Calibration", as published in the Journal of Research of the National Institute of Standards and Technology, Vol. 97, No. 3, 1992.

Compressibility factor $=\left(V_{\text {NOM }}\right)(231)(k T)(P)$

where

\begin{tabular}{|l|l|}
\hline $\mathrm{V}_{\text {NOM }}$ & Nominal volume of Prover in gal \\
\hline$k T$ & Thermal compressibility of water in (atm) ${ }^{-1}$ \\
\hline$P$ & Pressure in atm \\
\hline
\end{tabular}

And

$k T=50.83101 \times 10^{-8}-3.68293 \times 10^{-9} t+7.263725 \times 10^{-11} t^{2}-6.597702 \times 10^{-13} t^{3}+2.87767 \times 10^{-15} t^{4}$

where $\mathrm{k} T$ is in $(\mathrm{kPa})^{-1}$ and $1 \mathrm{~atm}=101325 \mathrm{~Pa}$ (exactly).

The thermal compressibility of water for the reference temperature $60{ }^{\circ} \mathrm{F}\left(15.56{ }^{\circ} \mathrm{C}\right)$ is $4.66264002 \times 10^{-9} / \mathrm{kPa}$. LPG provers are calibrated at a nominal reference point at a specified temperature and pressure, typically $60{ }^{\circ} \mathrm{F}$ and 100 psig. A pressure of 100 psig correlates to 6.8 atmospheres. The following equation was used to calculate the compressibility factor:

Compressibility factor $=\left(V_{\text {Nom }}\right)(231)(k T)(P)$

Compressibility factor $=100$ gal $\left(231 \mathrm{in}^{3} /\right.$ gal $)\left(4.72442 \times 10^{-5} / \mathrm{atm}\right)(6.8 \mathrm{~atm})=7.4 \mathrm{in}^{3}$ or 0.032 gal

$1 \quad$ Example of Pressure Corrections

The following example is printed from a Lotus 1, 2, 3 program written by L. F. Eason, Metrologist (NC) to perform calculation for volume transfer. The program was modified by Georgia Harris (NIST) to provide calculations and corrections for LPG prover testing. 


\section{VOLUME TRANSFER CALIBRATION - METAL LPG PROVER}

\begin{tabular}{||ll}
\hline \hline DATE: 04/09/91 & \\
\hline COMPANY NAME: & Handbook 145 Example \\
ADDRESS: & 12321 Some Street \\
CITY, STATE: & Anywhere, USA \\
\hline NOMINAL VOLUME OF PROVER: & 100 GALLONS \\
PROVER SERIAL NO: & $100-234$ LP \\
MANUFACTURER: & Provers Unlimited \\
NUMBER OF DELIVERIES REQUIRED: & $1(0-15)$ \\
\hline
\end{tabular}

DATA FOR INDIVIDUAL STANDARD DELIVERIES

\begin{tabular}{|c|c|c|c|c|c|c|c|}
\hline $\begin{array}{l}\text { DROP } \\
\text { NO }\end{array}$ & $\begin{array}{l}\text { VOL } \\
(\text { GAL) }\end{array}$ & $\begin{array}{l}\text { METAL } \\
\text { (MS/SS) }\end{array}$ & $\begin{array}{l}\text { EXP } \\
\text { COEF }\end{array}$ & $\begin{array}{l}\text { TEMP } \\
\text { DEG C }\end{array}$ & $\begin{array}{l}\text { TEMP } \\
\text { DEG F }\end{array}$ & $\begin{array}{l}\text { WATER } \\
\text { DENSITY }\end{array}$ & $\begin{array}{l}\text { DELTA } \\
\text { (CU IN) }\end{array}$ \\
\hline 1 & 100 & stainless & 0.00003 & 15.55 & 59.99 & 0.999013 & 0 \\
\hline $\begin{array}{r}\text { TYPE O } \\
\text { COEFFICIE } \\
\text { WATER T } \\
\text { WATER } \\
\text { GAUGE } \\
\text { GAUGE } \\
\text { GAUGE A } \\
\text { GAUGE A } \\
\text { GAUGE A } \\
\text { DELIV } \\
\text { UNKNOW }\end{array}$ & $\begin{array}{l}\text { TAL FOR TI } \\
\text { F EXPANSI } \\
\text { RATURE: } \\
\text { SITY: } \\
\text { PSIG: } \\
\text { PSIG: } \\
\text { PSIG: } \\
\text { PSIG: } \\
\text { PSIG: } \\
\text { VOLUME A } \\
\text { OVER'S ERR }\end{array}$ & $\begin{array}{l}{ }^{\circ} \mathrm{F}: \\
\text { AT } 100 \text { PSI }\end{array}$ & & & $\begin{array}{l}\text { mild stee } \\
0.000018 \\
15.55 \mathrm{C} \\
59.99 \mathrm{~F} \\
0.999013 \\
0.09 \text { gal } \\
0.02 \text { gal } \\
-0.05 \text { gal } \\
-0.10 \text { gal } \\
-0.16 \text { gal } \\
100.0000 \\
4.2 \mathrm{in}^{3}\end{array}$ & $\mathrm{~cm}^{3}$ & \\
\hline \multicolumn{8}{|c|}{ ב" ADJUSTMENT INSTRUCTIONS } \\
\hline \multicolumn{8}{|c|}{$\begin{array}{l}\text { To adjust prover to deliver exactly } 100 \text { gallons at } 60 \mathrm{~F} \text {, adjust scale to read }-0.032 \text { gallons or }-7.4 \mathrm{in}^{3} \text {, at } 100 \text { psig. Move to } \\
-0.032 \text { gals, }-7.4 \mathrm{in}^{3} \text {, by } 0.34 \text { inches if } 4 " \text { lower scale. }\end{array}$} \\
\hline \multicolumn{8}{|c|}{ PROVER PRESSURE CORRECTIONS } \\
\hline & psig & 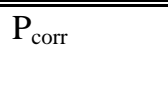 & $\begin{array}{l}\text { Prover } \\
\text { Error }\end{array}$ & Prover Error & \multicolumn{3}{|c|}{ " Volume of the Adjusted Prover (gal) } \\
\hline & $\begin{array}{l}0 \\
50 \\
100 \\
150 \\
200\end{array}$ & $\begin{array}{l}-0.108 \\
-0.054 \\
0.000 \\
0.034 \\
0.078\end{array}$ & $\begin{array}{c}-0.108 \\
-0.054 \\
0.000 \\
0.034 \\
0.078 \\
\text { Adj. }\end{array}$ & $\begin{array}{l}-0.090 \\
-0.036 \\
0.018 \\
0.052 \\
0.096 \\
\text { Not Adj. }\end{array}$ & \multicolumn{3}{|l|}{$\begin{array}{l}99.829 \\
99.946 \\
100.000 \\
100.034 \\
100.078\end{array}$} \\
\hline
\end{tabular}




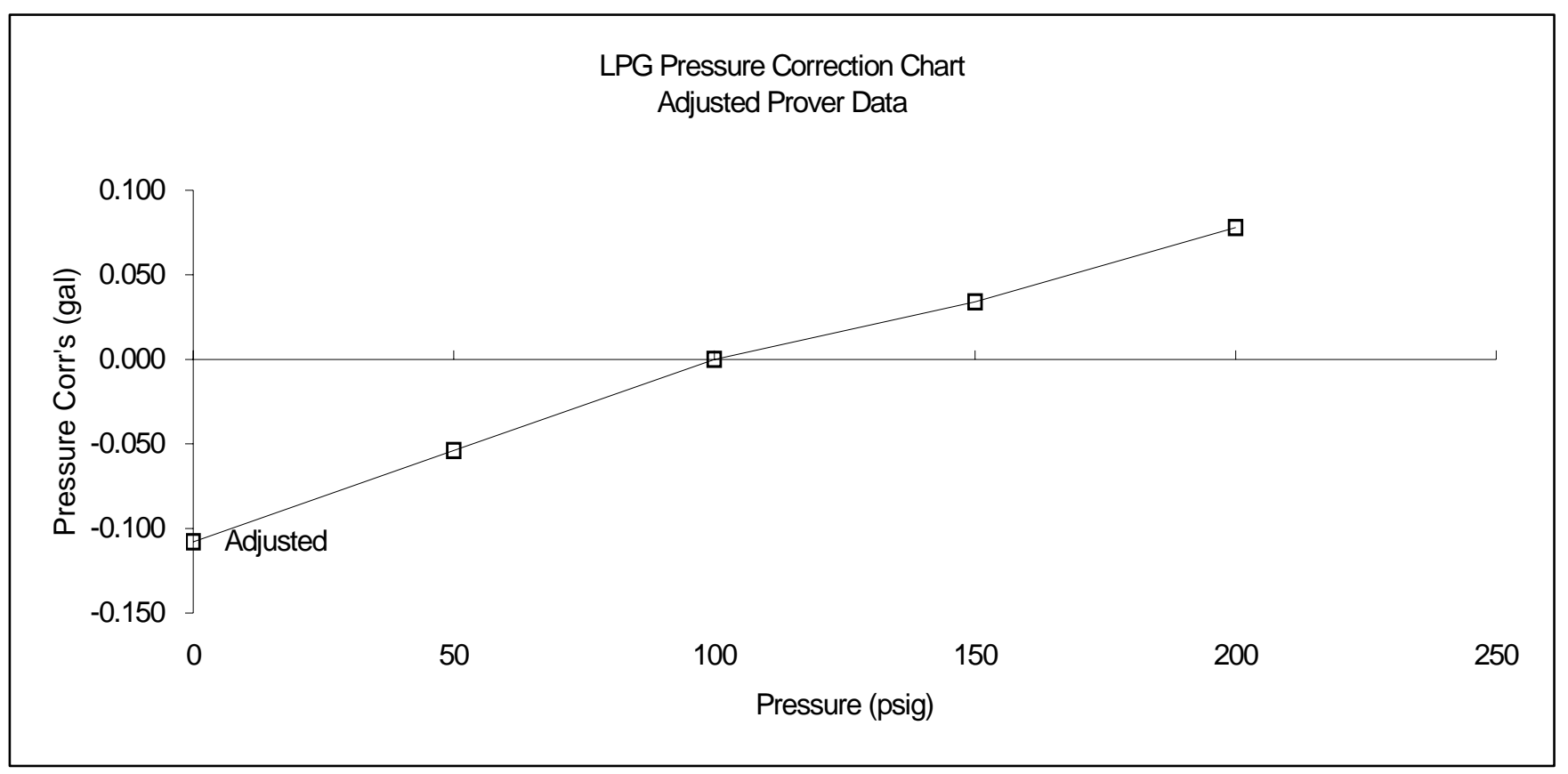





\section{SOP $26^{1}$}

\section{Standard Operating Procedure for Calibration of Dynamic Small Volume Provers by the Water Draw Method ${ }^{2}$}

\section{$1.0 \quad$ Introduction}

\subsection{Purpose of Test}

This procedure may be used to calibrate dynamic small volume prover systems such as those used to conduct liquid metering device (e.g., Positive Displacement, Turbine) provings at wholesale marketing terminals. A volumetric water draw process is used.

\subsection{Prerequisites}

1.2.1 Verify that the standards used have been calibrated and that a valid certificate is available. The standard calibration should include a neck scale calibration as recommended in SOP 18 or SOP 19.

\subsubsection{Verify the cleanliness of the water to be used.}

1.2.3 Verify that the person performing the calibrations is trained and proficient in carrying out this test procedure and related liquid calibration procedures.

1.2.4 The water draw location should provide for a stable ambient temperature. Direct sunlight must be avoided. An enclosed shelter is preferred.

\subsection{Methodology}

\subsection{Scope, Precision, Accuracy}

This procedure is applicable for the calibration of a dynamic small volume prover (SVP) system within the limitations of the standards available. The precision attainable will depend directly on the care used in the various procedures required for this test. Strict observance of drainage times, internal cleanliness of vessels used, careful volumetric readings (menisci) and the adherence to the sequence of events outlined in this procedure are essential.

\footnotetext{
${ }^{1}$ Certain commercial equipment, instruments, or materials are identified in this publication in order to specify the experimental procedure adequately. Such identification is not intended to imply recommendation or endorsement by the National Institute of Standards and Technology, nor is it intended to imply that the materials or equipment identified are necessarily the best available for the purpose.

${ }^{2}$ Non-SI units are predominately in common use in State legal metrology laboratories, and/or the petroleum industry for many volumetric measurements, therefore non-SI units have been used to reflect the practical needs of the laboratories performing these measurements as appropriate.
} 


\subsection{Summary}

The small volume prover system (SVP) must be filled with clean water and purged of all entrapped air. Using an external pressure source (pump, head tank), the calibrated volume section of the SVP is discharged into a calibrated "wet-down" vessel while the SVP system remains packed with clean water. This "water-draw" process is repeated three times for each calibrated volume section within the SVP system. The calibrated vessel volume and SVP volume are corrected for the effects of temperature and pressure to establish a volume at standard reference conditions. The established SVP calibrated volume is programmed and sealed into the SVP control electronics console to establish the reference for dynamic liquid measurement device proving.

\subsection{Equipment}

2.3.1 A graduated neck stainless steel calibrated vessel (including neck scale calibration) whose volume is equivalent to the SVP calibrated section. The water draw procedure may also be implemented using multiple smaller calibrated vessel readings (e.g., 15 gal SVP water drawn using three readings of a 5 gal calibrated vessel also having had a neck scale calibration).

2.3.2 Supply of clean pressurized water (minimum $15 \mathrm{psi}$ ). If a pump system is used, care should be taken to provide a bypass loop to prevent excessive liquid heating during dead-ended conditions.

2.3.3 Auxiliary piping and valves required to direct the water from the SVP to the calibrated vessel to perform the water draw. This is a vendor supplied kit or accessory option and is necessary to perform the water draw test.

2.3.4 Three temperature sensing devices with a resolution of $0.1^{\circ} \mathrm{F}$ or better are required to measure inlet water, outlet water and position sensor mounting temperature. In order to properly measure inlet and outlet temperatures, an adequate thermometer well must be available in the plumbing and filled with a suitable liquid medium.

\section{$2.4 \quad$ Procedure}

\subsubsection{Cleanliness Verification}

Fill and drain the calibrated standard vessel and check for any soiling that would affect drainage, as evidenced by clinging droplets or greasy films. Fill and circulate clean water through the SVP. Check for any foreign material in the discharge stream. Circulate until discharge is clean. Discharge water should be handled in an environmentally safe manner since the SVP system may have previously filled with petroleum products. 
A thorough cleaning of the internals of the SVP system is required prior to the set-up for the water draw process.

\subsubsection{Air Purge and Temperature Stabilization}

All air must be purged from the SVP system to implement a successful water draw. Vent the SVP system from the highest possible point with the pressurized water source attached. Cycle the SVP Displacer several times in both directions to help release any trapped air pockets. Continue to circulate clean water through the system until the SVP system temperature is stabilized. This will help minimize variability and uncertainty in the procedure.

\subsubsection{Leak Detection}

SVP systems have some form of elastomeric or fluoropolymer seals between the displacer and the wall of the calibrated pipe section. A leak past one of these seals will cause an inaccurate water draw. It is prudent to conduct a leak detection test as defined by the SVP vendor prior to the water draw process. A typical leak check procedure is illustrated in Appendix A.

\subsubsection{Downstream Volume Calibration}

2.4.4.1 Return the SVP displacer to the upstream park position. Adjust water inlet/outlet valves to permit displacer travel downstream. Move the displacer downstream to the first sensor position and with the calibrated standard vessel filled.

2.4.4.2 With the SVP displacer automatically stopped at the first sensor position, empty the contents of the standard vessel. Use a $30 \mathrm{~s}$ drain after cessation of flow on bottom drain type standards or a $30 \mathrm{~s}$ pour/10 s drain on neck drain type standards, touching off any adhering drops from the neck to complete the drain. This constitutes the "wet-down" condition.

2.4.4.3 Start the movement of the SVP displacer downstream discharging the water into the standard vessel. While the standard vessel is filling the following data should be recorded on Form-A (downstream section):

Inlet Water Temperature $\quad-\quad T_{1}\left( \pm 0.1^{\circ} \mathrm{F}\right)$

Outlet Water Temperature $\quad-\quad T_{2}\left( \pm 0.1^{\circ} \mathrm{F}\right)$

Position Sensor Mounting Temperature (Ambient) $-T_{d}\left( \pm 0.5^{\circ} \mathrm{F}\right)$

Outlet Water Pressure $\quad-\quad P( \pm 1.0 \mathrm{psi})$ 
The displacer movement should stop automatically at the final sensor position using the vendor supplied water draw apparatus. The easiest method is to use a standard vessel that is the same nominal volume of the SVP system. This permits direct comparison of the standard vessel volume to the SVP volume with a single scale reading. Multiple readings of a smaller standard vessel can be used (i.e., a 5 gal standard vessel can be filled three times to calibrate a 15 gal SVP) but will increase uncertainty of measurement. The process is more complicated since only the last fill of the standard vessel can be stopped automatically. The previous fillings must be stopped manually by the operator and does not duplicate SVP use in field.

2.4.4.4 Read and record the standard vessel scale reading on Form-A. Measure and record the average temperature of the standard vessel water $\left(T_{m}\right)$ by submersion of the thermometer into the fluid. Average these temperature readings if using multiple readings from standard vessels smaller than the nominal value of the SVP. After the final standard vessel water temperature reading is taken, move the SVP displacer downstream past the final sensor position.

\subsubsection{Upstream Volume Calibration}

2.4.5.1 Adjust the water inlet/outlet valves to permit displacer travel upstream. Move the SVP displacer to the final sensor position filling the standard vessel.

2.4.5.2 With the SVP displacer stopped at the first sensor position, dump the contents of the standard vessel. Use a $30 \mathrm{~s}$ drain after cessation of flow on bottom drain type standards or a $30 \mathrm{~s}$ pour/ $10 \mathrm{~s}$ drain on neck drain type standards, touching off any adhering drops from the neck to complete the drain. This constitutes the "wet-down" condition.

2.4.5.3 Start the movement of the SVP displacer upstream discharging the water into the standard vessel. While the standard vessel is filling the following data should be recorded on Form A (upstream section):

$\begin{array}{lll}\text { Inlet Water Temperature } & - & T_{1}\left( \pm 0.1^{\circ} \mathrm{F}\right) \\ \text { Outlet Water Temperature } & - & T_{2}\left( \pm 0.1^{\circ} \mathrm{F}\right)\end{array}$

Sensor Mounting Temperature (Ambient) $-T_{d}\left( \pm 0.5^{\circ} \mathrm{F}\right)$

Outlet Water Pressure $\quad-\quad P( \pm 1.0 \mathrm{psi})$

The displacer movement should stop automatically at the final sensor position using the vendor supplied water draw apparatus. 
The easiest method is to use a standard vessel that is the same nominal volume of the SVP system. This permits direct comparison of the standard vessel volume to the SVP volume with a single scale reading. Multiple readings of a smaller standard vessel can be used (i.e., a 5 gal standard vessel can be filled three times to calibrate a 15 gal SVP). The process is more complicated since only the last fill of the standard vessel can be stopped automatically. The previous fillings must be stopped manually by the operator.

2.4.5.4 Read and record the standard vessel scale reading on Form A. Measure and record the average temperature of the standard vessel water $\left(T_{m}\right)$ by submersion of the thermometer into the fluid. Average these temperature readings if using multiple readings from standard vessels smaller than the nominal value of the SVP. After the final standard vessel water temperature reading is taken, move the SVP displacer upstream past the first sensor position.

\subsubsection{Repeated Runs}

Sections 2.4.4 and 2.4.5 should be completed at least two more times each. A minimum of three runs should be completed for each calibrated volume section of the SVP system. In some SVP systems the downstream and upstream volumes are not equal due to internal displacer geometry. It should be noted that some SVP systems have more than one calibrated volume section. Each volume section must be water drawn independently.

\subsection{Calculations}

A summary of the water draw calculations is provided in Form B (Small Volume Prover - Water Draw Calculations.) Form B provides the necessary calculations for each calibrated section of the SVP in one direction. The result obtained from Form B will be the net SVP volume corrected for $60^{\circ} \mathrm{F}$ and 0 psig. The new net volume value, $V_{t p}$, must be entered into the SVP control electronics for use during dynamic operation of the SVP system.

The net SVP volume corrected to $60^{\circ} \mathrm{F} \& 0$ psig is determined using the equation:

$$
V_{t p}=V_{m} * T_{m p} * C_{t s} * C_{p l} * C_{p s}
$$

Eqn. 1

where:

\begin{tabular}{|c|l|}
\hline$V_{t p}$ & Volume, corrected for temperature and pressure \\
\hline$V_{m}$ & Volume in the measure (uncorrected) \\
\hline$T_{m p}$ & $\begin{array}{l}\text { Correction for the difference in the temperature between } \\
\text { test measure and the small volume prover, SVP }\end{array}$ \\
\hline
\end{tabular}




\begin{tabular}{|c|l|}
\hline$C_{t s}$ & Correction for the effect of temperature on the prover \\
\hline$C_{p l}$ & Correction for compressibility of the prover liquid \\
\hline$C_{p s}$ & Correction for the pressure on the standard prover \\
\hline
\end{tabular}

During the water draw process the SVP system is pressurized, therefore a pressure correction must be applied. The $C_{p l}$ factor corrects for the compressibility of the water in the SVP and the $C_{p s}$ factor corrects for the effects of pressure on the SVP tube.

The temperature effects on both the test measure and the SVP materials are corrected for with the $C_{t s}$ factor. The calibrated section of the SVP is a tube, thus the temperature compensation is applied only in two dimensions. A twodimension thermal coefficient of expansion is used for the SVP tube material (i.e., two times the linear coefficient of thermal expansion). The temperature effects in the third dimension are corrected using a linear thermal coefficient of expansion for the position sensor mounting material.

The final factor, $T_{m p}$, corrects for the difference in water temperature between the test measure and the SVP system. This correction factor can be obtained from the table available in API Chapter 11.2.3 - "Water Calibration of Volumetric Provers". This table of correction factors is derived using the Wagenbreth equation for density of water at a given temperature $\left(\rho_{w}\right)$. The correction factor, $C_{t d w}$, is determined by solving the equation:

$$
C_{t d w}=\frac{\rho_{t m}}{\rho_{t p}}=\frac{V_{p}}{V_{m}}
$$

where

\begin{tabular}{|c|l|}
\hline$C_{t d w}$ & Correction for the liquid thermal expansion of water \\
\hline$\rho_{t m}$ & Density of the water in the test measure \\
\hline$\rho_{t p}$ & Density of the water in the prover \\
\hline$V_{P}$ & Volume in the prover \\
\hline$V_{m}$ & Volume in the test measure \\
\hline
\end{tabular}

\subsection{Measurement Assurance}

4.1 If a check standard is used (See SOP 20, SOP 30), repeat the process for the unknown artifact on the check standard, without adjustments.

4.2 Plot the check standard volume and verify it is within established limits. Alternatively a $t$-test may be incorporated to check the observed value against thean accepted value.

4.3 The mean of the check standard values is used to evaluate bias and drift over time. 
4.4 Check standard values are used to calculate the standard deviation of the measurement process.

4.5 When a check standard is not used, a range chart may be used to monitor repeatability and estimate the standard deviation of the measurement process using the equation:

$$
s_{p}=\frac{\bar{R}}{d_{2}^{*}}
$$

5.05 Assignment of Uncertainty

5.1 The limits of expanded uncertainty, $U$, include estimates of the standard uncertainty of the laboratory volumetric standards used, $u_{s}$, plus the standard deviation of the process, $s_{p}$, at the $95 \%$ level of confidence. See SOP 29 for the complete standard operating procedure for calculating the uncertainty.

5.2 The standard uncertainty for the standard, $u_{s}$, is obtained from the calibration report. The combined standard uncertainty, $u_{c}$, is used and not the expanded uncertainty, $U$, therefore the reported uncertainty for the standard will usually need to be divided by the coverage factor $k$. For multiple use of the same standard, uncertainty is additive.

5.3 The standard deviation of the measurement process from control chart performance (See SOP No. 20 and SOP 30).

5.4.1. The value for the standard deviation of the process, $s_{p}$, is obtained from the control chart data of the check standard, or may be estimated using the range from the control chart, using large volume transfer procedures.

5.5 Other standard uncertainties usually included at this calibration level include uncertainties associated with the ability to read the meniscus, only part of which is included in the process variability, the thermal coefficients of expansion for both the standard and the prover under test, use of proper temperature corrections, the accuracy of temperature measurements, water density equation, round robin data showing reproducibility, environmental variations over time, positioning of the prover sensor at the start and stop swiches, or alternatively the diverter errors of flow direction valves, the modulus of elasticity for pressure corrections to volume, and bias or drift of the standard.

\subsection{References}

6.1 Manual of Petroleum Measurement Standards; Chapter 11.2.3 - Water Calibration of Volumetric Provers; First Edition, August 1984. 


\section{Appendix A - Typical Leak Detection Procedure}

All Small Volume Prover systems have some form of displacer that travels with the liquid through the calibrated tube section. In addition there is some type of valve that is used to control the direction of the displacer to make a calibration run. The displacer and direction valve contain dynamic elastomeric seals. A leak past these seals will cause inaccurate dynamic performance and cause a false water draw measurement. The integrity of these seals must be verified before a water draw test can be considered valid.

Typically a SVP leak check is similar to that described below. Specific instructions and measurement equipment to be followed for each SVP model must be supplied by the vendor.

a) Block the SVP inlet and outlet using a blind flange or double/block and bleed valve (bubble tight shut off).

b) Fill the SVP with water and bleed all air from the system.

c) Launch the displacer down the flow tube.

d) Attach a dial indicator as illustrated below to measure the movement of optical switch shaft. A downstream movement of 0.004 in or less in 5 min indicates the system is leak free. An indicator movement of greater then 0.004 in indicates that a system leak is present and displacer/valve seals should be inspected or replaced.

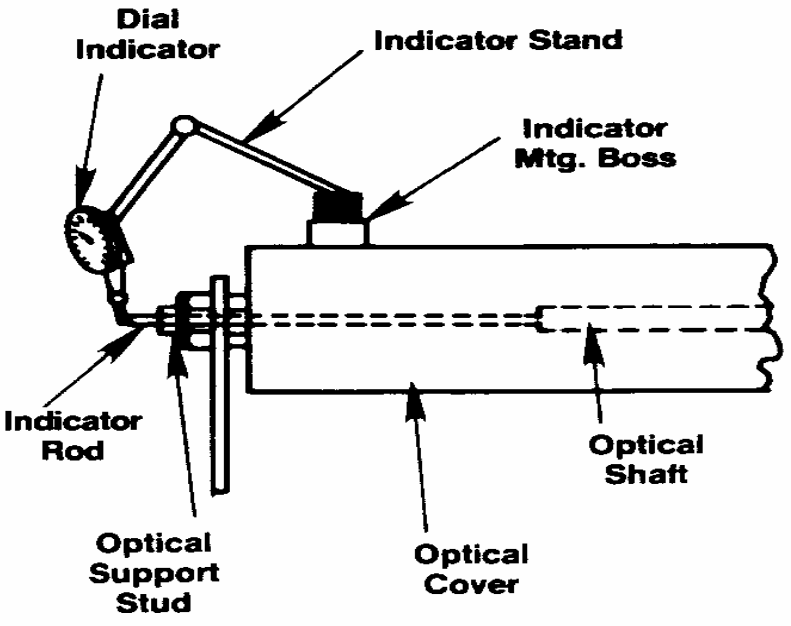

To use seal detector kit, remove screw trom boss on optical cover, thread indicator stand into hole. Mount dial indicator onto indicator stand. Remove screw from end of optical support stud. With prover piston in position for seal leak test as described in instruction manual, insert indicator rod thru hole in support stud until it rests against optical shaft of prover. Position dial indicator against end of indicator rod and proceed with leak detection test per instruction manual. When using the seal leak detector kit, removal of optical sensor cover is not necessary.

CAUTION: Remove indicator rod before taking prover out of run mode as damage to indicator and/or optical system may result. 


\section{Small Volume Prover \\ Water Draw Data Summary}

Form A

Customer:
Address:

Serial No.:

Model No.:
Date:

Time:

Calibrator:

Standard I.D.:

\begin{tabular}{|c|c|c|c|c|c|c|c|}
\hline $\begin{array}{c}\text { Draw } \\
\text { No. }\end{array}$ & $\begin{array}{c}\text { Inlet } \\
\text { Water } \\
\operatorname{Temp}\left(T_{1}\right)\end{array}$ & $\begin{array}{c}\text { Outlet } \\
\text { Water } \\
\operatorname{Temp}\left(T_{2}\right)\end{array}$ & $\begin{array}{c}\text { Prover } \\
\text { Temp } \\
\left(T_{p}\right)\end{array}$ & $\begin{array}{c}\text { Test } \\
\text { Measure } \\
\text { Temp }\left(T_{m}\right)\end{array}$ & $\begin{array}{c}\text { Sensor } \\
\text { Mounting } \\
\text { Temp }\left(T_{d}\right)\end{array}$ & $\begin{array}{c}\text { Water } \\
\text { Press. } \\
(P)\end{array}$ & $\begin{array}{c}\text { Test } \\
\text { Measure } \\
\text { Scale (in }{ }^{3}\end{array}$ \\
\hline
\end{tabular}

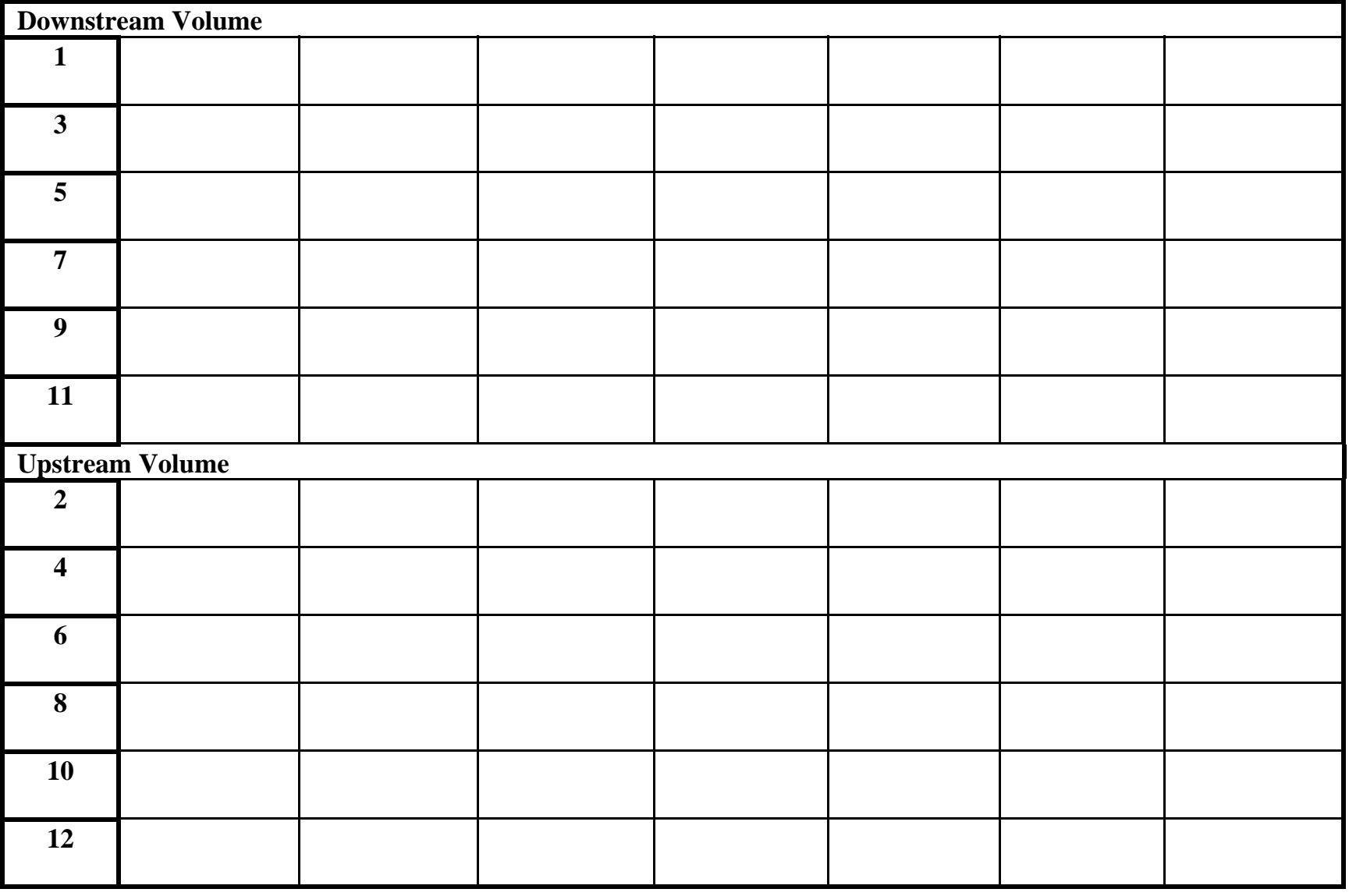

$T_{p}=\mathrm{SVP}$ water temperature, Average of $\mathrm{T} 1$ and $\mathrm{T} 2$

$T_{m}=$ Temperature of water in Test Measure

$P=$ Water pressure during test draw

$T_{d}=$ Temperature of displacer position sensors 


\section{Small Volume Prover - Water Draw Calculations}

Form B

Customer:

Serial No.:

Model No.:
Volume: Downstream

SVP Tube Inside Diameter (D):

SVP Tube Wall Thickness (t):
Upstream

inches

inches

\begin{tabular}{|c|c|}
\hline $\begin{array}{l}\begin{aligned} V_{t p}= & \text { Net Volume Corrected for } 60 \mathrm{~F} \& 0 \mathrm{psig} \\
& =V_{m} * T_{m p} * C_{t s} * C_{p l} * C_{p s}\end{aligned} \\
T_{m p}=\text { Temperature differential factor for water } \\
\quad \text { from API Chapter } 11.2 .3\end{array}$ & $\begin{array}{l}T_{p}=\text { SVP Temperature } \\
T_{d}=\text { SVP Sensor Temperature } \\
T_{m}=\text { Test Measure Temperature } \\
P=\text { Water pressure during test draw } \\
\text { Emod = Modulus of elasticity of the SVP tube } \\
\quad \text { material }\end{array}$ \\
\hline $\begin{aligned} C_{t s}= & \text { Correction factor for temperature of the } \\
& \text { test measure, SVP tube and sensor } \\
\text { mounting material } & \frac{1+\left(T_{m}-60\right) * \text { ALPHAtm }}{[1+(T p-60) * A L P H A s v p][1+(T d-60) * A L P H A s e n s]}\end{aligned}$ & $\begin{aligned} & =[ \\
C_{p l}= & \text { Correction for the compressibility of } \\
& \text { water } \\
= & 1-(0.0000032 * P)\end{aligned}$ \\
\hline 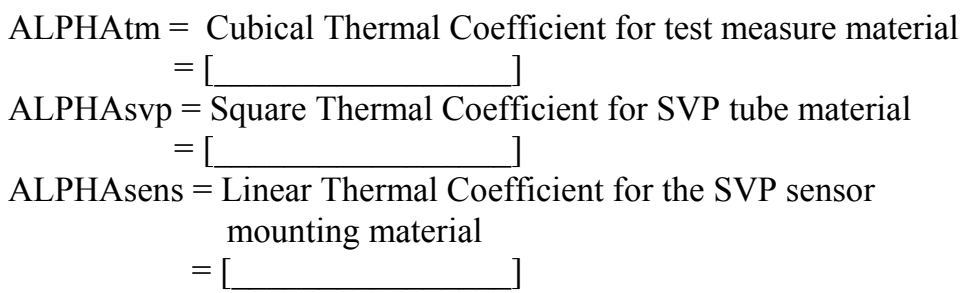 & $\begin{aligned} C_{p s}= & \text { Correction for pressure on the SVP } \\
\text { tube } & =\frac{1}{1+\frac{P * D}{(\text { Emod }) * t}}\end{aligned}$ \\
\hline
\end{tabular}

\begin{tabular}{|c|c|c|c|c|c|c|c|c|c|c|}
\hline $\begin{array}{c}\text { Test } \\
\text { Measure } \\
\text { Volume } \\
\left(\text { in }^{3}\right)\end{array}$ & $\begin{array}{l}\text { Scale } \\
\text { Vol + } \\
\left(\text { in }^{3}\right) \\
\end{array}$ & $\begin{array}{c}\text { Reading } \\
\text { Vol - } \\
\left(\text { in }^{3}\right)\end{array}$ & $\begin{array}{c}\text { Actual } \\
\text { Volume } \\
V_{m} \\
\left(\mathrm{in}^{3}\right)\end{array}$ & $\begin{array}{c}\text { SVP } \\
\text { Temp } \\
T_{p} \\
\end{array}$ & $\begin{array}{c}\text { Test } \\
\text { Measure } \\
\text { Temp } \\
\mathbf{T}_{\mathrm{m}} \\
\end{array}$ & $\begin{array}{c}\text { Temp } \\
\text { Diff. }\end{array}$ & $\begin{array}{c}\text { Diff. } \\
\text { Temp. } \\
\text { Factor } \\
T_{m p}\end{array}$ & $\begin{array}{c}\text { SVP } \\
\text { Sensor } \\
\text { Temp } \\
T_{d}\end{array}$ & $\begin{array}{c}\text { Material } \\
\text { Correct. } \\
\text { Factor } \\
C_{t s} \\
\end{array}$ & $\begin{array}{c}\text { Volume } \\
\text { Adjusted to } \\
{ }^{60} 0^{\circ} \mathrm{F} \\
V_{m}^{*} T_{m p} * C_{t s}\end{array}$ \\
\hline & & & & & & & & & & \\
\hline & & & & & & & & & & \\
\hline & & & & & & & & & & \\
\hline & & & & & & & & & & \\
\hline
\end{tabular}

Repeatibiliy Verification:

Max. Adjusted Volume - Min. Adjusted Volume

Min. Adjusted Volume

* 100

A) Average of Consecutive runs Repeating within $0.02 \%$

\begin{tabular}{|r|}
\hline$\%$ \\
\hline in $^{3}$ \\
\hline \\
\hline $\mathrm{in}^{3}$ \\
\hline gal \\
\hline
\end{tabular}




\author{
SOP SVP \\ Standard Operating Procedure \\ For \\ Gravimetric Calibration of Dynamic Small Volume Provers ${ }^{2}$
}

Introduction

\title{
$1.1 \quad$ Purpose of Test
}

This procedure describes the calibration of the "to deliver" volume of dynamic small volume provers (SVP) that may be used as volumetric measuring standards. The procedure uses gravimetric calibration principles to minimize calibration uncertainties. Accordingly, the procedure is especially useful for high accuracy calibrations. The procedure does not incorporate measurement control steps to ensure the validity of the standards and the measurement process; additional precautions must be taken. The procedure makes use of an electronic balance and is suitable for all sizes of gravimetric calibrations only limited by the capacity and resolution of the balance. The procedure can be used for both upstream and downstream calibrations. Each direction will be treated as a separate calibration.

\subsection{Prerequisites}

1.2.1 Verify that valid calibration certificates are available for the standards used in the test.

1.2.2 Verify that the standards and instruments (e.g., thermometer, barometer, and hygrometer) to be used have sufficiently small standard uncertainties for the level of calibration. Reference standards should not be used for gravimetric calibration.

1.2.3 Verify that the balance used is in good operating condition with sufficiently small process standard deviation as verified by a valid control chart or preliminary experiments to ascertain its performance quality when a new balance is put into service. The accuracy of the balance and weighing procedures should be evaluated to minimize potential bias in the measurement process.

1.2.4 Verify that the operator is experienced in precision weighing techniques and has had specific training in SOP 2, SOP 4, SOP 29, GMP 10, and gravimetric calibrations such as those used in SOP 14.

1.2.5 Verify that an adequate supply of distilled or de-ionized water (see GLP 10 ) is available.

\footnotetext{
${ }^{1}$ Certain commercial equipment, instruments, or materials are identified in this publication in order to specify the experimental procedure adequately. Such identification is not intended to imply recommendation or endorsement by the National Institute of Standards and Technology, nor is it intended to imply that the materials or equipment identified are necessarily the best available for the purpose.

${ }^{2}$ Non-SI units are predominately in common use in State legal metrology laboratories, and/or the petroleum industry for many volumetric measurements, therefore non-SI units have been used to reflect the practical needs of the laboratories performing these measurements as appropriate.
} 
1.2.6 Verify that the laboratory facility is free of air currents and/or temperature fluctuations where the SVP will be set up for testing.

1.2.7 Verify that the laboratory facilities meet the following minimum conditions to meet the expected uncertainty possible with this procedure:

Table 1. Laboratory environmental conditions

\begin{tabular}{||c|c|c||}
\hline \hline Procedure & Temperature & $\begin{array}{c}\text { Relative } \\
\text { Humidity }\end{array}$ \\
\hline \hline $\begin{array}{c}\text { SVP/ Large Volume } \\
\text { Gravimetric }\end{array}$ & $\begin{array}{c}20^{\circ} \mathrm{C} \text { to } 23^{\circ} \mathrm{C} \text {, a set point } \pm 2{ }^{\circ} \mathrm{C}, \\
\text { maximum change } 1.0^{\circ} \mathrm{C} / \mathrm{h}\end{array}$ & $\begin{array}{c}40 \% \text { to } 60 \% \\
\pm 10 \% \text { maximum change } / 4 \mathrm{~h}\end{array}$ \\
\hline
\end{tabular}

1.2.8 All necessary maintenance to the test artifact must be completed by the device owner prior to starting the gravimetric calibration. It is advisable to perform a static leak test prior to performing the test. Replace the seals on the prover if there is any doubt as to their integrity. If "as found" data is required, that data should be obtained before any seal replacements.

1.2.9 The prover inlet and outlet must be blocked by the device owner before calibration by using a blind flange or double-block and bleed valve.

1.2.10 The device owner must provide all necessary manufacturers' manuals as well as trained personnel to operate the device.

$2 \quad$ Methodology

2.1 Scope, Precision, Accuracy

The procedure is applicable for the calibration of any size of measuring container SVP that, when filled with water, will not overload the electronic balance used. Typical containers SVPs range in capacity from 15 gal to 120 gal. The precision of calibration will depend on strict adherence to the various steps of the procedure. The accuracy attainable will depend on the uncertainties of the standard weights, the air buoyancy, density of water, thermal expansion corrections that are made, and the repeatability of the SVP.

\subsection{Summary}

The mass of the water delivered by the SVP is determined by weighing the water on an electronic balance and comparing it to mass standards. Volume is derived from mass using the equations provided.

2.3 Equipment and Standards

2.3.1 Electronic balance having sufficient capacity to weigh the loaded vessel. The sensitivity of the balance will be a limiting factor in the accuracy of the measurement. The resolution and repeatability should be smaller than the accepted uncertainty of the calibration.

2.3.2 Calibrated mass standards with adequate accuracy and NIST traceable mass values. Ordinarily, weights of ASTM Class 2 or 3 specifications, or equivalents are required. 
2.3.3 Thermometer, calibrated to $\pm 0.1^{\circ} \mathrm{C}$ for measuring the temperature of the water, prover, and detector bar; $\pm 0.5^{\circ} \mathrm{C}$ for measuring the temperature of the air and calculating the air density, traceable to NIST.

2.3.4 Barometer, calibrated to $\pm 1 \mathrm{~mm} \mathrm{Hg}$ and a hygrometer, calibrated to $\pm 5 \%$ for calculating the air density, traceable to NIST.

2.3.5 Pressure gauge for determining the prover pressure, with calibration traceable to NIST. (Include the uncertainty of the pressure gauge in the uncertainty calculations.)

2.3.6 Distilled or de-ionized water and methods to verify its purity (See GLP No. 10).

\section{$2.4 \quad$ Procedure}

2.4.1 Install SVP volumetric test kit per manufacturer's instructions. (Provided by device owner.)

2.4.2 Connect water supply to prover.

2.4.2.1 In general, ensure that all air is bled from the system, suitable water supply is provided and the device temperature is in equilibrium with that of the water supply. Set device valves as appropriate for the test to be conducted.

2.4.2.2 For Calibron (brand) SVPs, turn water supply on, and open appropriate valves to eliminate entrapped air according to manufacturer's instructions. After all air is bled off, close associated valves. Then open the appropriate valves and allow water to circulate until the temperature has stabilized.

2.4.2.3 For Daniels (brand) SVPs, establish valve position for control of upstream or downstream flow.

2.4.3 Install certified thermometers to record air temperature, water temperature, detector bar temperature $\left(T_{d}\right)$, and prover temperature $\left(T_{p}\right)$.

2.4.4 Install calibrated pressure gauge to record prover pressure $\left(P_{p}\right)$.

2.4.5 Connect prover control cable to controller (from the volumetric test kit.)

2.4.6 Apply power to the prover and the water draw circuit. One of the valves will switch on immediately. Note which valve switches on, and mark it as the overboard or bypass valve. The other valve is the draw valve and will only be on while the flag is between the two volume switches.

2.4.7 Record all of the prover-specific variables on the data entry form.

Note: All references in the following weighing options to the empty receiving vessel assume that the empty receiving vessel has been placed in a "wet-down" condition. This wet down condition is achieved when the 
vessel has been filled with water and then drained using the same process that will be used throughout this calibration.

\subsubsection{Weighings (Option A)}

2.4.8.1 Zero the balance and record the balance indication as $O_{1}$. Place a standard mass, $M_{s 1}$, on the balance platform ( $M_{s 1}$ should be slightly larger than the mass of the empty receiving vessel.) Record the balance indication as $\mathrm{O}_{2}$.

2.4.8.2 Place the empty receiving vessel on balance platform and record the balance indication as $\mathrm{O}_{3}$. Caution: the receiving vessel must be dry on the outside for all weighings.

2.4.8.3 Record air temperature, barometric pressure and humidity at the time of these measurements.

2.4.8.4 Zero the balance and record the balance indication as $\mathrm{O}_{4}$.

2.4.8.5 Manipulate the system to cause the prover piston to move to the starting position and begin the water draw sequence. Record all pertinent test artifact temperatures and pressures during the water draw sequence. Immediately upon completion of the water draw sequence, place the filled receiving vessel on the balance and record the balance indication as $O_{6}$. Read and record the temperature of the water in the container immediately after weighing.

2.4.8.6 Remove the filled receiving vessel and place a standard mass, $M_{\mathrm{s} 2}$, on the balance platform ( $M_{s 2}$ should be slightly larger than the mass of the filled vessel.) Record the balance indication as $\mathrm{O}_{5}$.

2.4.8.7 Record the air temperature, barometric pressure and humidity at the time of these measurements.

2.4.8.8 Make five duplicate runs with two runs at a flow rate differing from the others by at least $25 \%$. The measured result $\left(V_{60}\right)$ of each of these calibration runs must repeat within $0.02 \%$.

\subsubsection{Weighings (Option B)}

2.4.9.1 Place mass standards that approximate the mass of the empty transfer vessel (with a lid) and adequate filter paper or other clean, lint-free padding material (to protect the standards being used) on the electronic balance. With these items on the balance, zero the balance. Note: the padding materials must be included on all measurements or their mass treated as tare.

2.4.9.2 Place additional mass standards approximating the nominal mass of the water volume to be measured on the balance. Take care to place the weights on filter paper or other appropriate protective padding. Record this balance indication as $O_{1}$. 
2.4.9.3 Remove all mass standards. Record the air temperature, barometric pressure, and relative humidity readings.

2.4.9.4 Place the empty receiving vessel on the balance, with the padding material and zero the balance indication. Remove the transfer vessel, lid, and padding material and record the base empty vessel reading (B).

2.4.9.5 Manipulate the system to cause the prover piston to move to the starting position and begin the water draw sequence filling the receiving vessel. Read and record all pertinent test artifact temperatures and pressures during the water draw sequence. Place the lid on the receiving vessel to limit evaporation.

2.4.9.6 Immediately prior to weighing full vessel record balance reading as $\left(d_{1}\right)$. This reading will be used to calculate drift while filling the vessel.

2.4.9.7 Place the filled vessel and all padding material on the balance. If needed, add known mass standards as tare weights to bring the water mass up to the mass of the standards used for $O_{1}$. This balance reading is recorded as $\mathrm{O}_{2}$. Record the mass of all tare weights.

2.4.9.8 Remove the filled receiving vessel and record the balance indication as $\left(d_{2}\right)$. This reading will be used to calculate drift over the entire process.

2.4.9.9 Immediately after removing the filled receiving vessel from the balance, record the temperature of water in the vessel.

2.4.9.10 Make five duplicate runs with two runs at a flow rate differing from the others by at least $25 \%$. The measured result $\left(V_{60}\right)$ of each of these calibration runs must repeat within $0.02 \%$.

3 Calculations

3.1 Compute the volume at the temperature of the measurement, $V_{t}$, for each determination using the equation:

\section{(Option A)}

$$
V_{T}=\left[O_{6(\text { filled })} \frac{M_{s 2}\left(1-\frac{\rho_{a}}{\rho_{s 2}}\right)}{\left(O_{5}-O_{4}\right)}-O_{3(\text { drained })} \frac{M_{s 1}\left(1-\frac{\rho_{a}}{\rho_{s 1}}\right)}{\left(O_{2}-O_{1}\right)}\right]\left(\frac{1}{\rho_{w}-\rho_{a}}\right)
$$


Table 2. Variables for volume equation

\begin{tabular}{|c|l||}
\hline Variable & \\
\hline \hline$M_{s}, M_{s 1}, M_{s 2}$ & mass of standards \\
\hline$\rho_{s}$ & density of $M_{S}$ \\
\hline$\rho_{w}$ & density of water at the temperature of measurement \\
\hline$\rho_{a}$ & density of air at the conditions of calibration \\
\hline$V_{t}$ & Volume at the temperature of the test \\
\hline
\end{tabular}

(Option B)

$$
\begin{aligned}
& V_{T}=\left\{\left[O_{2 c}\left(\frac{M_{s}}{O_{1}}\right)\left(1-\frac{\rho_{a}}{\rho_{s}}\right)\right]-M_{t}\left(1-\frac{\rho_{a}}{\rho_{t}}\right)\right\}\left(\frac{1}{\rho_{w}-\rho_{a}}\right) \\
& O_{2 c}=O_{2}+\left\{\left[\frac{\left(d_{1}+d_{2}\right)}{2}\right]-B\right\}
\end{aligned}
$$

Table $3 . \quad$ Variables for volume equations

\begin{tabular}{||c|l||}
\hline \hline Variable & \multicolumn{1}{|c|}{ Description } \\
\hline \hline$O_{1}$ & Observation \#1, balance reading for mass standard \\
\hline$O_{2}$ & Observation \#2, balance reading for water delivered from prover \\
\hline$O_{2 c}$ & Drift compensated $O_{2}$ reading \\
\hline$d_{1}$ & Drift while filling the vessel \\
\hline$d_{2}$ & Drift over entire process \\
\hline$B$ & Base balance reading drift is based on \\
\hline$M_{S}$ & Mass of mass standards (true mass, vacuum mass) \\
\hline$M_{t}$ & Mass of tare weights \\
\hline$\rho_{a}$ & Air density \\
\hline$\rho_{s}$ & Density of $\mathrm{M}_{\mathrm{S}}$ \\
\hline$\rho_{t}$ & Density of $\mathrm{M}_{\mathrm{t}}$ \\
\hline$\rho_{w}$ & Water density \\
\hline
\end{tabular}


3.2 Compute $V_{60}$, the volume at $60^{\circ} \mathrm{F}$, for each run, using the equation:

$$
\begin{aligned}
& V_{60}=\frac{V w}{C C F} \\
& \text { where } \\
& C P L_{p}=\left[1-\left(\left(0.0000032 * P_{p}\right)\right]\right. \\
& C T S_{p}=\left\{\left(1+\left[\left(T_{p}-T_{b}\right) * G_{a}\right]\right) *\left(1+\left[\left(T_{d}-T_{b}\right) * G_{l}\right]\right)\right\} \\
& C P S_{p}=1+\left(\frac{\left(P_{p} * I D\right)}{E * W T}\right) \\
& C C F=C P L_{p} * C T S_{p} * C P S_{p}
\end{aligned}
$$

Table 4.

Additional Variables for Volume Equations

\begin{tabular}{|c|l||}
\hline \hline Variable & \multicolumn{1}{|c||}{ Description } \\
\hline \hline$T_{b}$ & Reference (Base) temperature \\
\hline$T_{d}$ & Detector bar temperature (Temperature, detector) \\
\hline$T_{p}$ & Prover temperature (Temperature, prover) \\
\hline$P_{p}$ & Prover pressure (Pressure, prover) in psig \\
\hline$E$ & Modulus of elasticity (flow tube) \\
\hline$W T$ & Wall Thickness of flow tube \\
\hline$I D$ & Inside Diameter of flow tube \\
\hline$G_{l}$ & Coefficient of linear expansion (switchbar) \\
\hline$G_{a}$ & Coefficient of flow tube area thermal expansion \\
\hline$C P L$ & Correction for the pressure on the liquid \\
\hline$C T S$ & Correction for the temperature on the standard prover \\
\hline$C P S$ & Correction for the pressure on the standard prover \\
\hline$C C F$ & Combined correction factor \\
\hline
\end{tabular}

3.3 Calculate water density using the equation provided in GLP 10.

3.4 Calculate the air density per SOP 2.

3.5 Calculate the uncertainty for the calibration using Appendix B: 
$4 \quad$ Measurement Assurance

4.1 Record and plot standard deviations of each five run calibration to determine shortterm variations of the measurement process.

$5 \quad$ Assignment of Uncertainties

The limits of expanded uncertainty, $U$, include estimates of the standard uncertainty of the mass standards used, $u_{s}$, plus the uncertainty of measurement, $s_{p}$, at the $95 \%$ level of confidence. See SOP 29 for the complete standard operating procedure for calculating the uncertainty.

5.1 The standard uncertainty for the standard, $u_{s}$, is obtained from the calibration report. The combined standard uncertainty, $u_{c}$, is used and not the expanded uncertainty, $U$, therefore the reported uncertainty for the standard will usually need to be divided by the coverage factor $k$.

5.2 Standard deviation of the measurement process from control chart performance (See SOP 17 or 20.)

The value for $s_{p}$ is obtained from the control chart data or estimated based on the range of duplicate measurements over time. This value will incorporate a repeatability factor related to the precision of the weighings.

5.3 Other standard uncertainties usually included for this type of calibration level include uncertainties associated with water temperature measurements, thermometer accuracy, calculation of air density, and standard uncertainties associated with the density of the standards used or the lack of internal cleanliness.

$6 \quad$ References

6.1 Manual of Petroleum Measurement Standards; Chapter 11.2.3 - Water Calibration of Volumetric Provers; First Edition, August 1984. 


\section{Gravimetric Calibration Data Sheet}

Company Name:

Address:

City, State, Zip:

Representative:

Phone:

Email:

Company URL:

General Description

Manufacturer:

Model Number:

Condition:

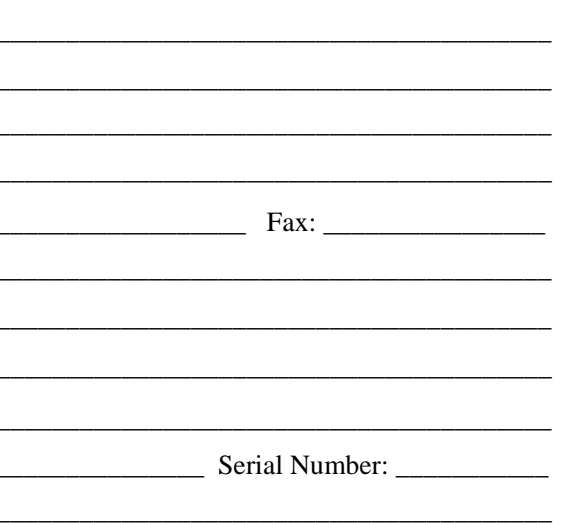

Test No:

Purchase Order No:

Date Scheduled:

Date Received:

Date Tested:

Date Returned:

Next Appointment:
Compressibility factor for water

Reference Temperature(Tb) $\left({ }^{\circ} \mathrm{F}\right)$

Reference Temperature $\left({ }^{\circ} \mathrm{C}\right)$

Reference Pressure (psig)
3.2000E-06 Area Thermal Expansion Coefficient (Ga)

$\frac{60}{15.55555556}$

Detector Thermal Expansion Coefficient (GI)

Modulus of Elasticity (flow tube) (E)

Flow Tube Inside Diameter (inches) (ID)

Flow Tube Wall Thickness (inches) (WT)

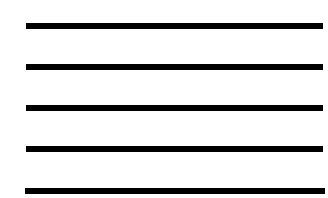

Total True Mass

\begin{tabular}{|l|l|}
\hline \multicolumn{2}{|c|}{ Standards Used } \\
\hline Full Vessel & Empty Vessel \\
\hline & \\
\hline & \\
\hline & \\
\hline & \\
\hline & \\
\hline & \\
\hline & \\
\hline
\end{tabular}

Observations

\begin{tabular}{|c|c|c|c|c|c|}
\hline Fill Number & Fill \# 1 & Fill \# 2 & Fill \# 3 & Fill \# 4 & Fill \# 5 \\
\hline Flow Rate & Fast & Fast & Fast & Slow & Slow \\
\hline \multicolumn{6}{|l|}{ Run Time (sec) } \\
\hline \multicolumn{6}{|l|}{ Zero Balance, $O_{1}$} \\
\hline \multicolumn{6}{|l|}{ Balance Reading $\mathrm{O}_{2}$ (Standards Empty) } \\
\hline \multicolumn{6}{|l|}{ Balance Reading $O_{3}$ (Empty Vessel) } \\
\hline \multicolumn{6}{|l|}{ Zero Balance, $O_{4}$} \\
\hline \multicolumn{6}{|l|}{ Balance Reading $O_{5}$ (Standards Full) } \\
\hline \multicolumn{6}{|l|}{ Balance Reading $O_{6}$ (Full Vessel) } \\
\hline \multicolumn{6}{|l|}{ Air Temperature $\left({ }^{\circ} \mathrm{C}\right)$} \\
\hline \multicolumn{6}{|l|}{ Barometric Pressure (mmHg) } \\
\hline \multicolumn{6}{|l|}{ Relative Humidity (\% RH) } \\
\hline \multicolumn{6}{|l|}{ Water Temperature $\left({ }^{\circ} \mathrm{C}\right)$} \\
\hline \multicolumn{6}{|l|}{ Detector Bar Temperature $\left(T_{d}\right)\left({ }^{\circ} \mathrm{C}\right)$} \\
\hline \multicolumn{6}{|l|}{ Prover Temperature $\left(T_{p}\right)\left({ }^{\circ} \mathrm{C}\right)$} \\
\hline Prover pressure $\left(P_{p}\right)(\mathrm{psig})$ & & & & & \\
\hline
\end{tabular}


Example uncertainty components listed in order of effect on total uncertainty:

- Standard deviation of the measurement process, $s_{p}$

- Water temperature

- Reproducibility

- Mass calibration uncertainty

- Water density

- Prover temperature

- Water compressibility

- Detector temperature

- Prover pressure

- Area thermal expansion (Ga)

- Air temperature

- Detector thermal expansion (Gl)

- Barometric pressure

- Relative humidity

- Modulus of elasticity

- Flow tube diameter (ID)

- Tube wall thickness (WT) 

